\title{
A ANÁLISE HARMÔNICA NO ESTUDO DAS PRECIPITAÇÕES PLUVIAIS NO MUNICÍPIO DE BANDEIRANTES, PR.
}

MARIA APPARECIDA VALÉRIO FELTRIN

Engenheira-Bgrōnoma

Orientador: Prot. Or. Humberto de Campos

Dissertação apresentada à Escola Superior de Agricultura "Luiz de Queiroz", da Universidade de São Paulo, para obtenção do título de Mestre em Estatística e Experimentação Agronômica.

\footnotetext{
$P|R A C| C A B A$

Esłado de São Paulo - Brasil Junho, 1980
} 
ii.

A meus pais,

A meu irmão,

A meu esposo. 
iii.

\section{AGRADECIMENTOS}

Ao Dr. Humberto de Campos, pela orientação precisa e segura .

Ao Dr. F. Pimentel Gomes, pelo estímulo e amizade.

Ao Dr. Izaias Rangel Nogueira, pelo incentivo e sabe doria.

Aos demais Professores do Departamento de Matemática e Estatística da ESALQ, pelos ensinamentos e dedicação.

Aos Funcionários do Departamento de Matemática e Estatística, pela colaboração e convivência.

A Familia Kimura, pelo acesso aos dados de proprieda de da Fazenda Nomura.

A colega Leda Maria do Amaral Gurgel Garrido, pelo companheirismo em todas as horas.

Ao amigo Carlos Monteiro, pelas sugestões e apoio re cebidos.

A todos que, direta ou indiretamente, contribuiram para a execução deste trabalho. 


\section{T $N D$ ICE}

Pág.

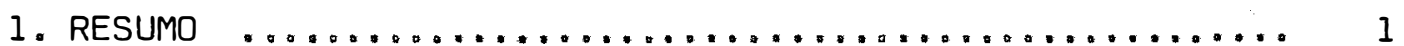

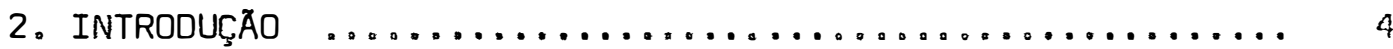

3. REVISÃO DE LITERATURA $\ldots \ldots \ldots \ldots \ldots \ldots \ldots \ldots \ldots \ldots \ldots \ldots$

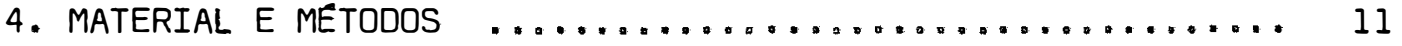

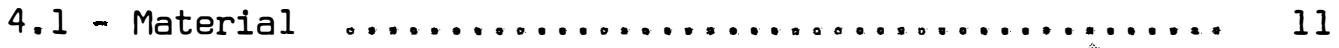

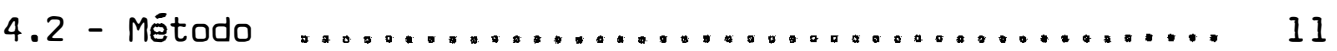

4.2 .1 - Desenvolvimento teórico ............ 12

4.2 .2 - Modelo matemático $\ldots \ldots \ldots \ldots \ldots \ldots \ldots \ldots \ldots$

4.2.3 - Estimativa dos parâmetros, suas varłáncias e

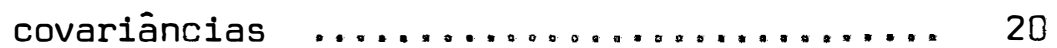

4.2 .4 - Transformação de dados .............. 29

4.2 .5 - Análise de variância $\ldots \ldots \ldots \ldots \ldots \ldots \ldots \ldots$

4.2 .5 .1 - Teste de normalidade $\ldots \ldots \ldots \ldots 30$

4.2.5.2 - Quadros de análise de variància .. 32

4.2.6 - Intervalo de confiança para os parâmetros es

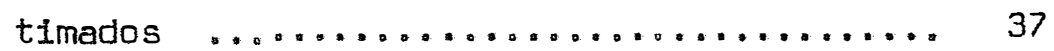

4.2 .7 - Equação de regressão $\ldots \ldots \ldots \ldots \ldots \ldots \ldots \ldots$

5. RESULTADOS E DISCUSSÃO $\ldots \ldots \ldots \ldots \ldots \ldots \ldots \ldots \ldots \ldots \ldots \ldots \ldots \ldots \ldots$

5.1 - Estimativa das Precipitações Mensais Para o Perỉodo Anual (Janeiro a Dezembro) .................. 40

5.1.1 - Modelo matemático .................. 40

5.1 .2 - Estimativa dos parāmetros ............ 41 
Pág :

5.1 .3 - Análise de variância $\ldots \ldots \ldots \ldots \ldots \ldots \ldots . \ldots 42$

5.1 .3 .1 - Teste de normalidade $\ldots \ldots \ldots .42$

5.1.3.2 - Quadros de análise de variância .. 43

5.1 .4 - Variàncias dos parâmetros estimados ....... 48

5.1 .5 - Intervalos de confiança $\ldots \ldots \ldots \ldots \ldots \ldots . . .48$

5.1 .6 - Equação de regressão .............. 49

5.1 .7 - Representação gráfica ............. 51

5.2 - Estimativa das Precipitações Mensais para o Período

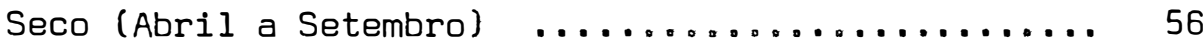

5.2 .1 - Modelo matemático $\ldots \ldots \ldots \ldots \ldots \ldots \ldots$

5.2 .2 - Estimativa dos parâmetros $\ldots \ldots \ldots \ldots \ldots . \ldots 57$

5.2 .3 - Análise de variância $\ldots \ldots \ldots \ldots \ldots \ldots \ldots . \ldots \ldots$

5.2 .3 .1 - Teste de normalidade $\ldots \ldots \ldots \ldots 58$

5.2.3.2 - Quadros de análise de variância .. 59

5.2 .4 - Variâncias dos parâmetros estimados ..... 62

5.2 .5 - Intervalos de confiança $\ldots \ldots \ldots \ldots \ldots \ldots 63$

5.2 .6 - Equação de regressão $\ldots \ldots \ldots \ldots \ldots \ldots \ldots 64$

5.2 .7 - Representação gräfica ............ 65

5.3 - Estimativa das Precipitações Mensais para o Período Chuvoso (Outubro a Março) .................. 69

5.3 .1 - Modelo matemático $\ldots \ldots \ldots \ldots \ldots . \ldots . \ldots 6$

5.3 .2 - Estimativa dos parâmetros .......... 70 
Päg。

5.3 .3 - Análise de variāncia .............. 71

5.3.3.1 - Teste de normalidade $\ldots . . . \ldots 71$

5.3.3.2 - Quadros de análise de variāncia .. 72

5.3 .4 - Variáncias dos parámetros estimados $\ldots \ldots .74$

5.3 .5 - Intervalos de confiança ............ 74

5.3 .6 - Equação de regressão ............. 75

5.3 .7 - Representação gráfica a........... 76

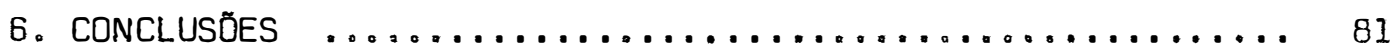

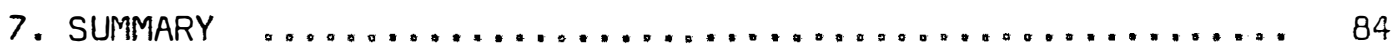

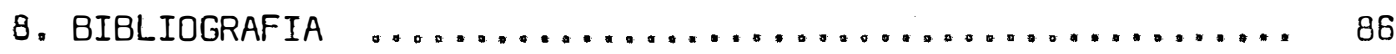

9. APENDICES $\ldots \ldots \ldots \ldots \ldots \ldots \ldots \ldots \ldots \ldots \ldots \ldots \ldots \ldots \ldots \ldots \ldots \ldots \ldots$ 


\section{RESUMO}

No presente trabalho foi aplicada a análise harmônica aos valores mensais, de chuvas, referentes ao Municipio de Bandeirantes (PR), num período de 48 anos ( 1930 a 1977).

Os dados originais, em milímetros, foram ajustados a meses de trinta dias e, posteriormente, foram transformados para $Y=\sqrt{x}$.

Foram determinados os componentes harmônicos do elemento climático analisado, para três casos distintos: período anual, período seco e período chuvoso.

A estabilidade destes componentes harmônicos foi verificada, através da análise de variáncia, para cada um dos trés ce sos, apös a verificação da normalidade dos componentes envolvidos na análise. 
Estabeleceram-se os intervalos de confiança para os contrastes ortogonais e para as amplitudes dos componentes harmôni cos considerados e determinaram-se as equações de regressão para os três casos estudados, com os seguintes resultados:

a) Perfodo anual (janeiro a dezembro):

$$
\begin{aligned}
8_{t}=9,77 & +3,360495 \operatorname{sen}(30 t+70,590522)^{\circ}+ \\
& +0,252515 \operatorname{sen}(60 t+60,704294)^{\circ}+ \\
& +1,171624 \operatorname{sen}(90 t+281,383787)^{\circ}
\end{aligned}
$$

$t=1,2,3, \ldots, 12$

$9_{t}$ é a estimativa da raiz quadrada da precipitação em milímetros, para o més $t$.

b) Período seco (abril a setembro):

$$
\begin{aligned}
& q_{t}=7,44+0,882221 \operatorname{sen}(60 t+8,327296)^{\circ}+ \\
&+1,065809 \operatorname{sen}(120 t+73,821315)^{\circ} \\
& t=1,2, \ldots, 6
\end{aligned}
$$

c) Período chuvoso (outubro a março):

$$
\begin{aligned}
& q_{t}=12,10+1,255940 \operatorname{sen}(50 t+206,899439)^{\circ}+ \\
&+0,675725 \operatorname{sen}(120 t+295,448617)^{0}+ \\
&+0,411450 \operatorname{sen}(180 t+270)^{0} \\
& t=1,2, \ldots, 6
\end{aligned}
$$

As principais conclusões obtidas, foram: 
a) Bandeirantes apresenta um período seco (abril a setembro) e um período chuvoso (outubro a março) bem definidos, sendo este o res ponsável por $69,40 \%$ da precipitação anual.

b) Para o período anual, o modelo ora determinado explica $98,02 \%$ das variações devidas a meses, e estima-se um máxima de chuvas durante o mès de janeiro, e um mínimo, durante o mês de agosto.

c) Para o período seco, a equação de regressão estimada explica $99,54 \%$ das variações devidas a meses e estima-se um mínimo de chuvas para o mès de agosto.

d) Para o período chuvoso, a equação de regressão estimada explica $100 \%$ das variações devidas a meses e estima-se um máximo de chuvas durante o mès de janeiro. 


\section{INTRODUÇÃO}

Dia a dia, maior se torna a preocupação do Homem com os fatores responsáveis pela produtividade agrícola. A escassez dos produtos agrícolas, associada a fatores tais como o crescimento po-pulacional, a perda de produção devida à incidência de pragas, doen ças e intempéries, tem sido motivo de constantes pesquisas em busca de novas técnicas que aumentem o rendimento por área plantada e garantam colheiras abundantes.

A crise do petróleo, fez com que os olhos da tecnolo gia se voltassem para fontes energéticas outras, principalmente as renováveis, como o álcool, extraído dos vegetais, que, segundo Buck minster fuller, é a estrutura básica dos combustíveis e demais deri vados do petróleo.

Dentre os muitos problemas enfrentados pelos agricul 
tores e técnicos, no processo de produção, encontra-se a principal fonte de água. para a agricultura: as chuvas.

Estas, apresentando uma distribuição desuniforme, ora com grandes períodos de estiagem, ora com consideráveis aguaceiros de curta duração que superam a capacidade de retenção de água pelo solo, têm comprometido o desenvolvimento, a colheitas a industriali zação, o armazenamento e a distribuição da produção aģrícola,bem co mo a preservação dos recursos naturais.

Embora o termo "precipitação" tenha uma abrangência muito maior, no presente trabalho, será empregado com referência, apenas, ao elemento chuva.

Através de previsões das precipitações mensais para cada local, pode se montar um esquema de suprimento nos períodos de estiagem, por meios de planos de irrigação e captação, e, nos períodos de chuvas excessivas, por meio de dispositivos de drenagem, açudes e barragens.

Em Bandeirantes (PR), embora as alturas pluviométricas diárias venham sendo tomadas desde 1930, não existe nenhum estü do feito a este respeito.

O presente trabalho visa, através de um estudo a res peito das precipitações naquele Município, a auxiliar os responsāveis técnicos pelo planejamento e engenharia rural, no sentido de se obter um aproveitamento mais racional da água na agricultura.

Admitindo a precipitação mensal um fenômeno cíclico, 
aconselha-se o emprego da análise harmônica em seu estudo. Desta for ma, pretende-se a obtenção de equações interpretativas do fenômeno, para os períodos anual, chuvoso e seco. 


\section{REVISÃO DE LITERATURA}

CONRAD e POLLAK (1950) utilizaram a análise harmônica no estudo de fenômenos climáticos que apresentam tendência periō dica. Apresentaram a marcha do método e exemplificaram através da análise de um fenômeno com curso anual e de outro com cusso diário.

BLISS (1958) utilizou a regressão periódica no estudo de fenômenos biológicos e climatológicos que apresentam tendência cíclíca, não sendo, por isso, explicados pela regressão polinomial. Comprovou que, se os dados de observação mudam simetricamente durante o ciclo, o fenômeno pode ser explicado pela curva da função seno. Nos casos em que a mudança dos dados de observação não é simé trica, o fenômeno pode ser explicado pela síntese de várias curvas senoidais de períodos diferentes.

GODOY et alii (1959) apresentaram um trabalho sobre 
análise dos totais anuais de alturas pluviométricas em Campinas(SP) durante 57 anos. Para que as observações pudessem ser analisadas, procuraram uma transformação adequada, concluindo que $y=\log (x+5)$ era a que melhor se ajustava para o caso em questão.

AMARAL (1968) estimou as precipitações mensais de Pe lotas (RS) para um período de 52 anos (1900 a 1951). Testou a esta bilidade dos componentes harmónicos pelo método da análise de variància e concluiu serem significativas as ondas anual, semestral e quadrimestral. Através do teste de compliticidade verificou serem estas três ondas responsáveis por $91,2 \%$ da variação das precipitações médias mensais.

Aplicando o mesmo método na estimativa das precipitações mensais de Morro Velho (MG), no período de 1855 a 1951, aquele autor discutiu o problema de transformação dos dados de observação e concluiu ser a onda anual responsável por 99,3\% da variação entre médias mensais.

ANDERSDN (1971) apresentou a teoria sobre funções com tendència cíclica, através de estudo matricial detalhado da análise harmónica, para cálculo dos componentes de regressão.

DUARTE (1974) estabeleceu a curva epidemiológica da Ferrugem do Cafeeiro na Zona da Mata (MG) utilizando a análise harmónica. Verificou que os dados são explicados pela curva do seno, apresentando um máximo de infecção em junho e um mínimo, em dezembro. 
THIEBAUT (1976) estimou as precipitaçöes médias mensais em Viçosa (MG) baseando-se em dados de cinquenta anos(1924-1973). Obteve três equações de regressão para os seguintes períodos: perío do seco (abril a setembro), período chuvoso (outubro a março) e período anual (janeiro a dezembro). Verificou a estabilidade dos componentes harmónicos através da análise de variância e determinou os intervalos de confiança dos contrastes ortogonais envolvidos. Concluiu que, da variação total devida a meses, a onda semestral responde por $91,96 \%$ no período chuvoso e por $82,58 \%$ no período seco, en quanto que, para o período anual, a onda anual foi responsável por $95,02 \%$ da variação devida a meses.

SILVA (1977) estimou as precipitações médias penta... dais de Pelotas (RS) através da análise harmônica aplicada a dados referentes ao período de 1900 a 1951. Submeteu os dados originais à transformação $\sqrt[3]{x}$ para posteriormente analisá-los. Sugere que esta transformação seja adotada universalmente para trabalhos em que se utilizem dados de precipitações pluviais.

Pelo teste de estabilidade concluiu serem significativas as ondas semestral, quadrimestral e a 35ă harmônica. Através do teste de completicidade observou que $40,09 \%$ da variação entre as precipitações pluviais pentadais é explicada por estas ondas.

PEREIRA (1978) aplicou a Regressão Periódica aos valores das alturas pluviométricas mensais no Município de Grajaü(MA) para um período de 45 anos. Visando a uniformização das variâncias 
10 .

dos dados, empregou a transformação $y=\log (x+35)$ e determinou a equação de regressão, a partir dos dados transformados, que explica $99,75 \%$ das precipitações mensais. 
11.

\section{MATERIAL E METODOS}

\section{1 - Material}

Os dados de alturas pluviais mensais, em milímetros: foram fornecidos pelo. Setor de Meteorologia da Fazenda Nomura, situada no Municipio de Bandeirantes (PR).

o pluviômetro usado na obtençäo dos dados é do tipo "Ville de Paris", instalado a $440 \mathrm{~m}$ de altitude, latitude $23^{\circ} 15^{\prime} \mathrm{s}$ e longitude $50^{\circ} 23^{\prime} \mathrm{W}$.

As observações referem-se ao perílodo de 1930 a 1977. num total de quarenta e oito anos.

\section{2 - Mëtodo}

A metodologia usada na análise harmônica baseia-se nas funções trigonométricas seno e coseno, sendo desenvolvida pela álgetra matricial. 


\subsection{1 - Desenvolvimento teörico}

Uma função $f(t)$ é periódica de período $T>0$, se, para todo $t$, ocorrer

$$
f(t \pm T)=f(t)
$$

ou ainda,

$$
f(t \pm n T)=f(t) \quad n=0,1,2, \ldots
$$

As funções trigonométricas sen $t$ e cos $t$ são funções periódicas, de período $T=360^{\circ}$, ou seja:

$$
\begin{aligned}
& \operatorname{sen}(t \pm n 360)^{0}=\operatorname{sen} t^{0} \\
& \cos (t \pm n 360)^{\circ}=\cos t^{0} \quad n=0,1,2, \ldots
\end{aligned}
$$

A função, representada pela série trigonométrica de FOURIER,

$$
f(t)=a_{0}+\sum_{j=1}^{\infty} a_{j} \operatorname{sen}\left(j \theta t+A_{j}\right)
$$

é periódica, de período $T$, onde $\theta=\frac{360^{\circ}}{T}$, sendo $\theta$ chamado frequência angular.

$$
\begin{aligned}
& \text { Desenvolvendo-se }(1) \text {, tem-se: } \\
& \begin{aligned}
f(t)=a_{0} & +a_{1} \operatorname{sen}\left(\theta t+A_{1}\right)+a_{2} \operatorname{sen}\left(2 \theta t+A_{2}\right)+\ldots+ \\
& +a_{j} \operatorname{sen}\left(j \theta t+A_{j}\right)+\ldots
\end{aligned}
\end{aligned}
$$

Budak e Fomin (1973), citados por PEREIRA (1978),con sideram esta função uma soma de componentes senoidais com frequências distintas, e sendo T um perfolo comum a todos os componentes. 
0 componente senoidal com frequência angular $\theta_{j}=j \theta$ ë o j-ésimo harmônico da função periödica. 0 primeiro harmônico,tam bém chamado onda fundamental, tem o mesmo período e a mesma frequên cia que a função.

$$
\text { Os coeficientes } a_{j}\left(a_{j}>0\right) \text { e } A_{j}\left(0^{\circ}<A_{j}<360^{\circ}\right) \text { são }
$$

denominados respectivamente, amplitude harmônica e ângulo fase.

Desenvolvendo o seno da soma para cada um dos harmô-

nicos em (2), tem-se:

$$
\begin{aligned}
f(t)=a_{0} & +a_{3}\left(\operatorname{sen} \theta t \cos A_{1}+\operatorname{sen} A_{1} \cos \theta t\right)+ \\
& +a_{2}\left(\operatorname{sen} 2 \theta t \cos A_{2}+\operatorname{sen} A_{2} \cos 2 \theta t\right)+\ldots+ \\
& +a_{j}\left(\operatorname{sen} j \theta t \cos A_{j}+\operatorname{sen} A_{j} \cos j \theta t\right)+\ldots
\end{aligned}
$$

Fazendo

$$
\begin{array}{rrr}
a_{1} \operatorname{sen} A_{1}=p_{1} & a_{1} \cos A_{1}=q_{1} \\
a_{2} \operatorname{sen} A_{2}=p_{2} & a_{2} \cos A_{2}=a_{2} \\
\ldots & \ldots & \ldots \\
a_{j} \operatorname{sen} A_{j}=p_{j} & \ldots & a_{j} \cos A_{j}=q_{j} \\
\ldots & \ldots & \ldots
\end{array}
$$

e substituindo-se estes valores em (3), tem-se:

$$
\begin{aligned}
f(t)=a_{0} & +q_{1} \operatorname{sen} \theta t+p_{1} \cos \theta t+ \\
& +q_{2} \operatorname{sen} 2 \theta t+p_{2} \cos 2 \theta t+\ldots+ \\
& +q_{j} \operatorname{sen} j \theta t+p_{j} \cos j \theta t+\ldots
\end{aligned}
$$


14.

Para o j-ésimo harmônico, tem-se:

$$
p_{j}=a_{j} \operatorname{sen} A_{j} \quad \text { e } \quad q_{j}=a_{j} \cos A_{j},
$$

portanto,

$$
\begin{aligned}
& a_{j}^{2}=p_{j}^{2}+q_{j}^{2} \\
& \frac{p_{j}}{q_{j}}=\operatorname{tg} A_{j}
\end{aligned}
$$

ou ainda:

$$
\begin{aligned}
& a_{j}=\mid \sqrt{p_{j}^{2}+\frac{q_{j}^{2}}{j}} \\
& A_{j}=\operatorname{arctg}\left(\frac{p_{j}}{q_{j}}\right)
\end{aligned}
$$

Os parâmetros $p_{j}, q_{j}, a_{j}$ e $A_{j}$ são representados graficamente na Figura 1.

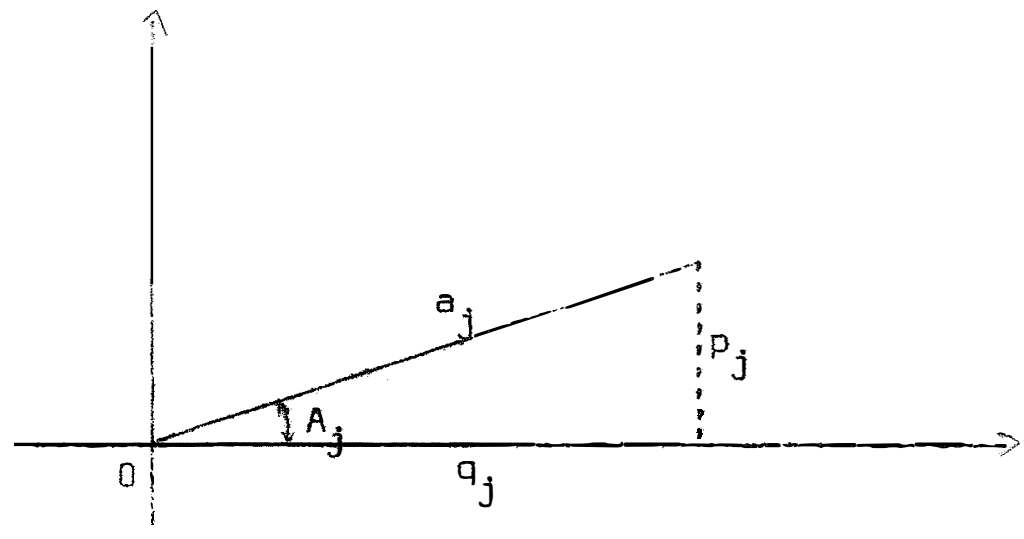

Figura 1 - Parâmetros do j-ésimo harmônico. 
o quadrante ao qual pertence o arco $A_{j}$ é determinado pelos sinałs dos parámetros $p_{j}$ e $q_{j}$, segundo $(\xi)$, conforme descrito abaixo:

\begin{tabular}{ccc}
$\begin{array}{c}\text { Sinal do } \\
\text { parâmetro } \\
P_{j}\end{array}$ & $\begin{array}{c}\text { Sinal do } \\
\text { paràmetro } \\
q_{j}\end{array}$ & $\begin{array}{c}\text { Quadrante a que } \\
\text { pertence o arco } \\
A_{j}\end{array}$ \\
\hline+ & + & $1^{8}$ \\
- & - & 28 \\
- & - & $3^{8}$ \\
\hline
\end{tabular}

\subsection{2 - Modelo matemätico}

Seja $Y_{t}$ a precipitação mensal observada para $t=1$, $2, \ldots, T$, onde $t$ representa os meses em que foram tomadas as medidas, e T é o comprimento do período a ser estudado.

$$
\text { O modelo a ser utilizado, oriundo da série de Fourier, }
$$

é:

$$
Y_{t}=a_{0}+\sum_{j=1}^{k} a_{j} \operatorname{sen}\left(j \theta t+A_{j}\right)+e_{t}
$$

onde: $a_{0}=$ média geral $\bar{Y}$;

$k$ = maior inteiro que não supera $T / 2$;

$a_{j}=$ amplitude do j-ésimo componente harmônico:

$A_{j}=$ àngulo fase do $j$-ésimo componente harmónico; 
16.

$$
\begin{gathered}
e_{t}=\text { efeito residual referente a t-ésima observação, } \\
\qquad e_{t} \cap N\left(0 ; \sigma^{2}\right) .
\end{gathered}
$$

Desenvolvendo o seno da soma em (9), obtém-se:

$$
\begin{gathered}
Y_{t}=a_{0}+\sum_{j=1}^{k}\left(a_{j} \operatorname{sen} A_{j} \cos j \theta t+a_{j} \cos A_{j} \operatorname{sen} j \theta t\right)+e_{t} \\
\text { Fazendo-se em }(10) .
\end{gathered}
$$

$$
\begin{aligned}
& p_{j}=a_{j} \operatorname{sen} A_{j} \\
& q_{j}=a_{j} \cos A_{j} \\
& y_{t}=y_{t}-a_{0}
\end{aligned}
$$

de tal modo que

$$
\begin{aligned}
& a_{j}=\left|\sqrt{p_{j}^{2}+q_{j}^{2}}\right|, p / j=1,2, \ldots,(k-1) \\
& a_{k}=\left|\sqrt{p_{k}^{2}+q_{k}^{2}}\right|
\end{aligned}
$$

para o caso de $T$ ímpar, e

$$
a_{k}=\left|\sqrt{p_{k}^{2}}\right|=\left|p_{k}\right|
$$

para o caso de $T$ par

$$
A_{j}=\operatorname{arctg}\left(\frac{p_{j}}{q_{j}}\right)
$$

o modelo matemático passa a ser apresentado sob a forma,

$$
y_{t}=\sum_{j=1}^{k}\left(p_{j} \cos j \theta t+q_{j} \operatorname{sen} j \theta t\right)+e_{t}
$$


para o caso de $T$ impar,$~ e$

$$
y_{t}=\sum_{j=1}^{k-1}\left(p_{j} \cos j \theta t+q_{j} \operatorname{sen} j \theta t\right)+p_{k} \cos k \theta t+e_{t}
$$

para o caso de $T$ par.

$$
\begin{aligned}
& \text { Qu, ainda, } \\
& \begin{aligned}
y_{t}=p_{1} \cos \theta t & +p_{2} \cos 2 \theta t+\ldots+p_{k} \cos k \theta t+ \\
& +q_{1} \operatorname{sen} \theta t+q_{2} \operatorname{sen} 2 \theta t+\ldots+ \\
& +q_{k} \operatorname{sen} k \theta t+e_{t}
\end{aligned}
\end{aligned}
$$

para o caso de $T$ impar, e

$$
\begin{aligned}
y_{t}=p_{1} \cos \theta t & +p_{2} \cos 2 \theta t+\ldots+p_{(k-1)} \cos (k-1) \theta t+ \\
& +p_{k} \cos k \theta t+q_{1} \operatorname{sen} \theta t+q_{2} \operatorname{sen} 2 \theta t+ \\
& +\ldots+q_{(k-1)} \operatorname{sen}(k-1) \theta t+e_{t}
\end{aligned}
$$

para o caso de $T$ par.

$$
\text { O sistema de equações pode ser representado matricial }
$$

mente por:

$$
Y=X \beta+\varepsilon \quad,
$$

onde: $[Y]$ = vetar das observações $y_{t}$

$[x]$ = matriz dos coeficientes:

$[B]$ = vetor dos parâmetros $p_{j} \otimes q_{j^{3}}$

$\left[\varepsilon_{]}\right]$= vetor dos erros aleatóríos. 
Assim:

$$
Y=\left[\begin{array}{c}
y_{1} \\
y_{2} \\
\vdots \\
y_{T}
\end{array}\right]
$$

$X=\left[\begin{array}{ccccc}\cos \theta & \cdots & \cos k \theta \operatorname{sen} \theta & \cdots & \operatorname{sen} k \theta \\ \cos 2 \theta & \cdots & \cos 2 k \theta \operatorname{sen} 2 \theta & \cdots & \operatorname{sen} 2 k \theta \\ \cos 3 \theta & \cdots & \cos 3 k \theta \operatorname{sen} 3 \theta & \cdots & \operatorname{sen} 3 k \theta \\ \vdots & \vdots & \vdots & \vdots & \vdots \\ \cos T \theta & \cdots & \cos T k \theta \operatorname{sen} T \theta & \cdots & \operatorname{sen} T k \theta\end{array}\right]$

quando $T$ é impar, e:

$X=\left[\begin{array}{ccccc}\cos \theta & \cdots & \cos k \theta \operatorname{sen} \theta & \cdots & \operatorname{sen}(k-1) \theta \\ \cos 2 \theta & \cdots & \cos 2 k \theta \operatorname{sen} 2 \theta & \cdots & \operatorname{sen} 2(k-1) \theta \\ \cos 3 \theta & \ldots & \cos 3 k \theta \operatorname{sen} 3 \theta & \cdots & \operatorname{sen} 3(k-1) \theta \\ \vdots & \vdots & \vdots & \vdots & \vdots \\ \cos T \theta & \cdots & \cos T k \theta \operatorname{sen} T \theta & \cdots & \operatorname{sen} T(k-1) \theta\end{array}\right]$

quando $T \vec{e}$ par. 
19.
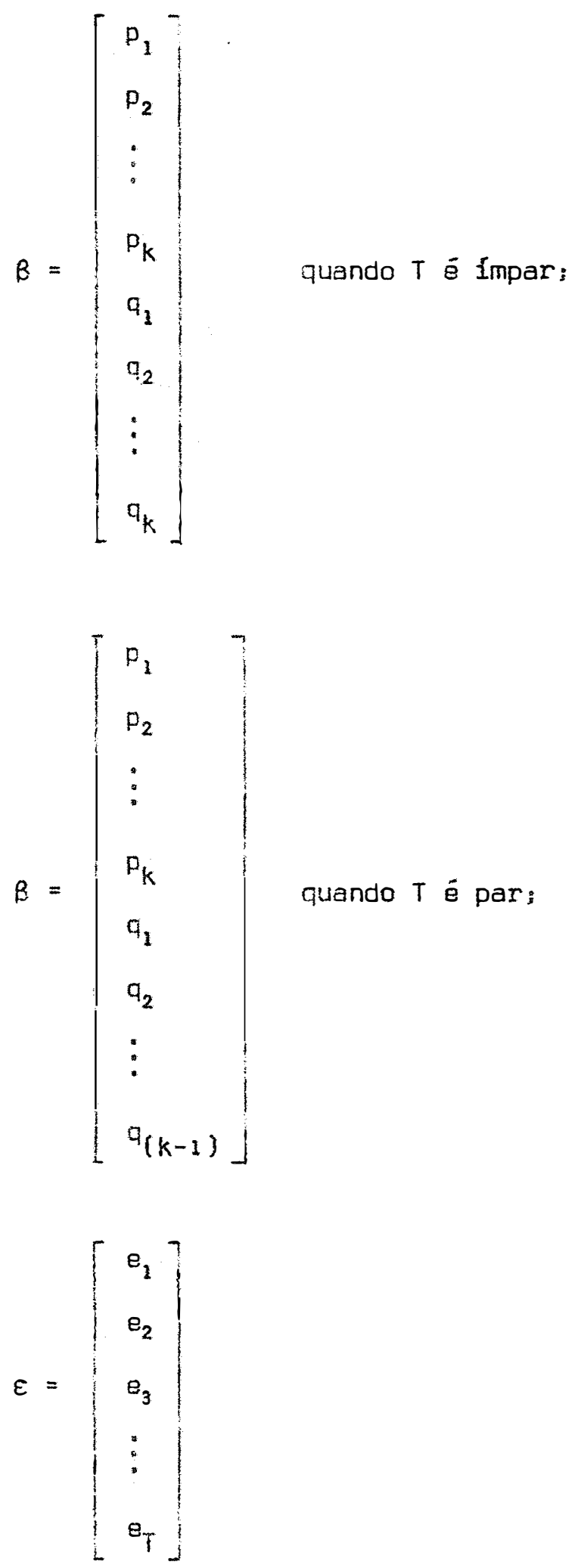
4.2 .3 - Estimativa dos parâmetros, suas variâncias e cova riâncias

Através do método dos quadrados mínimos, chega-se à solução do sistema de equações, obtendo-se

$$
\hat{B}=S^{-1} X \cdot Y,
$$

onde a matriz S é não-singular, resultante da multiplicação da trans posta da matriz $X$ pela própria matriz $X$ obtendo-se: 


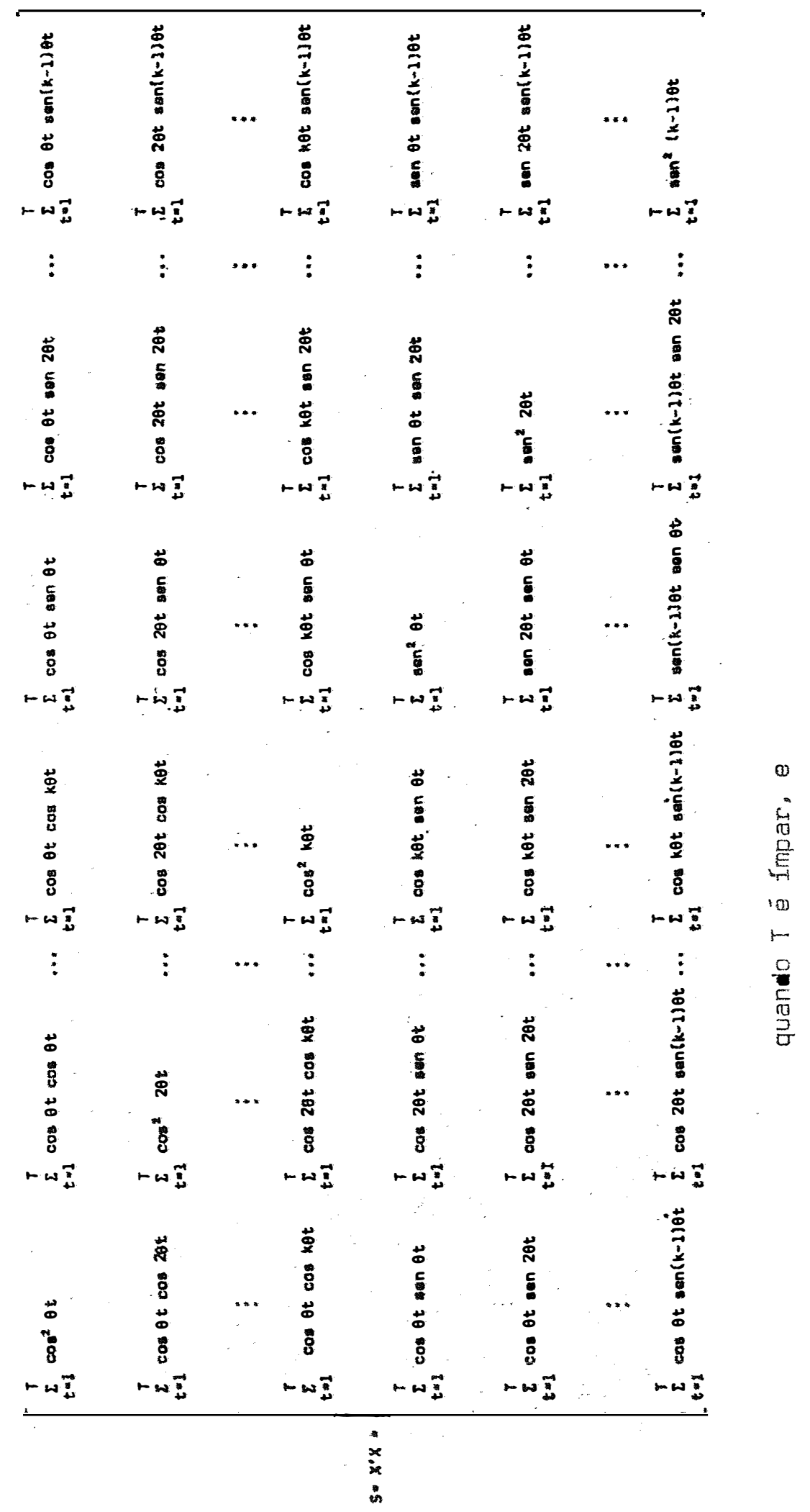




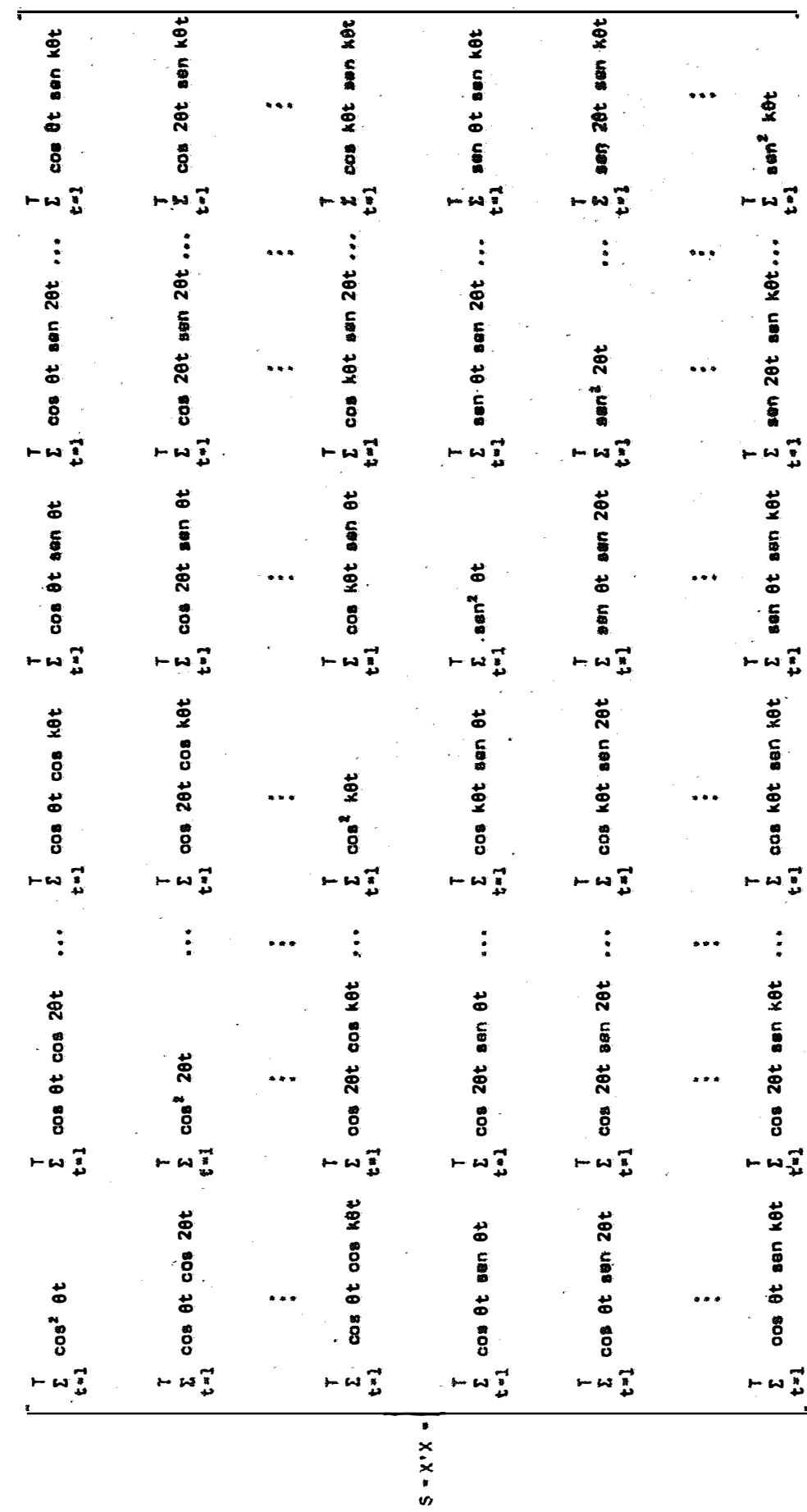


ANDERSON (1971) através das fórmulas de Euler,

$$
\begin{aligned}
& \cos \theta=\frac{1}{2}\left(e^{i \theta}+e^{-i \theta}\right), \\
& \operatorname{sen} \theta=\frac{1}{21}\left(e^{i \theta}-e^{-i \theta}\right) .
\end{aligned}
$$

e.

$$
e^{i \theta}=\cos \theta+i \operatorname{sen} \theta
$$

comprova que:

$$
\begin{aligned}
& \sum_{t=1}^{T} \cos ^{2} j \theta t=\frac{T}{2}, \quad \text { para } j=1,2, \ldots,(k-1), \\
& \sum_{t=1}^{T} \cos ^{2} k \theta t=\frac{T}{2}, \quad \text { quando } T \hat{e} \text { impar, } e \\
& \sum_{t=1}^{T} \cos ^{2} k \theta t=T \quad \& \quad \text { quando } T \text { é par } \\
& \sum_{t=1}^{T} \operatorname{sen}^{2} j \theta t=\frac{T}{2}, \quad \text { para } j=1,2, \ldots k \\
& \sum_{t=1}^{T} \cos j \theta t \operatorname{sen} 1 \theta t=0 \text {, para }\left\{\begin{array}{l}
j=1,2, \ldots, k \\
1=1,2, \ldots, k
\end{array}\right. \\
& \left.\sum_{t=1}^{T} \cos j \theta t \cos i \theta t=0, \text { para } j \neq 1\right\}_{j=1,2, \ldots, k} \\
& \sum_{t=1}^{T} \operatorname{sen} j \theta t \operatorname{sen} 1 \theta t=0, \quad \text { para } j \neq 1\left\{\begin{array}{l}
j=1,2, \ldots, k \\
1=1,2, \ldots, k
\end{array}\right.
\end{aligned}
$$


Desta forma, a matriz $S$ pode ser escrita:

$$
S=\left[\begin{array}{cccccccc}
T / 2 & 0 & \cdots & 0 & 0 & 0 & \cdots & 0 \\
0 & T / 2 & \cdots & 0 & 0 & 0 & \cdots & 0 \\
\vdots & \vdots & \vdots & \vdots & \vdots & \vdots & \vdots & \vdots \\
0 & 0 & \cdots & T / 2 & 0 & 0 & \cdots & 0 \\
0 & 0 & \cdots & 0 & T / 2 & 0 & \cdots & 0 \\
0 & 0 & \cdots & 0 & 0 & T / 2 & \cdots & 0 \\
\vdots & \vdots & \vdots & \vdots & \vdots & \vdots & \vdots & \vdots \\
0 & 0 & \cdots & 0 & 0 & 0 & \cdots & T / 2
\end{array}\right]
$$

quando $T$ é impar, e

$$
S=\left[\begin{array}{cccccccc}
T / 2 & 0 & \cdots & 0 & 0 & 0 & \cdots & 0 \\
0 & T / 2 & \cdots & 0 & 0 & 0 & \cdots & 0 \\
\vdots & \vdots & \vdots & \vdots & \vdots & \vdots & \vdots & \vdots \\
0 & 0 & \cdots & T & 0 & 0 & \cdots & 0 \\
0 & 0 & \cdots & 0 & T / 2 & 0 & \cdots & 0 \\
0 & 0 & \cdots & 0 & 0 & T / 2 & \cdots & 0 \\
\vdots & \vdots & \vdots & \vdots & \vdots & \vdots & \vdots & \vdots \\
0 & 0 & \cdots & 0 & 0 & 0 & \cdots & T / 2
\end{array}\right]
$$

quanto $T$ è par.

A matriz $X \cdot Y$ resulta $\mathrm{em}$ : 


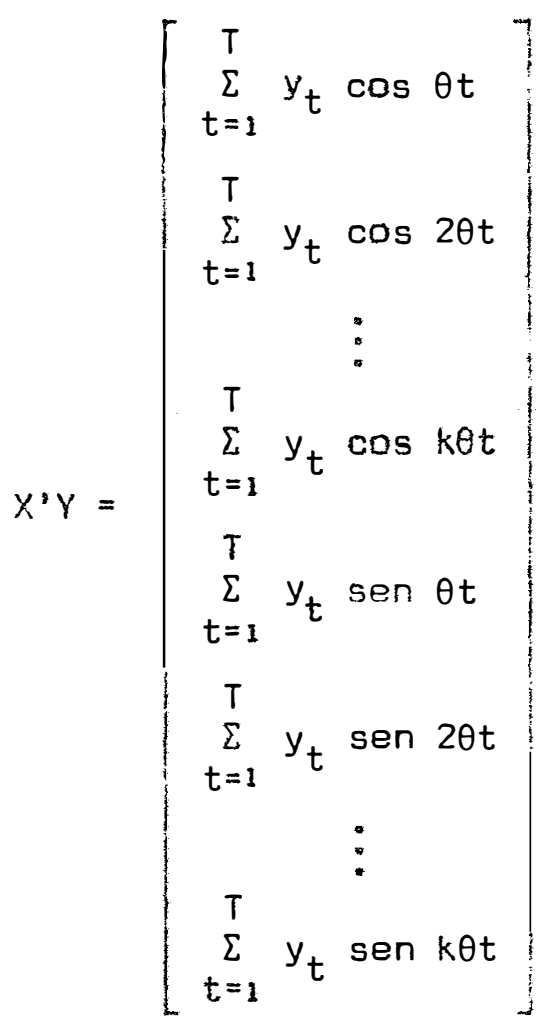

quando $T$ é Impar, e

$$
X^{\prime} \gamma=\left[\begin{array}{ccc}
T & & \\
\sum_{t=1} & y_{t} & \cos \theta t \\
T & & \\
\sum_{t=1} & y_{t} & \cos 2 \theta t \\
T & \vdots \\
t=1 & y_{t} & \cos k \theta t \\
T & & \\
\sum_{t=1} & y_{t} & \operatorname{sen} \theta t \\
T & & \\
\sum_{t=1} & y_{t} & \operatorname{sen} 2 \theta t \\
T & & \\
\sum & y_{t} \operatorname{sen}(k-1) & \theta t
\end{array}\right]
$$

quando $T$ é par. 
As estimativas dos parämetros $p_{j}$ e $q_{j}$, através da ma triz $\hat{\beta}$, são:

$$
\begin{aligned}
\hat{p}_{1} & =\frac{2}{T} \sum_{t=1}^{T} y_{t} \cos \theta t \\
\hat{p}_{2} & =\frac{2}{T} \sum_{t=1}^{T} y_{t} \cos 2 \theta t \\
\vdots & \hat{p}_{k}=\frac{2}{T} \sum_{t=1}^{T} y_{t} \cos k \theta t \\
\hat{p}_{k} & =\frac{1}{T} \sum_{t=1}^{T} y_{t} \cos k \theta t \\
\hat{q}_{1} & =\frac{2}{T} \sum_{t=1}^{T} y_{t} \operatorname{sen} \theta t \\
\hat{q}_{k} & =\frac{2}{T} \sum_{t=1}^{T} y_{t} \operatorname{sen} k \theta t \\
\hat{q}_{2} & =\frac{2}{T} \sum_{t=1}^{T} y_{t} \operatorname{sen} 2 \theta t
\end{aligned}, \text { quando } T \dot{e} \text { Impar, } \theta
$$

As variāncias e covariâncias dos parâmetros estimados são obtidas na matriz de dispersão $D=S^{-1} \sigma^{2}$, sendo: 


$$
\begin{aligned}
& V\left(\hat{p}_{j}\right)=\frac{2 \sigma^{2}}{T} \quad \text { para } j=1,2, \ldots,(k-1) \\
& V\left(\hat{p}_{k}\right)=\frac{2 \sigma^{2}}{T} \quad \text { quando } T \text { émpar, e } \\
& V\left(\hat{p}_{k}\right)=\frac{\sigma^{2}}{T} \quad \text { quando } T \text { é par } \\
& V\left(\hat{q}_{j}\right)=\frac{2 \sigma^{2}}{T} \quad \text { para } j=1,2, \ldots, k
\end{aligned}
$$

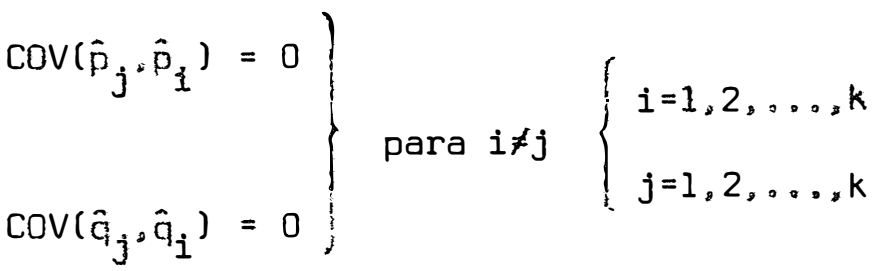

$$
\begin{aligned}
& \operatorname{Cov}\left(\hat{p}_{j}, \hat{q}_{i}\right)=0 \quad \text { para }\left\{\begin{array}{l}
i=1,2, \ldots, k \\
j=1,2, \ldots, k
\end{array}\right.
\end{aligned}
$$

Como as covariâncias são todas nulas, conclui-se que os parâmetros estimados são independentes.

Será também de interesse determinar as variâncias das estimativas das amplitudes dos componentes harmónicos $\left(a_{j}\right)$.

Devido a complexidade existente para a determinação exata destas variâncias, foi utilizado o processo de diferenciação: para a obtenção de seus valores aproximados.

Se $\hat{a}_{j}=\left|\sqrt{\hat{p}_{j}^{2}+\hat{q}_{j}^{2}}\right|$, da equação $(14)$, e conhecendo- se as variáncias e covariâncias de $\hat{p}_{j}$ e $\hat{q}_{j}$, equações (22) a (28). 


$$
\begin{aligned}
& d\left(\hat{a}_{j}\right)=\frac{2 \hat{p}_{j}}{2 \sqrt{\hat{p}_{j}^{2}+\hat{a}_{j}^{2}}} d \hat{p}_{j}+\frac{2 \hat{a}_{j}}{2 \sqrt{\hat{p}_{j}^{2}+\hat{a}_{j}^{2}}} d \hat{a}_{j} \\
& {\left[d\left(\hat{a}_{j}\right)\right]^{2}=\frac{\hat{p}_{j}^{2}}{\hat{p}_{j}^{2}+\hat{a}_{j}^{2}}\left(d \bar{p}_{j}\right)^{2}+\frac{\hat{q}_{j}^{2}}{\hat{p}_{j}^{2}+\hat{q}_{j}^{2}}\left(d \hat{a}_{j}\right)^{2}+} \\
& +\frac{2 \hat{p}_{j} \hat{q}_{j}}{\hat{p}_{j}^{2}+\hat{q}_{j}^{2}}\left(d \hat{p}_{j}\right)\left(d \hat{q}_{j}\right) \\
& V\left(\hat{a}_{j}\right) \simeq \frac{\hat{p}_{j}^{2}}{\hat{p}_{j}^{2}+\hat{q}_{j}^{2}} V\left(\hat{p}_{j}\right)+\frac{\hat{q}_{j}^{2}}{\hat{p}_{j}^{2}+\hat{q}_{j}^{2}} V\left(\hat{a}_{j}\right)+ \\
& +\frac{2 \hat{p}_{j} \bar{q}_{j}}{\hat{p}_{j}^{2}+\hat{q}_{j}^{2}} \operatorname{cov}\left(\hat{p}_{j}, \bar{q}_{j}\right) \text {. }
\end{aligned}
$$

$\operatorname{Como} \operatorname{cov}\left(\hat{p}_{j}, \hat{q}_{j}\right)=0$, equação $(28)$.

$$
v\left(\hat{a}_{j}\right) \simeq \frac{\hat{p}_{j}^{2}}{\hat{p}_{j}^{2}+\hat{q}_{j}^{2}} v\left(\hat{p}_{j}\right)+\frac{\hat{q}_{j}^{2}}{\hat{p}_{j}^{2}+\hat{q}_{j}^{2}} v\left(\hat{q}_{j}\right)
$$

Como pelas equações $\{22\}$ a (25),

$$
\begin{aligned}
& V\left(\hat{p}_{j}\right)=V\left(\hat{q}_{j}\right]=\frac{2 \sigma^{2}}{T}, \text { para } j=1,2, \ldots(k-1) \\
& V\left(\hat{p}_{k}\right)=V\left(\hat{q}_{k}\right]=\frac{2 \sigma^{2}}{T}, \text { quando } T \vec{e} \text { ímpar, e } \\
& V\left\{\hat{p}_{k}\right)=\frac{\sigma^{2}}{T}, \text { quando } T \vec{e} \text { par. }
\end{aligned}
$$

chega-se, através de (29), a: 
29.

$$
\begin{aligned}
& V\left(\hat{a}_{j}\right) \simeq \frac{2 \sigma^{2}}{T}, j=1,2, \ldots(k-1) \quad \text { quando } T \text { é ímpar, e (31) } \\
& V\left(\hat{a}_{k}\right) \simeq \frac{2 \sigma^{2}}{T} \quad \Rightarrow \quad \text { quando } T \text { è par } \\
& V\left(\hat{a}_{k}\right) \simeq \frac{\sigma^{2}}{T} \quad s \quad \text { (32) } \\
& A V\left(\hat{a}_{j}\right) \text { coincide sempre com } V\left(\hat{p}_{j}\right)(j=1,2, \ldots, k), \text { pe - }
\end{aligned}
$$

lo método aproximado adotado.

\subsection{4 * Transformação dos Dados}

Uma das exigèncias do modelo matemático e dos testes de significância é que os erros aleatörios tenham distribuição normal.

Quando isto não ocorre, hä necessidade de se fazer a aproximação normai através de transformação nos dados.

AMARAL (1968) aconselha uma transformação baseada na förmula $\sigma_{x}=\beta x^{a}$. onde os valores $\underline{a}$ e $\underline{B}$ podem ser determinados para cada grupo de observações, sendo $x$ a média de precipitação men sal num perf́odo de $N$ anos e $\sigma_{x}$ o desvio padrão das observações utilizadas para o cálculo desta média. Determinado o valor de a aconselha a transformação $y=x^{(1-a)}$.

SILVA (1977) sugere a padronização da transformação para dados de precipitação, através da fórmula $y=\sqrt[3]{x}$.

No presente caso, utilizar-se-á uma transformação do 
tipo $y=x^{1 / c}$, procurando o valor mais adequado para $c$, em função do teste de normalidade dos dados.

\subsection{5 - Anälise de Variância}

Considerando-se que as observações mensais foram repetidas durante $N$ períodos ou anos, aconselha-se o emprego da análí se de variância para testar a estabilidade dos componentes harmônicos no decorrer dos $\mathrm{N}$ períodos estudados.

\subsubsection{1 - Teste de normalidade}

Para que a análise de variāncia possa ser aplicada aos contrastes, há necessidade de testarmos a normalidade dos mes mos, visando atender a uma das exigências do teste $F$.

AMARAL (1968) e THIEBAUT (1975) aconselham que isto seja feito através do teste de normalidade. para grandes amostras. apresentado por Fisher em 1941" no qual se comparam as medidas de assimetria $\left(g_{1}\right)$ e curtose $\left(g_{2}\right)$ dos contrastes, com as respectivas me didas de assimetria $\left(g_{1}=0\right)$ e curtose $\left(g_{2}=0\right)$ da distribuição nor mal, através do teste $\underline{t}$.

As estatísticas $g_{1}$ e $g_{2}$ são estimadas através das fór mulas:

$$
\begin{aligned}
& \hat{g}_{1}=\sqrt{\frac{W_{3}^{2}}{W_{2}^{3}}} \\
& \hat{g}_{2}=\frac{W_{4}}{W_{2}^{2}}
\end{aligned}
$$


31.

nas quais, para o contraste $p_{1}$, por exemplo, tem-se:

$$
\begin{aligned}
& W_{2}= \frac{\sum_{i=1}^{N}\left(\tilde{p}_{1 i}-\bar{p}_{1}\right)^{2}}{(N-1)} \\
& W_{3}=\frac{N \sum_{i=1}^{N}\left(\bar{p}_{1 i}-\bar{p}_{1}\right)^{3}}{(N-1)(N-2)} \\
& W_{4}=\frac{(N+1) \sum_{i=1}^{N}\left(\hat{p}_{1 i}-\bar{p}_{1}\right)^{4}-}{(N-I)(N-2)(N-3)}\left\{\begin{array}{l}
(N-1) \\
-\frac{3(N)}{N}\left[\sum_{i=1}^{N}\left(\hat{p}_{1 i}-\bar{p}_{1}\right)^{2}\right.
\end{array}\right\}
\end{aligned}
$$

Segundo aquele autor, $g_{1}$ e $g_{2}$ têm distribuição normal de média zero e desvios padrões dados por

$$
\begin{aligned}
& s\left(\hat{g}_{1}\right)=\sqrt{\frac{6 N(N-1)}{(N-2)(N+1)(N+3)}} \\
& s\left(\bar{g}_{2}\right)=\sqrt{\frac{24 N(N-1)^{2}}{(N-3)(N-2)(N+3)(N+5)}} .
\end{aligned}
$$

A distribuição de cada contraste serä considerada co mo aproximadamente normal se a um nível a de significāncia os valo res de $t$ calculados não superarem os da tabela, com $N-1$ graus de li berdade, comprovando-se as seguintes hipóteses de nulidade: 


$$
\begin{array}{rlrl}
H_{0}: g_{1}=0 & & H_{0}: g_{2}=0 \\
H_{1}: g_{1} \neq 0 & & H_{1}: g_{2} \neq 0 \\
t_{1}=\frac{\bar{g}_{1}}{s\left(\hat{g}_{1}\right)} & \\
t_{2}=\frac{\hat{g}_{2}}{s\left(\hat{g}_{2}\right)} &
\end{array}
$$

\subsubsection{2 - Quadros de anālise de variância}

Comprovada a normalidade dos contrastes, pode-se, en tão, aplicar a análise de variância, utilizando-se o teste $F$.

De acordo com BLISS (1958), AMARAL (1968) e PEREIRA (1978), a análise de variância para o presente caso, assemelha-se ao modelo empregado para blocos ao acaso, usando-se, para cada componen te harmônico, uma variância residual específica, relativa à variação apresentada no decorrer dos anos, conforme mostram as Tabelas 1 e 2.

Devido ao emprego de um resíduo específico para cada contraste, as estimativas das variâncias para as amplitudes estimadas deverão ser calculadas através da equação (29) em 4.2.3, pois, neste caso, não teremos necessariamente $\hat{V}\left(\hat{p}_{j}\right)=V\left(\hat{q}_{j}\right)$.

Segundo AMARAL (1968) deve-se aplicar a análise de variância, não apenas aos contrastes, mas também a cada amplitude dos componentes harmônicos, através da junção dos contrastes que a compõe, desde que as variâncias residuais destes contrastes sejam 
homogêneas. A junção acima citada, encontra-se representada nas Tabelas 3 e 4 .

Tabela $I$ - Análise de variância dos contrastes $\hat{p}_{j}$ e $\hat{q}_{j}$, para o caso de $T$ impar:

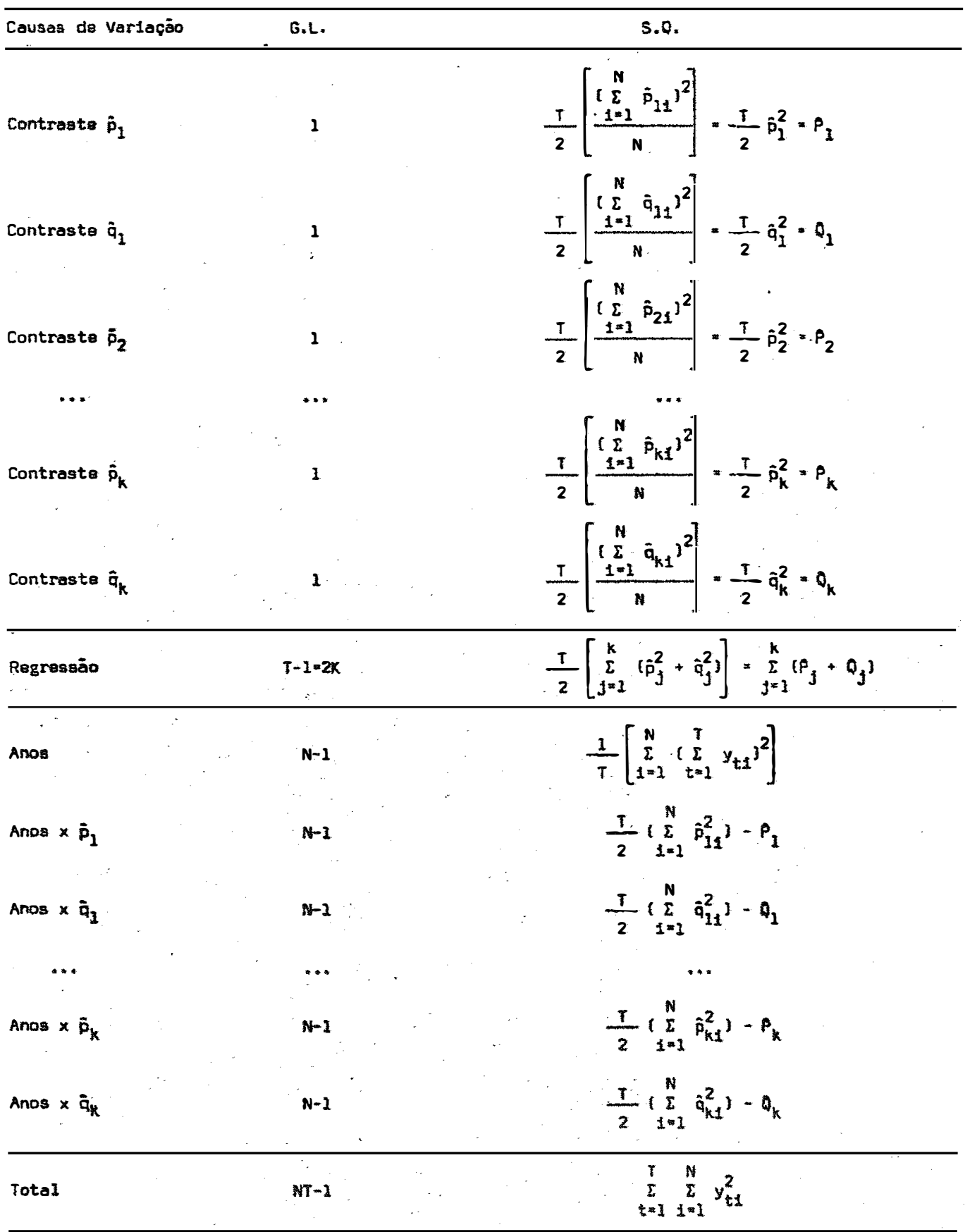


Tabela 2 - Anälise de variância dos contrastes $\hat{p}_{j}$ e $\hat{q}_{j}$ para o caso de $T$ par.

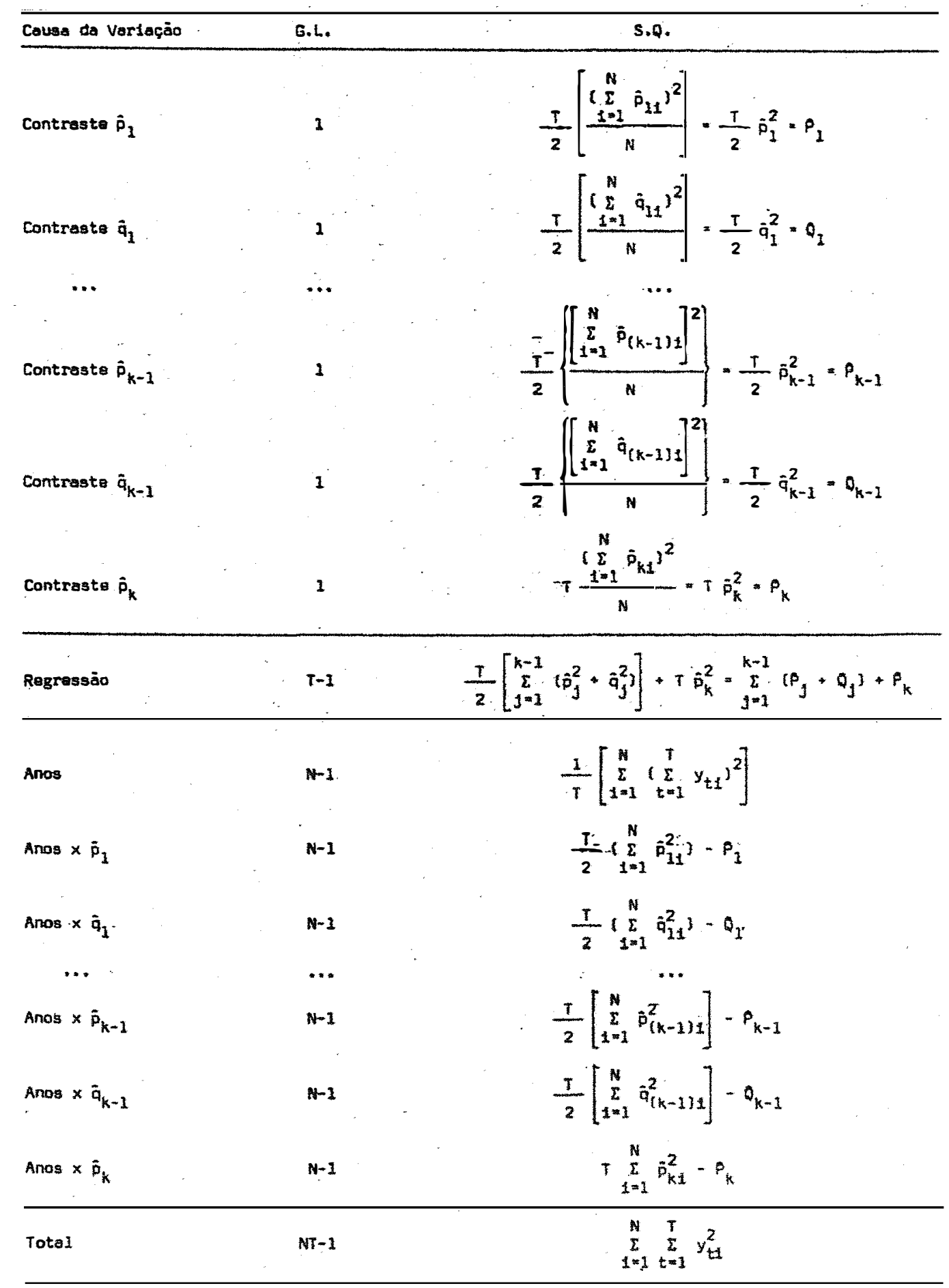


Tabela 3 - Análise de varianncia c amplitudes ì jo para o caso de $T$ inpar.

\begin{tabular}{|c|c|c|c|}
\hline Causas da Variação & G.L. & & $S . Q$. \\
\hline Amplitude $\hat{a}_{1}$ & 2 & & $\hat{P}_{2}+\hat{Q}_{1}$ \\
\hline Amplitude $\hat{a}_{2}$ & 2 & & $P_{2}+Q_{2}$ \\
\hline$\ldots$ & $\cdots$ & & $\ldots$ \\
\hline Amplitude $\hat{a}_{k}$ & 2 & & $\hat{P}_{k}+\hat{Q}_{k}$ \\
\hline Regressão & $T-1=2 k$ & & $\sum_{j=1}^{k}\left(\beta_{j}+\hat{Q}_{j}\right)$ \\
\hline Anos & $N-1$ & $\frac{1}{T}$ & $-\left[\sum_{i=1}^{N}\left(\sum_{t=1}^{T} y_{t i}\right)^{2}\right]$ \\
\hline Anos $\times \bar{a}_{1}$ & $2(N-1)$ & $\frac{T}{2} \sum_{i=1}^{N}$ & $\left\{\hat{p}_{11}^{2}+\ddot{q}_{1 \dot{1}}^{2}\right\}-\left(\hat{P}_{1}+\hat{Q}_{3}\right)$ \\
\hline$\cdots$ & $\cdots$ & & $\cdots$ \\
\hline Anos $\times \bar{a}_{k}$ & $2(\mathrm{~N}-1)$ & $\frac{T}{2} \sum_{i=1}^{N}$ & $\left\{\hat{p}_{k i}^{2}+\hat{q}_{k i}^{2}\right)-\left(\hat{p}_{k}+\hat{q}_{k}\right\}$ \\
\hline Total & $N T-1$ & & $\sum_{i=1}^{N} \sum_{t=1}^{T} y_{t i}^{2}$ \\
\hline
\end{tabular}


Tabela 4 - Análise de variância das amplitudes $\hat{a}_{j}$, para o caso de $T$ par.

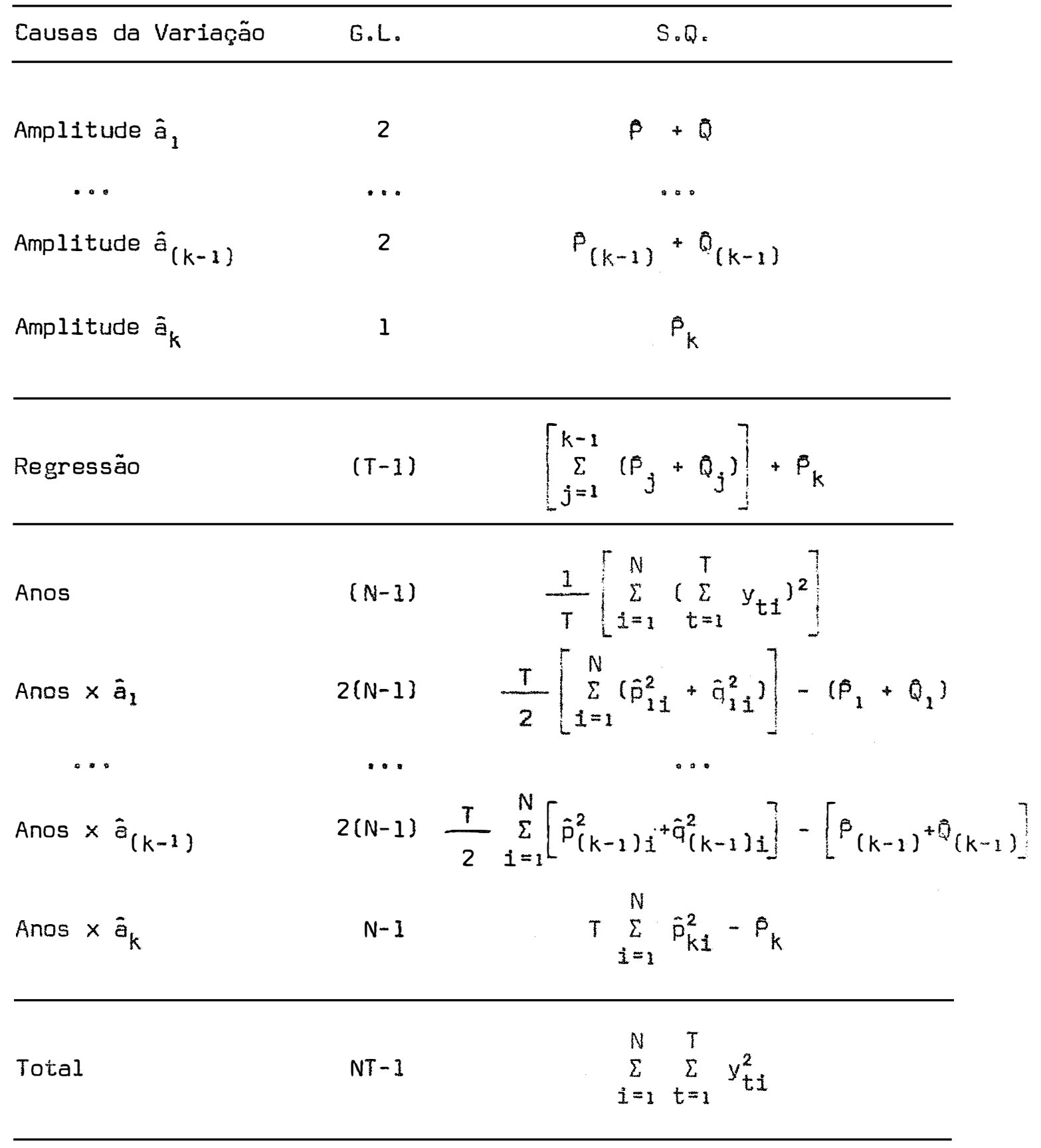




\subsection{6 - Intervalo de confiança para os parâmetros estimados}

De posse das estimativas $\hat{p}_{j}, \hat{q}_{j}$ e $\hat{a}_{j}$, e, dos quadrados médios de suas respectivas interações com anos, obtidos na anälise de variância (Tabelas 1,2, 3 e 4), pode-se determinar os intervalos de confiança para os parâmetros.

Para $p_{j}$ e $q_{j}$, o intervalo de confiança é dado por:

$$
\begin{aligned}
& \hat{p}_{j}-t \cdot s\left(\hat{p}_{j}\right) \leq p_{j} \leq \hat{p}_{j}+t \cdot s\left(\hat{p}_{j}\right) \\
& \hat{q}_{j}-t \cdot s\left(\hat{q}_{j}\right) \leq q_{j} \leq \hat{q}_{j}+t=s\left(\hat{q}_{j}\right)
\end{aligned}
$$

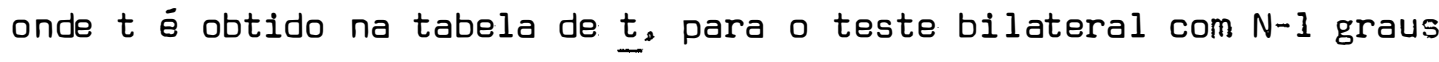
de liberdade, a um determinado nível $\alpha$ de significância.

$$
\begin{aligned}
& \text { Para } a_{j} \text { o intervalo de confiança é dado por: } \\
& \hat{a}_{j}-t \cdot s\left(\hat{a}_{j}\right) \leq a_{j} \leq \hat{a}_{j}+t \cdot s\left(\hat{a}_{j}\right)
\end{aligned}
$$

onde $t$ é obtido na tabela de $\underline{t}$, para o teste bilateral, a um determinado nível a de significância, com $2(\mathrm{~N}-1)$ graus de liberdade, exceto no caso de $a_{k}$ para $T$ par, quando o número de graus de liberdade será $\mathrm{N}-1$.

\section{2 .7 - Equação de regressão}

Determinados os componentes harmônicos significativos, através da análise de variância, pode-se estabelecer a equação de regressão para os dados observados. 
Para tanto, serão considerados todas os componentes harmônicos até o ültimo significativo.

Para melhor visualização utiliza-se, ainda, a representação gráfica de cada componente harmônico considerado, e a função resultante do conjunto destes componentes, através de curvas re presentadas em eixus ortogonais. 
39.

\section{RESULTADOS E DISCUSSÃ.O}

A metodologia descrita foi empregada considerando-se três casos distintos: primeiramente, foram estimadas as precipitações mensais para o período anual, de janeiro a dezembro; a seguir, foram estimadas as precipitações mensais apenas para o período seco, de abril a setembro; por ültimo, foram estimadas as precipitações mensais apenas para o período chuvoso, de outubro a março.

Os dados originais de precipitação mensal, em milíme tros, utilizados nos três casos, para a série de 48 anos, são encon trados no Apêndice l, e seu ajuste para meses de trinta dias, no Apèndice 2.

Nos três casos estudados, houve necessidade de se transformar os dados ajustados para meses de trinta dias, conforme citado em 4.2.4, visando-se a homogeinização das variáncias, atra- 
vés da fórmula

$$
y=\sqrt{x}=x^{1 / 2}
$$

Os dados transformados são encontrados no Apêndice 3.

\section{1 - Estimativa das Precipitações Mensais Para o Período Anual (janeiro a dezembro)}

Foi calculada a média aritmética dos 576 dados constantes do Apêndice 3, cujo valor obtido foi 9.77 . A seguir foram ob. tidos os desvios dos dados em relação à média, desvios estes constantes do Apêndice 4.

\section{1 .1 - Modelo matemático}

Nestas condições, para o período anual, ou seja, para $T=12$, o modelo matemätico oriundo de (21) em 4.2 .2 , é:

$$
\begin{aligned}
y_{t}=p_{1} \cos \theta t & +p_{2} \cos 2 \theta t+p_{3} \cos 3 \theta t+ \\
& +p_{4} \cos 4 \theta t+p_{5} \cos 5 \theta t+ \\
& +p_{6} \cos 6 \theta t+q_{1} \operatorname{sen} \theta t+ \\
& +q_{2} \operatorname{sen} 2 \theta t+q_{3} \operatorname{sen} 3 \theta t+ \\
& +q_{4} \operatorname{sen} 4 \theta t+q_{5} \operatorname{sen} 5 \theta t+e_{t}
\end{aligned}
$$

onde:

$$
\begin{aligned}
& \theta=\frac{360^{\circ}}{12}=30^{\circ} \\
& t=1,2, \ldots, 12 .
\end{aligned}
$$


Os componentes harmônicos considerados em (45), têm os seguintes períodos: $T=12$ meses (para $j=1$ ),$\frac{T}{2}=6$ meses (para $j=2$ ),$\frac{T}{3}=4$ meses (para $j=3$ ), $\frac{T}{4}=3$ meses (para $j=4$ ), $\frac{T}{5}=2,4$ meses (para $j=5$ ) e $\frac{T}{6}=2$ meses (para $j=6$ ).

Como para cada mês tem-se $N=48$ repetições,

$$
\begin{aligned}
y_{t i}=p_{1 i} \cos \theta t & +p_{2 i} \cos 2 \theta t+p_{3 i} \cos 3 \theta t+ \\
& +p_{4 i} \cos 4 \theta t+p_{5 i} \cos 5 \theta t+ \\
& +p_{6 i} \cos 6 \theta t+q_{1 i} \operatorname{sen} \theta t+ \\
& +q_{2 i} \operatorname{sen} 2 \theta t+q_{3 i} \operatorname{sen} 3 \theta t+ \\
& +q_{4 i} \operatorname{sen} 4 t+q_{5 i} \operatorname{sen} 5 \theta t+e_{t i}(46)
\end{aligned}
$$

Desta forma, a matriz $Y$ terá dimensões $T \times N$, ou seja, 12×48, sendo encontrada no Apêndice 4, na forma de $Y^{\prime}$.

\section{1 .2 - Estimativa dos parâmetros}

Conforme 4.2.3, a solução do sistema de equações,cal culada através de computador, resulta numa matriz $\hat{\beta}$, cujas dimensões são $11 \times 48$, contendo todos os $T-1=11$ contrastes estimados, para cada um $\operatorname{dos} N=48$ anos.

Os Apêndices 5, 6 e 7 apresentam, respectivamente, as matrizes $S^{-1}, X^{\prime}$ e $\bar{\beta}^{\prime}$.

Para efeito de obtenção da equação de regressäo refe rente ao período anual, cada um dos $T-1=11$ contrastes foi obtido através da média de seus valores estimados durante os $N=48$ anos. 
42 .

Com estes valores médios, foram calculadas as estima tivas de $a_{j}$ e $A_{j}$, conforme descrito em 4.2.2, equações (14), (16) e (17)。

A Tabela 5 contém as estimativas dos valores dos con trastes $\left(p_{j}\right.$ e $\left.q_{j}\right)$, bem como dos parāmetros $a_{j}$ e $A_{j}$.

Tabela 5 - Valores estimados de $p_{j}, q_{j}, a_{j}$ e $A_{j}$, referentes ao período anual.

\begin{tabular}{ccccc}
\hline$j$ & $\hat{p}_{j}$ & $\hat{q}_{j}$ & $\hat{a}_{j}$ & $\bar{A}_{j}$ \\
\hline 1 & 3,16951 & 1,11675 & 3,360495 & 70,590522 \\
2 & 0,22022 & 0,12356 & 0,252515 & 60,704294 \\
3 & $-1,14609$ & 0,24327 & 1,171624 & 281,983787 \\
4 & 0,20672 & 0,29366 & 0,359123 & 35,143375 \\
5 & 0,00822 & 0,11695 & 0,117239 & 4,020505 \\
6 & 0,23884 & - & 0,238840 & 90,000000 \\
\hline
\end{tabular}

\section{$5 \cdot 1.3$ - Anālise de variância}

\subsubsection{1 - Teste de normalidade}

Visando atender às exigências do teste $F$, empregado na anälise de variância, foi aplicado um teste de normalidade aos contrastes $\hat{p}_{j}$ e $\hat{q}_{j}$ obtidos para os $N=48$ anos, conforme descrito em 4.2 .5 .1 .

Os resultados finais dos cálculoss obtidos por computador, são encontrados na Tabela 6. 
Tabela 6 - Valores dos coeficientes de assimetria $\left(g_{1}\right)$ e curtose $\left(g_{2}\right)$ e os respectivos valores de $t$ calculados para os con trastes $p_{j}$ e $q_{j}$, dos componentes que farão parte da equa ção de regressão, para o período anual.

\begin{tabular}{ccccc}
\hline Contrastes & $\hat{\mathrm{g}}_{1}$ & $\hat{\mathrm{g}}_{2}$ & $\mathrm{t}_{1}$ & $\mathrm{t}_{2}$ \\
\hline$\hat{\mathrm{p}}_{1}$ & 0,689551 & 1,215114 & 2,009480 & 1,801778 \\
$\hat{\mathrm{q}}_{1}$ & 0,574995 & 1,344591 & 1,675641 & 1,993768 \\
$\hat{\mathrm{p}}_{2}$ & 0,093340 & 1,062189 & 0,272010 & 1,575021 \\
$\hat{\mathrm{q}}_{2}$ & 0,070757 & 0,477879 & 0,206200 & 0,708602 \\
$\hat{\mathrm{p}}_{3}$ & 0,465199 & 0,835950 & 1,355677 & 1,239551 \\
$\hat{\mathrm{q}}_{3}$ & 0,139887 & 0,556569 & 0,407658 & 0,825284 \\
\hline
\end{tabular}

Os desvios padrões de $g_{1} e g_{2}$ utilizados no "teste de $t$ ", apresentaram os seguintes valores:

$$
s\left(\hat{g}_{1}\right)=0,343149 \quad s \quad s\left(\hat{g}_{2}\right)=0,674397 .
$$

Os valores de $t$ calculados mostraram-se não significativos, o que permite aceitar as hipóteses de nulidade, ou sefa: $g_{1}=0$ e $g_{2}=0$

Neste caso, admite-se que os dados podem ser estudados através da distribuição normal.

\subsubsection{2 - Quadros de anālise de variância}

As Tabelas 7 e 8 apresentam os resultados obtidos nas anälises de variaancia aplicadas aos contrastes $p_{j}$ e $q_{j}$. 
Tabela 7 - Análise de variância aplicada aos contrastes $p_{j}$ e $q_{j}$ das precipitações mensais em Bandeirantes-PR, para o período anual.

\begin{tabular}{|c|c|c|c|c|}
\hline Causas de Variação & G.L. & $S . Q$. & Q.M. & $F$ \\
\hline Contraste $\mathrm{P}_{1}$ & 1 & & 2893,196936 & $228,92 * *$ \\
\hline Contraste $q_{1}$ & 1 & & 359,174272 & $27.64 * *$ \\
\hline Contraste $\mathrm{P}_{2}$ & 1 & & 13,967462 & 1,59 \\
\hline Contraste $q_{2}$ & 1 & & 4,397362 & 0,40 \\
\hline Contraste $P_{3}$ & 1 & & 378,297995 & $34,58 * *$ \\
\hline Contraste $q_{3}$ & 1 & & 17,044537 & 1,73 \\
\hline Contraste $\mathrm{P}_{4}$ & 1 & & 12,307373 & 0,95 \\
\hline Contraste $q_{4}$ & 1 & & 24.837152 & 3,33 \\
\hline Contraste $p_{5}$ & 1 & & 0.019486 & 0,002 \\
\hline Contraste $q_{5}$ & 1 & & 3,939189 & 0,44 \\
\hline Contraste $P_{6}$ & 1 & & 32,859722 & 3,61 \\
\hline Regressão & (11) & 3740,041486 & & \\
\hline Anos & 47 & 787,075492 & 16,746287 & $1,58 * *$ \\
\hline Anos $\times P_{1}$ & 47 & 594,019072 & 12,638704 & \\
\hline Anos $\times q_{1}$ & 47 & 610,737278 & 12,994410 & \\
\hline Anos $\times p_{2}$ & 47 & 412,708864 & 8,781040 & \\
\hline Anos $\times \mathrm{q}_{2}$ & 47 & 521,800898 & 11,102147 & \\
\hline Anos $\times P_{3}$ & 47 & 514,089781 & 10,938080 & \\
\hline Anos $\times \mathrm{q}_{3}$ & 47 & 462,020147 & 9,830216 & \\
\hline Anoss $\times \mathrm{P}_{4}$ & 47 & 606,280699 & 12,899589 & \\
\hline Anos $\times \mathrm{q}_{4}$ & 47 & 350,353066 & 7.454321 & \\
\hline Anos $\times P_{5}$ & 47 & 566,766098 & 12.058853 & \\
\hline Anos $\times q_{5}$ & 47 & 419,348427 & 8,922307 & \\
\hline Anos $\times P_{6}$ & 47 & 428,010898 & 9,106615 & \\
\hline Resíduo & $(517)$ & $\{5486,135228\}$ & 10,611480 & \\
\hline Total & 575 & 10013,252206 & & \\
\hline
\end{tabular}


Tabela 8 - Análise de varianncia aplicada aos contrastes $p_{f}$ e $q_{j}$ das precipitações mensais em Bandeirantes-PR, para o período anual, isolando apenas os contrastes referentes aos componentes harmónicos que farão parte da equação de regres sãos para o período anual.

\begin{tabular}{|c|c|c|c|c|}
\hline Causas de Variação & G.L. & S.Q. & Q.M. & $F$ \\
\hline Contraste $p_{2}$ & 1 & & 2893,196936 & $228,92 * *$ \\
\hline Contraste $\sigma_{1}$ & 1 & & 359,174272 & $27,64 * *$ \\
\hline Contraste $P_{2}$ & 1 & & 13,967462 & 1,59 \\
\hline Contraste $q_{2}$ & 1 & & 4,397362 & 0,40 \\
\hline Contraste $p_{3}$ & 1 & & 378,297995 & $34,58 * *$ \\
\hline Contraste $q_{3}$ & 1 & & 17.044537 & 1,73 \\
\hline Desvios da Regressão & 5 & 73,962922 & & \\
\hline Anos & 47 & 787.075492 & 16.746287 & $1,58 * \%$ \\
\hline Anos $\times \mathrm{P}_{1}$ & 47 & 594,019072 & 12,638704 & \\
\hline Anos $\times q_{1}$ & 47 & 610,737278 & 12,994410 & \\
\hline Anos $\times \mathrm{P}_{2}$ & 47 & 412,708864 & 8,781040 & \\
\hline Anos $\times a_{2}$ & 47 & 521,800898 & 11,102147 & \\
\hline Anos $\times p_{3}$ & 47 & 514,089781 & 10,938080 & \\
\hline Anos $\times \mathrm{G}_{3}$ & 47 & 462,020147 & 9,830216 & \\
\hline Anos $\times$ Desvios & 235 & 2370,759188 & 10,088337 & \\
\hline Resíduo & $(517)$ & $(5486,135228$ & 10,611480 & \\
\hline Total & 575 & 10013,252206 & & \\
\hline
\end{tabular}


De acordo com AMARAL (1968), citado em 4.2.5.2, as Tabelas 9 e 10 apresentam a anälise de variância das amplitudes dos componentes harmônicos.

Tabela 9 - Anälise de variáncia aplicada às amplitudes a das preci pitações mensais em Bandeirantes-PR, para o período anual.

\begin{tabular}{|c|c|c|c|c|}
\hline Causas de Variação & G.L. & $S . Q$. & Q.Ma & $F$ \\
\hline Amplitude $a_{l}$ & 2 & 3252,371208 & 1626,185604 & $126,88 * x$ \\
\hline Amplitude $a_{2}$ & 2 & 18,364824 & 9.182412 & 0,92 \\
\hline Amplitude $a_{3}$ & 2 & 395,342532 & 197,671266 & $19,04 * \%$ \\
\hline Amplitude $a_{4}$ & 2 & 37,144525 & 18,572262 & 1,82 \\
\hline Amplitude $a_{5}$ & 2 & 3.958675 & 1.979338 & 0,19 \\
\hline Amplitude $a_{6}$ & 1 & 32,859722 & 32,859722 & 3,61 \\
\hline Regressão & $(11)$ & $(3740,041486)$ & & \\
\hline Anos & 47 & 787,075432 & 16,746287 & $1,58 * *$ \\
\hline Anos $\times a_{1}$ & 94 & 1204,756350 & 12,816557 & \\
\hline Anos $\times a_{2}$ & 94 & 934,509762 & 9,941593 & \\
\hline Anos $\times a_{3}$ & 94 & 976,109928 & 10,384148 & \\
\hline Anos $\times a_{4}$ & 94 & 956,633765 & 10,176955 & \\
\hline Anos $\times a_{5}$ & 94 & 986,114525 & 10,490580 & \\
\hline Anos $\times a_{6}$ & 47 & 428,010898 & 9,106615 & \\
\hline Resíduo & $(517)$ & $\{5486,135228\}$ & 10,611480 & \\
\hline Total & 575 & 10013,252206 & & \\
\hline
\end{tabular}




\begin{tabular}{|c|c|c|c|c|}
\hline Causas de Variação & G.L. & S.P. & Q.M. & $\mathrm{F}$ \\
\hline Amplitude $a_{1}$ & 2 & 3252,371208 & 1626,185604 & $126,88 * *$ \\
\hline Amplitude $a_{2}$ & 2 & 18,364824 & 9,182412 & 0,92 \\
\hline Amplitude $a_{3}$ & 2 & 395,342532 & 197,671266 & $19,04 * *$ \\
\hline Desvios da Regressão & 5 & 73,962922 & & \\
\hline Anos & 47 & 787,075492 & 16,746287 & $1,58 * *$ \\
\hline Anos $\times a_{1}$ & 94 & 1204,756350 & 12,816557 & \\
\hline Anos $\times a_{2}$ & 94 & 934,509762 & 9,941593 & \\
\hline Anos $\times a_{3}$ & 94 & 976,109928 & 10,384148 & \\
\hline Anos $\times$ Desvios & 235 & 2370,759188 & 10.088337 & \\
\hline Resíduo & $\{517\}$ & $\{5486,135228\}$ & 10,611480 & \\
\hline Total & 575 & 10013,252206 & & \\
\hline
\end{tabular}

Pelos resultados obtidos. comprova-se que os componentes harmónicos que têm períodos anual, semestral e quadrimestral foram os responsáveis pela maior parte das variações observadas, res pectivamente $86,96 \%, 0,49 \%$ e $10,57 \%$ 


\section{1 .4 - Variâncias dos parâmetros estimados}

Conforme fol descrito em 4.2 .3 , equações de (22) a (28), através da matriz de dispersão, foram estimadas as variàncias dos contrastes $\hat{p}_{j}$ e $\hat{q}_{j}$ referentes aos componentes harmônicos considerados na equação de regressão, para o período anual, a saber:

$$
\begin{array}{ll}
V\left(\hat{p}_{1}\right)=2,1064 & V\left(\hat{q}_{1}\right)=2,1657 \\
V\left(\hat{p}_{2}\right)=1,4635 & V\left(\hat{q}_{2}\right)=1,8504 \\
V\left(\hat{p}_{3}\right)=1,8230 & V\left(\hat{q}_{3}\right)=1,6384
\end{array}
$$

Como as covariâncias são nulas, os parâmetros estima dos são ditos não correlacionados e as variâncias estimadas para a ${ }_{j}$, segundo (29), são:

$$
\begin{aligned}
& V\left(\hat{a}_{1}\right) \simeq 2,1129 \\
& V\left(\hat{a}_{2}\right) \simeq 1,5561 \\
& V\left(\hat{a}_{3}\right) \simeq 1,8150
\end{aligned}
$$

\section{1 .5 - Intervalos de confiança}

De posse das estimativas $\hat{p}_{j}, \hat{q}_{j}$ e $\hat{a}_{j}$, bem como de suas variâncias, foram calculados seus respectivos intervalos de confiança, para $\alpha=0,05$, encontrados na Tabela 11. 
Tabela 11 - Intervalos de confiança para os parámetros $p_{j}$, $q_{j}$ e a $a_{j}$, empregados na equação de regressão, para o perf́odo anual.

$$
\begin{aligned}
0,2523 & \leq p_{1} \leq 6,0867 \\
-1,8412 & \leq q_{1} \leq 4,0747 \\
0,4679 & \leq a_{1} \leq 6,2531 \\
-2,2114 & \leq p_{2} \leq 2,6518 \\
-2,6106 & \leq q_{2} \leq 2,8578 \\
0,0000 & \leq a_{2} \leq 2,7349 \\
-3,8600 & \leq p_{3} \leq 1,5678 \\
-2,3295 & \leq q_{3} \leq 2,8161 \\
0,0000 & \leq a_{3} \leq 3,8526
\end{aligned}
$$

\section{1 .6 - Equação de regressão}

Determinados os componentes a serem considerados, foi estabelecida a equação de regressão para estimar as precipitações mensais, em Bandeirantes (PR), referentes ao perfodo anual.

$$
\begin{aligned}
Q_{t}=9,77 & +3,360495 \operatorname{sen}(30 t+70,590522)^{0}+ \\
& +0,252515 \operatorname{sen}(60 t+60,704294)^{0}+ \\
& +1,171624 \operatorname{sen}(90 t+281,983787)^{0}
\end{aligned}
$$

onde: $\mathrm{P}_{t}=$ estimativa da raiz quadrada do valor observado para 0 mês t. 
50.

A presente equação de regressão explica $98,02 \%$ das variações devidas a meses.

Através da equação, foram estimadas as raízes quadra das das precipitações mensais para o período anual, encontradas na Tabela 12.

Tabela 12 - Estimativas e componentes harmönicos das raf́zes quadradas das precipitações mensais para o perf́odo anual, em Bandeirantes (PR).

\begin{tabular}{rcccccc}
\hline$t$ & Mês & $\bar{Y}$ & $A$ & $B$ & $c$ & $\hat{P}_{t}$ \\
\hline 1 & Jan & 9,77 & 3,303252 & 0,217116 & 0,243270 & 13,534372 \\
2 & Fev & 9,77 & 2,551889 & $-0,003104$ & 1,146090 & 13,465609 \\
3 & Mar & 9,77 & 1,116750 & $-0,220220$ & $-0,243270$ & 10,423994 \\
4 & Abr & 9,77 & $-0,617621$ & $-0,217116$ & $-1,146090$ & 7,789907 \\
5 & Mai & 9,77 & $-2,186501$ & 0,003104 & 0,243270 & 7,830607 \\
6 & Jun & 9,77 & $-3,169510$ & 0,220220 & 1,146090 & 7,967534 \\
7 & Jul & 9,77 & $-3,303250$ & 0,217116 & $-0,243270$ & 6,441328 \\
8 & Ago & 9,77 & $-2,551889$ & $-0,003104$ & $-1,146090$ & 6,069651 \\
9 & Set & 9,77 & $-1,116750$ & $-0,220220$ & 0,243270 & 8,677034 \\
10 & Out & 9,77 & 0,617621 & $-0,217116$ & 1,146090 & 11,317329 \\
11 & Nov & 9,77 & 2,186501 & 0,003104 & $-0,243270$ & 11,717069 \\
12 & Dez & 9,77 & 3,169510 & 0,220220 & $-1,146090$ & 12,014374 \\
\hline
\end{tabular}

onde: $\bar{Y}=$ média geral;
$A=$ componente harmónico anual;
$B=$ componente harmónico semestral;
$C=$ componente harmônico quadrimestral: 
51.

$\hat{q}_{t}=$ estimativa da raiz quadrada de precipitaçäo para o mês $t$.

\section{1 .7 - Representação gräfica}

Para melhor visualização, as Figuras 2, 3, 4 e 5 apre sentam a representação gráfica de cada componente harmônico considerado na equação de regressão e da função resultante do conjunto des tes componentes, para o período anual. 
52.

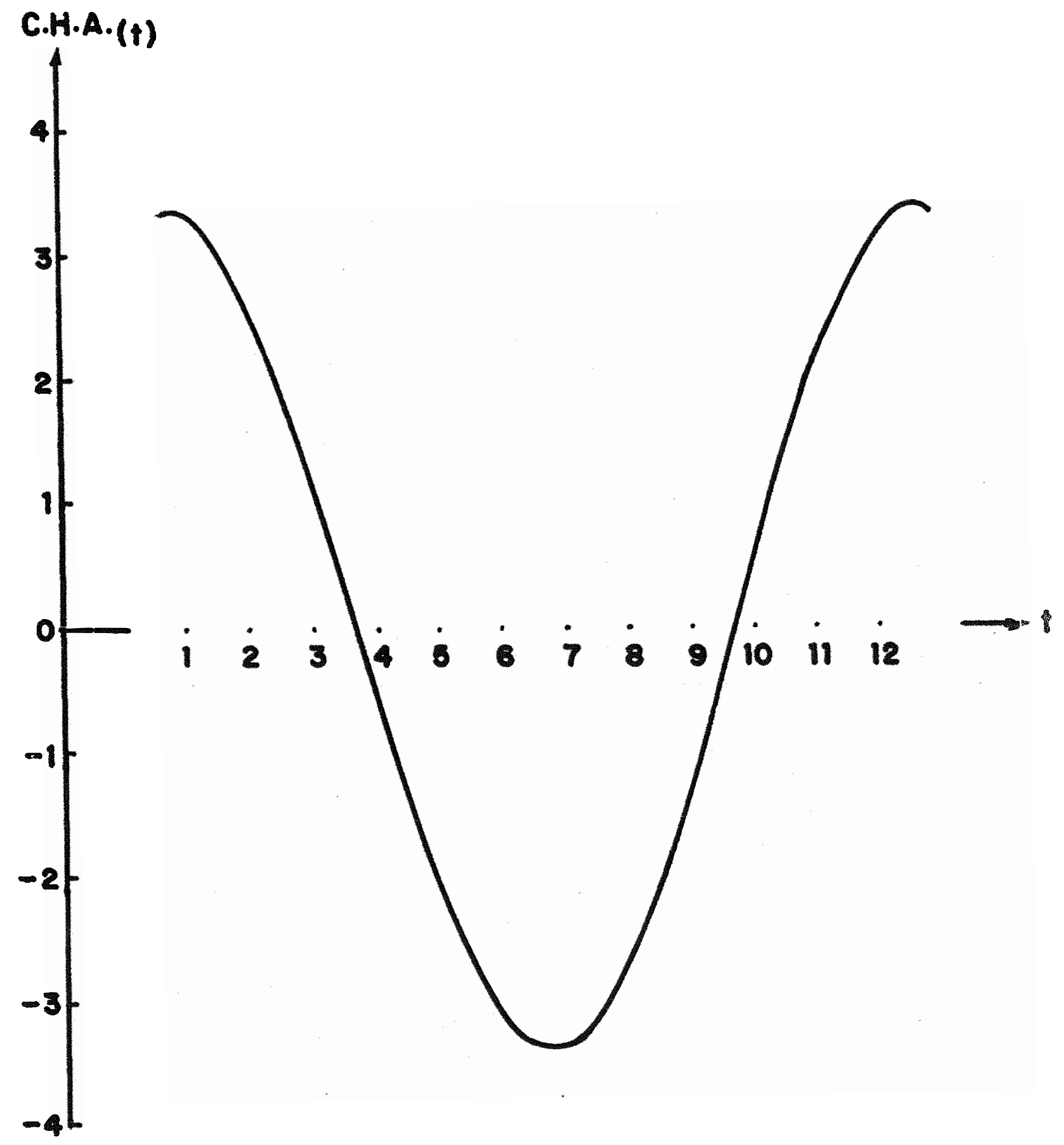

Figura 2 - Gráfico do componente harmônico anual.

$C \cdot H . A \cdot(t)=3,360495 \operatorname{sen}(30 t+70,590522)^{0}$ 


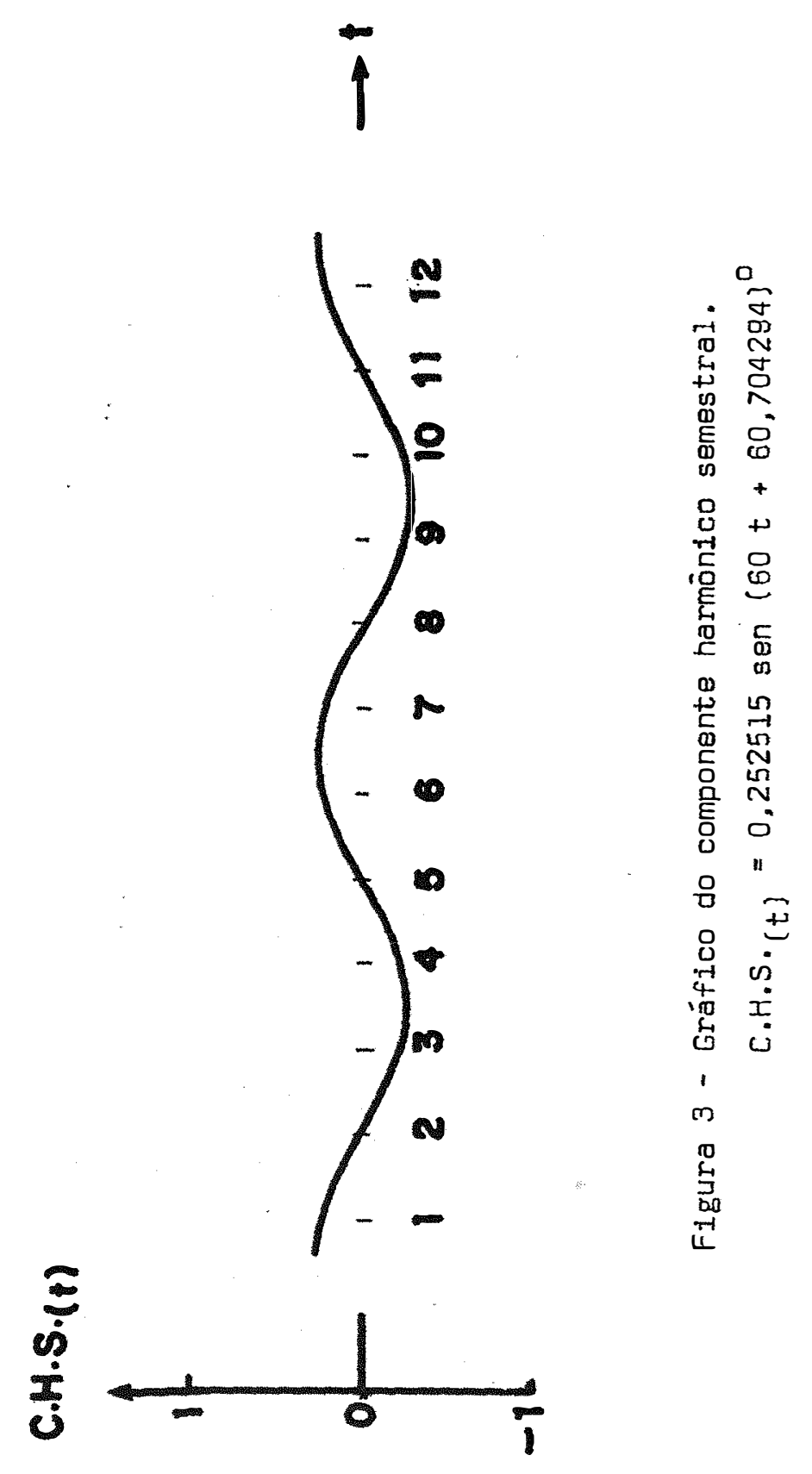


54.

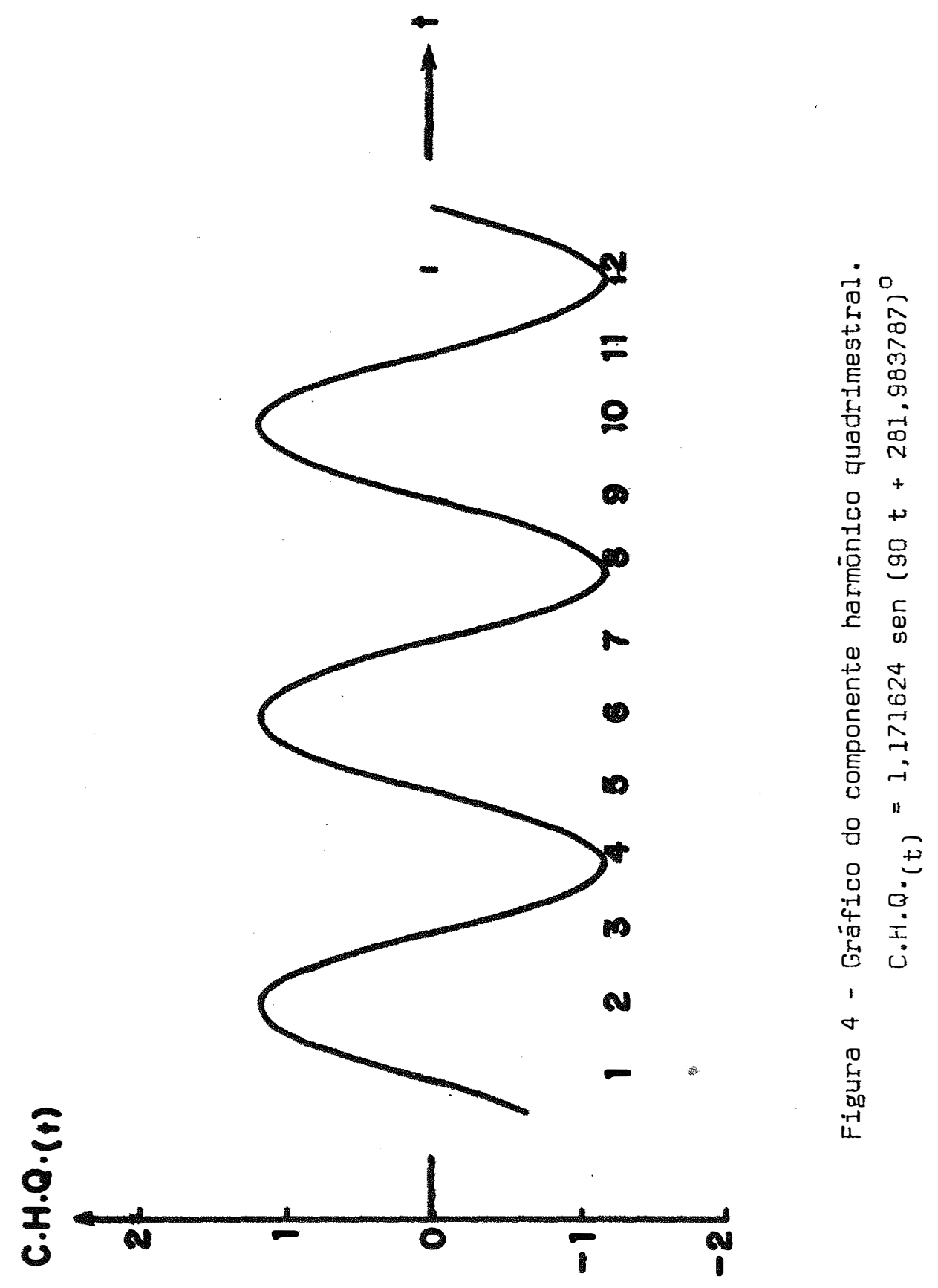


55.

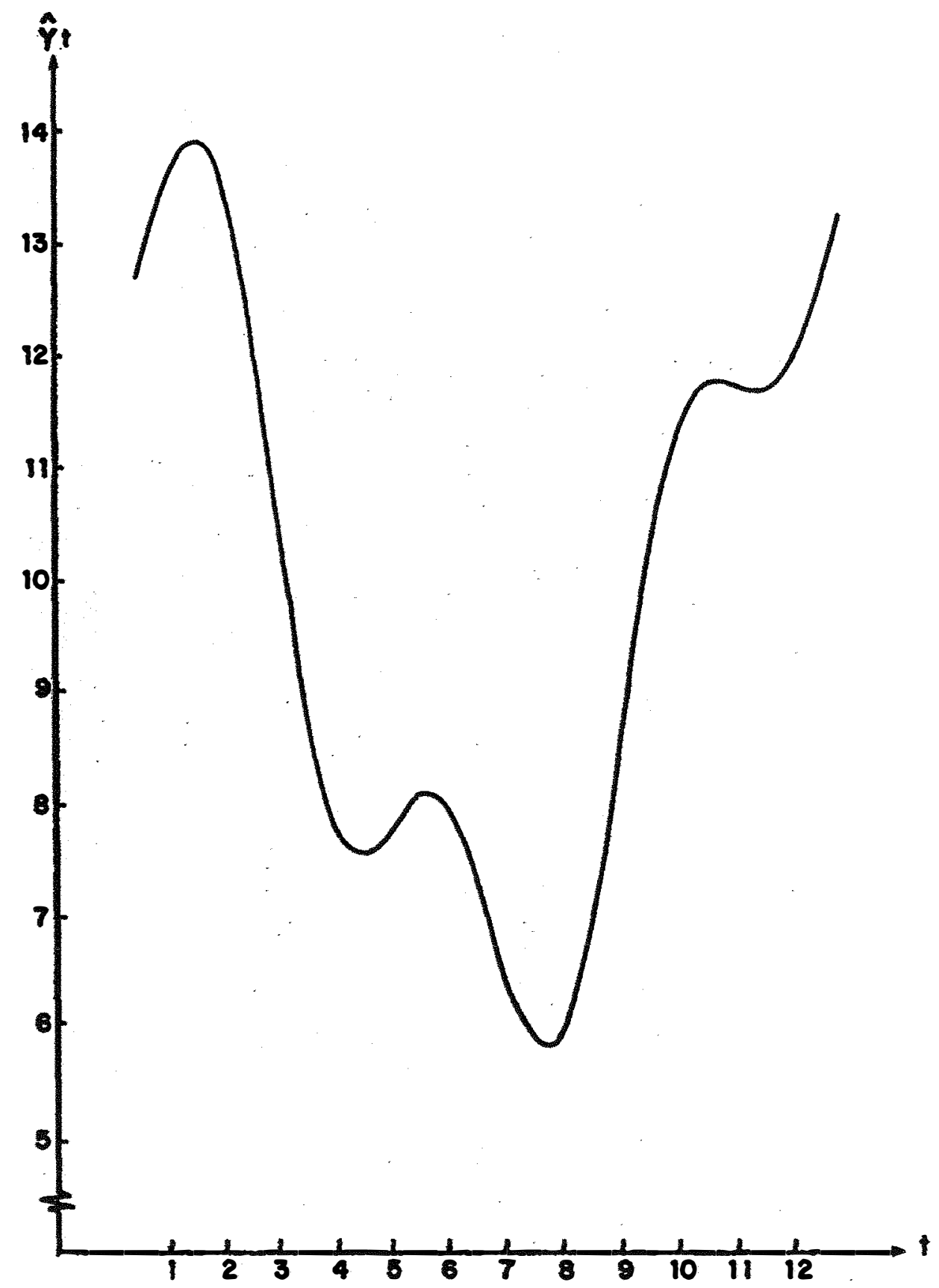

Figura 5 - Gráfico da equação de regressão para o período anual.

$$
\begin{aligned}
\hat{P}_{t}=9,77 & +3,360495 \operatorname{sen}(30 t+70,590522)^{\circ}+ \\
& +0,252515 \operatorname{sen}(60 t+60,704294)^{\circ}+ \\
& +1,171624 \operatorname{sen}(90 t+281,983787)^{\circ} .
\end{aligned}
$$




\section{2 - Estimativa das Precipltações Mensais Para o Período Seco (Abril a Setembro)}

A média aritmética dos 288 dados, contidos no Apêndi ce 3, estudados neste caso, apresentou valor igual a 7,44 e os des vios daqueles em relação a esta encontram-se no Apêndice 8.

\subsection{1 - Modelo matemätico}

No presente caso, onde $T=6$, o modelo matemático,oriundo de (21), em 4.2.2, tem a forma,

$$
\begin{aligned}
y_{t}=p_{1} \cos \theta t & +p_{2} \cos 2 \theta t+p_{3} \cos 3 \theta t+ \\
& +q_{1} \operatorname{sen} \theta t+q_{2} \operatorname{sen} 2 \theta t+e_{t}
\end{aligned}
$$

$$
\text { onde: } \begin{aligned}
\theta & =\frac{360^{\circ}}{6}=60^{\circ} \\
t & =1,2, \ldots, 6 .
\end{aligned}
$$

Os componentes harmônicos, considerados em (48), têm os seguintes períodos: $T=6$ meses (para $j=1$ ), $\frac{T}{2}=3$ meses (para $j=2$ ) e $\frac{T}{3}=2$ meses (para $j=3$ ).

Como tem-se $\mathrm{N}$ repetições para cada mês, pode-se es-

crever:

$$
\begin{aligned}
y_{t i}=p_{1 i} \cos \theta t & +p_{2 i} \cos 2 \theta t+p_{3 i} \cos 3 \theta t+ \\
& +q_{1 i} \operatorname{sen} \theta t+q_{2 i} \operatorname{sen} 2 \theta t+\theta_{t i}
\end{aligned}
$$


Desta forma, a matriz Y terá dimensões $T \times N$, ou seja, 6x48, sendo encontrada no Apèndice 8 , na forma de $Y^{\prime}$.

\subsection{2 - Estimativa dos parâmetros}

A solução do sistema, descrita em 4.2.3, é a matriz $\hat{\beta}^{\prime}$, cujas dimensões são $5 \times 48$, contendo todos os $T-1=5$ contrastes estimados para cada um dos $N=48$ anos.

Os Apêndices 9, 10 e 11 apresentam, respectivamente, as matrizes $S^{-1}, X^{\prime}$ e $\hat{B}^{\prime}$.

As médias dos valores estimados para cada contraste, no decorrer dos 48 anos, resultaram nas estimativas dos valores de $p_{j}$ e $q_{j}$, a partir dos quais, foram calculadas as amplitudes e àngulos fases dos componentes harmônicos, para a equação de regressão, de acordo com (14), (16) e (17) em 4.2.2. Estes valores são encontrados na Tabela 13.

Tabela 13 - Valores estimados de $p_{j}, q_{j}, a_{j}$ e $A_{j}$, referentes ao período seco.

\begin{tabular}{ccccc}
\hline$j$ & $\hat{p}_{j}$ & $\bar{q}_{j}$ & $\hat{a}_{j}$ & $\bar{A}_{j}$ \\
\hline 1 & 0,12777 & 0,87292 & 0,882221 & 8,327296 \\
2 & 1,02360 & 0,29697 & 1,065809 & 73,821335 \\
3 & $-0,06624$ & - & 0,066240 & 270,000000 \\
\hline
\end{tabular}




\subsection{3 - Anälise de variância}

\subsubsection{1 - Teste de normalidade}

Como no caso anterior, o teste de normalidade empregado, baseado nos coeficientes de assimetria e curtose, apresentou os resultados constantes da Tabela 14.

Tabela 14 - Valores dos coeficientes de assimetria $\left(g_{1}\right)$ e curtose $\left(g_{2}\right)$ e os respectivos valores de $t$ calculados para os contrastes $p_{j} e q_{j}$, dos componentes que farão parte da equação de regressão para o período seco.

\begin{tabular}{ccccc}
\hline Contrastes & $\hat{\mathrm{g}}_{1}$ & $\hat{\mathrm{g}}_{2}$ & $\mathrm{t}_{1}$ & $\mathrm{t}_{2}$ \\
\hline$\hat{\mathrm{p}}_{1}$ & 0,434481 & 1,009178 & 1,266157 & 1,496416 \\
$\hat{\mathrm{q}}_{1}$ & 0,051432 & 0,397690 & 0,149883 & 0,589697 \\
$\hat{\mathrm{p}}_{2}$ & 0,289267 & 0,685752 & 0,842977 & 1,016837 \\
$\hat{\mathrm{q}}_{2}$ & 0,040555 & 0,311727 & 0,118186 & 0,462230 \\
\hline
\end{tabular}

$$
s\left(\hat{g}_{1}\right)=0,343149, s\left(\hat{g}_{2}\right)=0,674397
$$

Comparados ao valor da tabela de $t$, para $\mathrm{N}-1=47$ graus de liberdade e $\alpha=0,05$, os valores de $t$ calculados mostraram-se não significativos, o que nos permite aceitar as hipóteses de nulidade, ou seja: $g_{2}=0$ e $g_{2}=0$. Neste caso, admite-se que os dados podem ser estudados através da distribuição normal. 
59.

\subsubsection{2 - Quadros de anālise de variância}

As Tabelas 15 e 16 apresentam os resultados obtidos nas análises de variância aplicadas aos contrastes $p_{j} e q_{j}$.

Tabela 15 - Análise de variância aplicada aos contrastes $p_{f} e q_{f}$ das precipitações mensais em Bandeirantes-PR, para o período seco.

\begin{tabular}{lcrrc}
\hline Causas de Variação & G.L. & S.Q. & Q.M. & $F$ \\
\hline Contraste $\hat{p}_{1}$ & 1 & & 2,351162 & 0,26 \\
Contraste $\hat{q}_{1}$ & 1 & & 109,728296 & $7,82^{* *}$ \\
Contraste $\hat{p}_{2}$ & 1 & & 150,878415 & $13,26^{* *}$ \\
Contraste $\hat{q}_{2}$ & 1 & & 12,699726 & 1,71 \\
Contraste $\hat{p}_{3}$ & 1 & & 1,263732 & 0,10 \\
\hline Regressão & $(5)$ & $(276,921331)$ & & \\
\hline Anos & 47 & 1080,952002 & 22,998979 & $2,09^{* *}$ \\
Anos $\times \hat{p}_{1}$ & 47 & 427,136322 & 9,088007 & \\
Anos $\times \hat{q}_{1}$ & 47 & 659,585377 & 14,033731 & \\
Anos $\times \hat{p}_{2}$ & 47 & 534,688794 & 11,376357 & \\
Anos $\times \hat{q}_{2}$ & 47 & 349,390059 & 7,433831 & \\
Anos $\times \hat{p}_{3}$ & 47 & 609,920718 & 12,977037 & \\
\hline Residuo & & & & \\
\hline Total & $(235)$ & $(2580,721270)$ & 10,981793 & \\
\hline & 287 & 3938,594603 & & \\
\hline
\end{tabular}

Como o único componente harmônico não significativo foi o bimestral $\left(\bar{p}_{3}=\hat{a}_{3}\right)$, este passa a ser considerado como des- 
vios da regressão e seu resíduo especifico, como a interação entre anos e desvios, conforme a Tabela 16.

Tabela 16 - Análise de variáncia aplicada aos contrastes $\hat{p}_{j}$ e $\hat{q}_{j}$ das precipitações mensais em Bandeirantes-PR, para 0 periodo seco, isolando apenas os contrastes referentes aos componentes harmônicos significativos para o perín do seco.

\begin{tabular}{lcrrr}
\hline Causas de Variação & G.L. & S.Q. & Q.M. & $F$ \\
\hline Contraste $\hat{p}_{1}$ & 1 & & 2,351162 & 0,26 \\
Contraste $\hat{q}_{1}$ & $I$ & & 109,728296 & $7,82^{* *}$ \\
Contraste $\hat{p}_{2}$ & 1 & & 150,878415 & $13,26 * *$ \\
Contraste $\hat{q}_{2}$ & 1 & & 12,699726 & 1,71 \\
Desvios da Regressão & 1 & & 1,263732 & 0,10 \\
\hline Anos & 47 & 1080,952002 & 22,998979 & $2,09 * *$ \\
Anos $\times \hat{p}_{1}$ & 47 & 427,136322 & 9,088007 & \\
Anos $\times \hat{q}_{1}$ & 47 & 659,585377 & 14,033731 & \\
Anos $\times \hat{p}_{2}$ & 47 & 534,688794 & 11,376357 & \\
Anos $\times \hat{q}_{2}$ & 47 & 349,390059 & 7,433831 & \\
Anos $\times$ Desvios & 47 & 609,920718 & 12,977037 & \\
\hline Residuo & & & & \\
\hline Total & $(235)$ & $(2580,721067)$ & 10,981793 & \\
\hline
\end{tabular}

Comparados os quadrados médios residuais dos contras tes e verificadas suas homogeneidades, foram feitas as análises de variância para os componentes harmōnicos, encontrados nas Tabelas 17 e 18. 
Tabela 17 - Análise de variância aplicada às amplitudes â ${ }_{j}$ das precipitações mensais em Bandeirantes-PR, para o período seco.

\begin{tabular}{lrrrr}
\hline Causas da Variação & G.L. & S.Q. & Q.M. & $F$ \\
\hline Amplitude $\hat{a}_{1}$ & 2 & 112,079458 & 56,039729 & $4,85^{* *}$ \\
Amplitude $\hat{a}_{2}$ & 2 & 163,578141 & 81,789070 & $8,70^{* *}$ \\
Amplitude $\hat{a}_{3}$ & 1 & 1,263732 & 1,263732 & 0,10 \\
\hline Anos & 47 & 1080,952002 & 22,998979 & $2,09^{* *}$ \\
Anos $\times \hat{a}_{1}$ & 94 & 1086,721699 & 11,560869 & \\
Anos $\times \hat{a}_{2}$ & 94 & 884,078853 & 19,405094 & \\
Anos $\times \bar{a}_{3}$ & 47 & 609,920718 & 12,977037 & \\
\hline Residuo & & & & \\
\hline Total & $(235)$ & $(2580,721067)$ & 10,981793 & \\
\hline
\end{tabular}

o único componente harmônico não significativo foi o bimestral, passando, portanto a ser considerado como desvios da regressão, conforme Tabela 18. 
Tabela 18 - Análise de variància aplicada às amplitudes à dos componentes harmônicos isolando apenas aqueles significati vos, para o período seco.

\begin{tabular}{lrrrr}
\hline Causas de Variação & G.L. & S.Q. & Q.M. & F \\
\hline Amplitude à̃ & 2 & 112,079458 & 56,039729 & $4,85^{* *}$ \\
Amplitude à ${ }_{2}$ & 2 & 163,578141 & 81,789070 & $8,70^{* *}$ \\
Desvios da Regressão & 1 & 1,263732 & 1,263732 & 0,10 \\
\hline Anos & 47 & 1080,952002 & 22,998979 & $2,09 * *$ \\
Anos $\times \hat{a}_{1}$ & 94 & 1086,721699 & 11,560869 & \\
Anos $\times \hat{a}_{2}$ & 94 & 884,078853 & 9,405094 & \\
Anos $\times$ Desvios & 47 & 609,920718 & 12,977037 & \\
\hline Residuo & & & & \\
\hline Total & $235)$ & $(2580,721067)$ & 10,981793 & \\
\hline
\end{tabular}

Pelos resultados das análises de variância fica comprovado serem os componentes harmônicos semestral e trimestral os responsāveis pela maior parte, correspondendo, respectivamente, a $40,47 \%$ e $59,07 \%$ da variação devida a meses.

\section{2 .4 - Variâncias dos parâmetros estimados}

De acordo com o descrito em 4.2.3, equações (22) a (28), através da matriz de dispersão, foram estimadas as variàncias dos contrastes $\hat{p}_{j}$ e $\hat{q}_{j}$, referentes aos componentes considerados na equação de regressão, para o período seco, a saber: 


$$
\begin{array}{ll}
V\left(\hat{p}_{1}\right)=3,0293 & V\left(\hat{q}_{1}\right)=4,6779 \\
V\left(\hat{p}_{2}\right)=3,7921 & V\left(\hat{q}_{2}\right)=2,4779
\end{array}
$$

Como as covariâncias são nulas, os parâmetros estima dos são ditos não correlacionados, e, as variâncias estimadas para $\hat{a}_{j}$, segundo (29), são:

$$
\begin{aligned}
& V\left(\hat{a}_{1}\right) \simeq 4,6433 \\
& V\left(\hat{a}_{2}\right) \simeq 3,6901
\end{aligned}
$$

\section{2 .5 - Intervalos de confiança}

De posse das estimativas $\hat{p}_{j}$, $\hat{q}_{j}$ e $\hat{a}_{j}$, bem como de suas variâncias, foram calculados seus respectivos intervalos de confiança, para $\alpha=0,05$, encontrados na Tabela 19.

Tabela 19 - Intervalos de confiança para os parâmetros $p_{j}, q_{j}$ e $a_{j}$, empregados na equação de regressão, para o período seco.

$$
\begin{aligned}
-3,3706 & \leq p_{1} \leq 3,6262 \\
-3,4744 & \leq a_{1} \leq 5,2202 \\
0,0000 & \leq a_{1} \leq 5,1703 \\
-2,8905 & \leq p_{2} \leq 4,9377 \\
-2,8670 & \leq a_{2} \leq 3,4610 \\
0,0000 & \leq a_{2} \leq 4,8885
\end{aligned}
$$




\section{2 .6 - Equação de regressão}

Determinados os componentes a serem considerados, foi estabelecida a equação de regressão para estimar as precipitações mensais em Bandeirantes (PR), referentes ao período seco:

$$
\begin{aligned}
q_{t}=7,44 & +0,882221 \operatorname{sen}(60 t+8,327296)^{0}+ \\
& +1,065809 \operatorname{sen}(120 t+73,821335)^{0}
\end{aligned}
$$

onde: $\widehat{\varphi}_{t}=$ estimativa da raiz quadrada da precipitação para o mếz $t$. A presente equação explica 99,54\% das variações devi das a meses.

Atravēs da equação determinada, foram calculadas as estimativas das raízes quadradas das precipitações mensais para o período seco, encontradas na Tabela 20.

Tabela 20 - Estimativas e componentes harmónicos das raízes quadradas das precipitações mensais para o período seco, em Bandeirantes (PR).

\begin{tabular}{cccccc}
\hline$t$ & Mês & $\bar{Y}$ & $A$ & $B$ & $P_{t}$ \\
\hline 1 & Abr & 7,44 & 0,819856 & $-0,254617$ & 8,008054 \\
2 & Mai & 7,44 & 0,692086 & $-0,768984$ & 7,365917 \\
3 & Jun & 7,44 & $-0,127770$ & 1,023600 & 8,338645 \\
4 & Jul & 7,44 & $-0,819856$ & $-0,254617$ & 6,368342 \\
5 & Ago & 7,44 & $-0,692086$ & $-0,768984$ & 5,981745 \\
6 & Set & 7,44 & 0,127770 & 1,023600 & 8,594185 \\
\hline
\end{tabular}


65.

onde: $\bar{Y}=$ média geral;

$A=$ componente harmónico semestral;
$B=$ componente harmônico trimestrai:
$\hat{P}_{t}=$ estimativa da raiz quadrada de precipitação para o mês $t$.

\subsection{7 - Representação gräfica}

As Figuras 6 e ? apresentam, respectivamente, os com ponentes harmónicos semestral e trimestral para o período seco.

A Figura 8 contém a função resultante do conjunto dos componentes harmónicos considerados na equação de regressão, para o período seco. 
66.

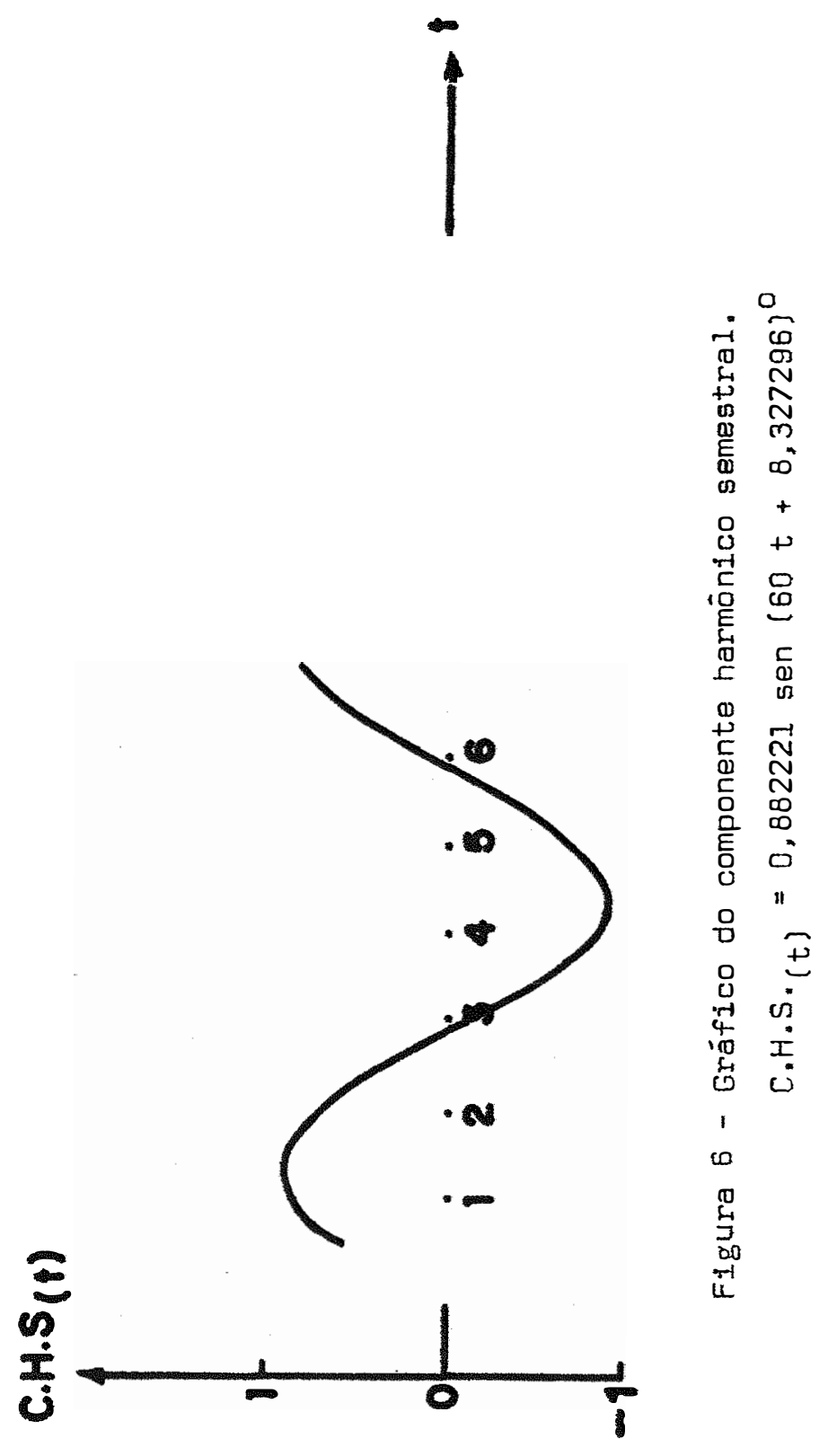


67.

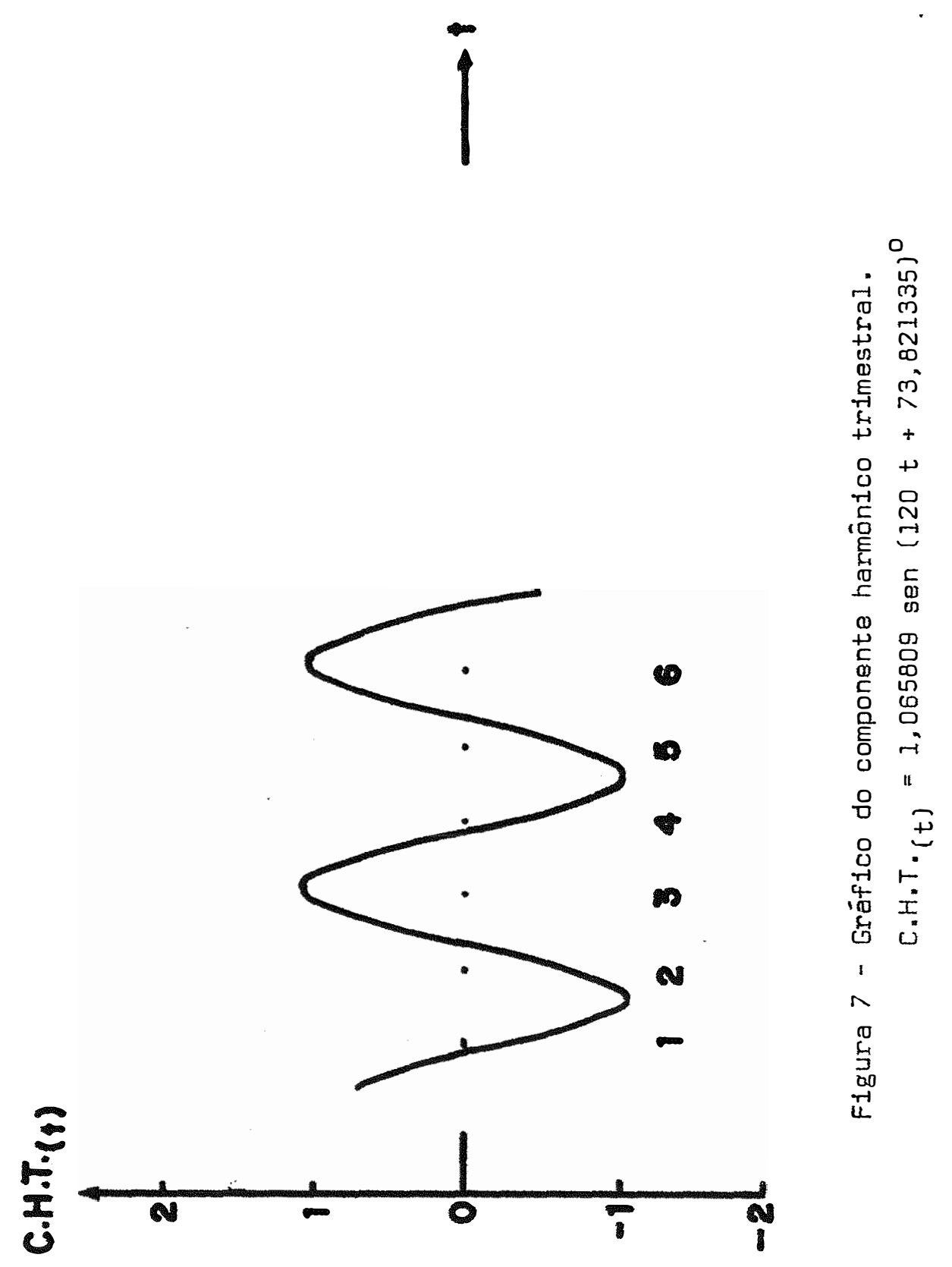


68.

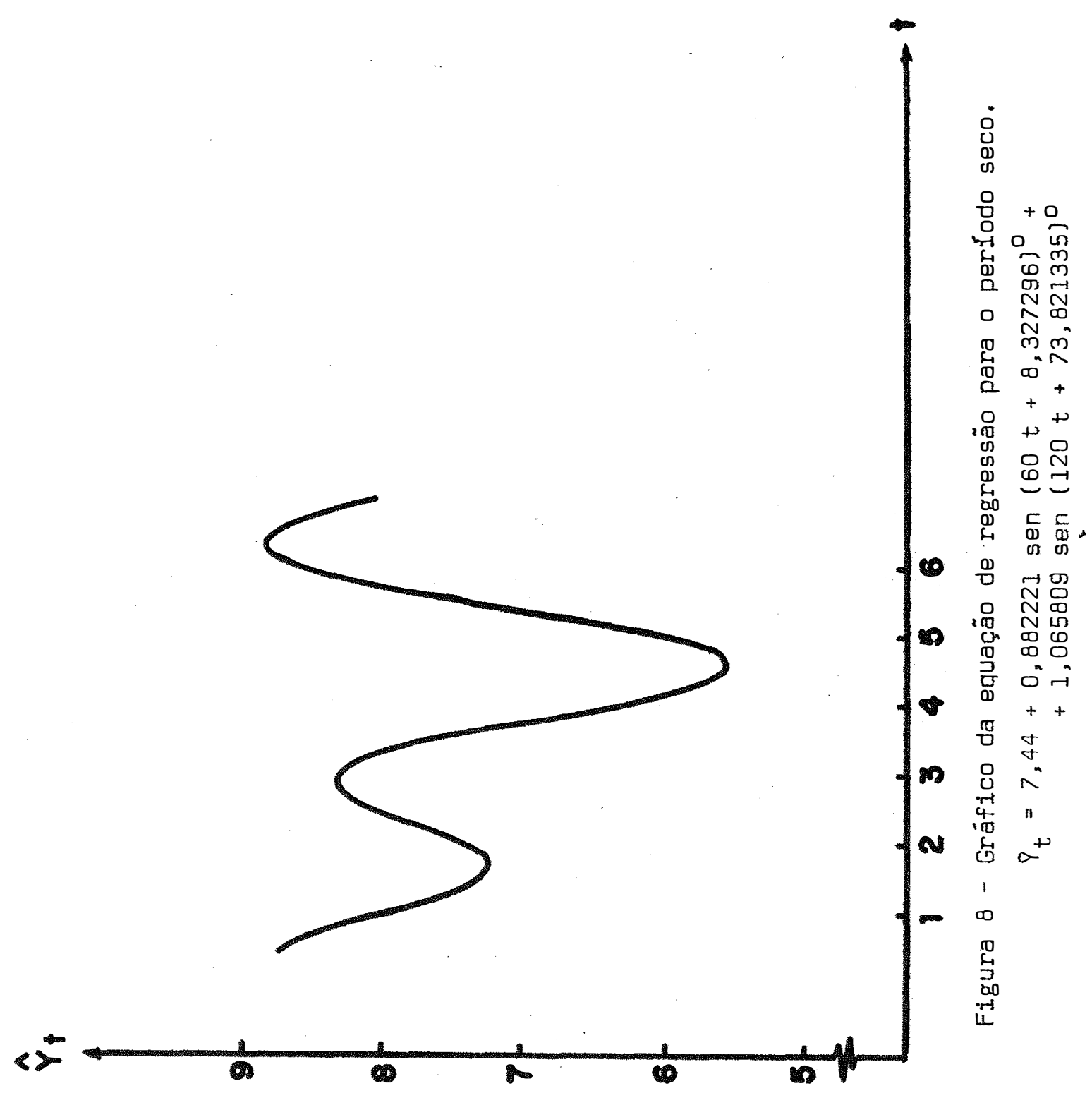




\section{3 - Estimativa das Precipitações Mensais Para o Período Chuvo- so (Outubro a Março)}

A média aritmética dos 288 dados contidos no Apêndice 3, referentes aos meses estudados neste caso, apresentou valor igual a 12,10 e os desvios daqueles em relação a esta, encontram- se no Apêndice 12.

\subsection{1 - Modelo matemātico}

Para o período chuvoso, onde $T=6$, o modelo matemático, a partir de (21), em 4.2.2, apresenta a seguinte forma:

$$
\begin{aligned}
y_{t}=p_{1} \cos \theta t & +p_{2} \cos 2 \theta t+p_{3} \cos 3 \theta t+ \\
& +q_{1} \operatorname{sen} \theta t+q_{2} \operatorname{sen} 2 \theta t+e_{t}
\end{aligned}
$$

$$
\text { onde: } \begin{aligned}
\theta & =\frac{360^{\circ}}{6}=60^{\circ}, \\
t & =1,2, \ldots 6 .
\end{aligned}
$$

Os componentes harmónicos a serem estudados, para o presente caso, apresentam os seguintes períodos: $T=6$ meses (para $j=1$ ) $: \frac{T}{2}=3$ meses (para $j=2$ ) e $\frac{T}{3}=2$ meses (para $j=3$ ). Como para cada mês tem-se $N=48$ repetições,

$$
\begin{aligned}
y_{t i}=p_{1 i} \cos \theta t & +p_{2 i} \cos 2 \theta t+p_{3 i} \cos 3 \theta t+ \\
& +q_{1 i} \operatorname{sen} \theta t+q_{2 i} \operatorname{sen} 2 \theta t+\varepsilon_{t i}
\end{aligned}
$$

Desta forma, a matriz Y terá dimensões $T \times N$, ou seja, $6 \times 48$ e pode ser encontrada no Apéndice 12, na forma $Y^{\prime}$. 


\section{3 .2 - Estimativa dos parâmetros}

Conforme a metodologia descrita em 4.2.3, a solução do sistema de equações obtida através de computador resulta numa ma triz $\hat{R}$, cujas dimensões são $5 \times 48$, contendo todos os $T-1=5$ contras tes estimados, para cada um dos $N=48$ anos.

As matrizes $S^{-1}, X^{\prime}$ e $\hat{B}^{\prime}$ são encontradas, respectivamente, nos Apêndices 9, 10 e 13.

Para efeito da obtenção da equação de regressão refẹ rente ao período chuvoso, cada um dos $T-1=5$ contrastes $\bar{e}$ obtido através da média aritmética de seus valores estimados durante os $N=48$ anos.

Com estes valores médios, foram calculadas as estima tivas $\hat{a}_{j}$ e $\hat{A}_{j}$, conforme descrito em 4.2.2, equações (14), (16) e (17). A Tabela 21 contém as estimativas dos valores dos con trastes $\left(p_{j} \text { e } q_{j}\right)_{\text {s }}$, bem como dos parâmetros $a_{j}$ e $A_{j}$.

Tabela 21 - Valores estimados de $p_{j}, q_{j}, a_{j}$ e $A_{j}$, referentes ao período chuvoso.

\begin{tabular}{ccccc}
\hline$j$ & $\hat{p}_{j}$ & $\hat{q}_{j}$ & $\hat{a}_{j}$ & $\hat{A}_{j}$ \\
\hline 1 & $-0,56822$ & $-1,12005$ & 1,255940 & 206,899439 \\
2 & $-0,61016$ & 0,29036 & 0,675725 & 295,448617 \\
3 & $-0,41145$ & - & 0,411450 & 270,000000 \\
\hline
\end{tabular}


71.

\section{3 .3 - Anālise de variância}

\subsubsection{1 - Teste de normalidade}

Visando atender às exigências do teste $F$, empregado na análise de variáncia, foi aplicado o teste de normalidade descri to em 4.2.5.1 aos contrastes $\hat{p}_{j}$ e $\hat{q}_{j}$, obtendo-se os resultados cons tantes da Tabela 22.

Tabela 22 - Valores dos coeficientes de assimetria $\left(g_{1}\right)$ e curtose $\left(g_{2}\right)$ e valores de $t$ calculados relativos a estes coeficientes, respectivamente $t_{1}$ e $t_{2}$ 。

\begin{tabular}{ccccc}
\hline Contrastes & $\hat{\mathrm{g}}_{1}$ & $\hat{\mathrm{g}}_{2}$ & $\mathrm{t}_{1}$ & $\mathrm{t}_{2}$ \\
\hline$\hat{\mathrm{p}}_{1}$ & 0,384616 & 0,248161 & 1,120843 & 0,367974 \\
$\hat{\mathrm{q}}_{1}$ & 0,092864 & 0,456767 & 0,270624 & 0,677297 \\
$\hat{\mathrm{p}}_{2}$ & 0,303608 & 0,888740 & 0,884769 & 1,317829 \\
$\hat{\mathrm{q}}_{2}$ & 0,036602 & 0,112991 & 0,106664 & 0,167544 \\
$\hat{\mathrm{p}}_{3}$ & 0,449940 & 0,646311 & 1,311207 & 0,958354 \\
\hline
\end{tabular}

Os desvios padrões de $\hat{\mathrm{g}}_{1}$ e $\hat{\mathrm{g}}_{2}$, utilizados no teste $t$ apresentaram os seguintes valores:

$$
\begin{aligned}
& s\left(\hat{g}_{1}\right)=0,343149, \quad s\left(\hat{g}_{2}\right)=0,674397 . \\
& \text { Comparados ao valor da tabela de } t \text {, para } N-1=47
\end{aligned}
$$

graus de liberdade e $\alpha=0,05$, os valores de $t$ calculados mostraram-se não significativos, o que torna possível a aceitação das hipóteses de nulidade, ou seja, $g_{1}=0$ e $g_{2}=0$. Conclui-se, pols, que a 
distribuição de frequências de cada contraste não difere da distribuição nomal de frequência, o que torna possível a aplicação do tes te $F$.

\subsubsection{2 - Quadros de anälise de variância}

A Tabela 23 apresenta os resultados obtidos na anäli se de variância aplicada aos contrastes $p_{j}$ e $q_{j}$.

Tabela 23 - Análise de variância aplicada aos contrastes $\hat{p}_{j}$ e $\hat{q}_{j}$, das precipitações mensais, em Bandeirantes-PR, para o período chuvoso.

\begin{tabular}{lcrrc}
\hline Causas de Variação & G.L. & S.Q. & Q.M. & $F$ \\
\hline Contraste $\hat{\mathrm{p}}_{1}$ & 1 & & 46,494738 & $5,61^{*}$ \\
Contraste $\hat{\mathrm{q}}_{1}$ & 1 & & 180,652887 & $18,94^{*}$ \\
Contraste $\hat{\mathrm{p}}_{2}$ & 1 & & 53,610659 & $4,67^{*}$ \\
Contraste $\hat{\mathrm{q}}_{2}$ & 1 & & 12,140573 & 1,15 \\
Contraste $\hat{\mathrm{p}}_{3}$ & 1 & & 48,756628 & $6,12^{*}$ \\
\hline Anos & & & & \\
Anos $\times \hat{\mathrm{p}}_{1}$ & 47 & 364,714833 & 7,759890 & 0,81 \\
Anos $\times \hat{\mathrm{q}}_{1}$ & 47 & 389,340027 & 8,283830 & \\
Anos $\times \hat{\mathrm{p}}_{2}$ & 47 & 448,369839 & 9,539784 & \\
Anos $\times \hat{\mathrm{q}}_{2}$ & 47 & 539,148028 & 11,471235 & \\
Anos $\times \hat{\mathrm{p}}_{3}$ & 47 & 495,535804 & 10,543315 & \\
\hline Resíduo & 47 & 374,428382 & 7,966561 & \\
\hline Total & & & & \\
\hline
\end{tabular}


Devido à homogeneidade dos quadrados médios residuais, foi possível a junção dos contrastes referentes ao mesmo componente harmônico, sendo obtida a análise de variância das amplitudes harmô nicas, apresentada na Tabela 24.

Tabela 24 - Análise de variāncia aplicada às amplitudes harmônicas $\bar{a}_{j}$, para o período chuvoso.

\begin{tabular}{|c|c|c|c|c|}
\hline Causas de Variação & G.L. & S.Q. & $Q . M$. & $F$ \\
\hline Amplitude $\hat{a}_{1}$ & 2 & 227,147625 & 113,573812 & $12,74^{* *}$ \\
\hline Amplitude $\hat{a}_{2}$ & 2 & 65,751232 & 32,875612 & 2,99 \\
\hline Amplitude $\bar{a}_{3}$ & 1 & 48,756628 & 48,756628 & $6,12^{*}$ \\
\hline Anos & 47 & 364,714833 & 7,759890 & $0,81^{*}$ \\
\hline Anos $\times \hat{a}_{1}$ & 94 & 837,709866 & 8,911807 & \\
\hline Anos $\times \bar{a}_{2}$ & 94 & 1034,683832 & 11,007275 & \\
\hline Anos $\times \hat{a}_{3}$ & 47 & 374,428382 & 7,966561 & \\
\hline Residuo & $(235)$ & $(2246,822080)$ & 9,560945 & \\
\hline Total & 287 & 2953,192358 & & \\
\hline
\end{tabular}

Pelos resultados obtidos fica comprovado que os três componentes harmōnicos são responsáveis pelas variações observadas, correspondendo, respectivamente, a 66,48\% (componente semestral), $19,25 \%$ (componente trimestral) e $14,27 \%$ (componente bimestral). 


\subsection{4 - Variâncias dos parâmetros estimados}

De acordo com o descrito em 4.2.3, equações (22) a (28), as estimativas das variâncias dos parâmetros estimados apresentam os seguintes valores:

$$
\begin{aligned}
& V\left(\hat{p}_{1}\right)=2,7613 \quad V\left(\hat{q}_{1}\right)=3,1799 \\
& V\left(\hat{p}_{2}\right)=3,8237 \quad V\left(\hat{q}_{2}\right)=3,5144 \\
& \hat{V}\left[\hat{p}_{3}\right\}=1,3278 \\
& \text { Como as covariâncias são nulas, os parâmetros estima } \\
& \text { dos são ditos não correlacionados e as variâncias estimadas para } \hat{a}_{j} \text {, }
\end{aligned}
$$
segundo (29), são:

$$
\begin{aligned}
& V\left(\hat{a}_{1}\right) \simeq 3,0942 \\
& V\left(\hat{a}_{2}\right) \simeq 3,7666 \\
& V\left(\hat{a}_{3}\right) \simeq 1,3278
\end{aligned}
$$

\section{3 .5 - Intervalos de confiança}

De posse das estimativas $\hat{p}_{j}, \bar{q}_{j} e \hat{a}_{j}$, bem como de suas variâncias, foram calculados seus respectivos intervalos de confiança, para $\alpha=0,05$, encontrados na Tabela 25. 
Tabela 25 - Intervalos de confiança para os parâmetros $p_{j}, q_{j} e a_{j}$, empregados na equação de regressão, para o período chuvoso.

$$
\begin{aligned}
-3,9083 & \leq p_{1} \leq 2,7718 \\
-4,7043 & \leq a_{1} \leq 2,4642 \\
0,0000 & \leq a_{3} \leq 4,7564 \\
-4,5406 & \leq p_{2} \leq 3,3202 \\
-3,4777 & \leq q_{2} \leq 4,0585 \\
0,0000 & \leq a_{2} \leq 4,5379 \\
-2,7276 & \leq p_{3} \leq 1,9047 \\
0,0000 & \leq a_{3} \leq 2,7276
\end{aligned}
$$

\subsection{6 - Equação de regressão}

Utilizando-se todos os componentes harmónicos, ficou estabelecida a equação de regressão para estimar as precipitações mensais, em Bandeirantes (PR), referentes ao período chuvoso.

$$
\begin{aligned}
P_{t}=12,10 & +1,255940 \operatorname{sen}(60 t+206,899439)^{\circ}+ \\
& +0,675725 \operatorname{sen}(120 t+295,448617)^{\circ}+ \\
& +0,411450 \operatorname{sen}(180 t+270)^{\circ}
\end{aligned}
$$

onde, $\hat{\varphi}_{t}=$ estimativa da raiz quadrada da precipitação para o mês $t$. A presente equação explica $100 \%$ das variações devidas a mesps, 
Através da equação determinada, foram calculadas as estimativas de precipitação mensal, para o período chuvoso, encontradas na Tabela 26.

Tabela 26 - Estimativas dos componentes harmónicos e das raízes qua dradas das precipitações mensais, em Bandeirantes (PR), para o período chuvoso.

\begin{tabular}{ccccccc}
\hline$t$ & Mès & P & A & B & $c$ & $P_{t}$ \\
\hline 1 & Out & 12,10 & $-1,254101$ & 0,556539 & 0,411450 & 11,812542 \\
2 & Nov & 12,10 & $-0,685882$ & 0,053621 & $-0,411450$ & 11,054943 \\
3 & Dez & 12,10 & 0,568220 & $-0,610160$ & 0,411450 & 12,468164 \\
4 & Jan & 12,10 & 1,254101 & 0,556539 & $-0,411450$ & 13,497844 \\
5 & Fev & 12,10 & 0,685882 & 0,053621 & 0,411450 & 13,249607 \\
6 & Mar & 12,10 & $-0,568220$ & $-0,610160$ & $-0,411450$ & 10,508824 \\
\hline
\end{tabular}

onde: $\bar{\gamma}=$ média geral;

$A=$ componente harmônico semestral;

$B$ = componente harmônico trimestral;

$C=$ componente harmônico bimestral;

$\bar{q}_{t}=$ estimativa da raiz quadrada de precipitação para o mês $t$.

\section{3 .7 - Representação gräfica}

As Figuras 9, 10 e 11 apresentam, respectivamente, os componentes harmônicos semestral, trimestral e bimestral, para o pe ríodo chuvoso.

A Figura 12 contém a função resultante do conjunto dos componentes harmônicos considerados na equação de regressão para o período chuvoso. 


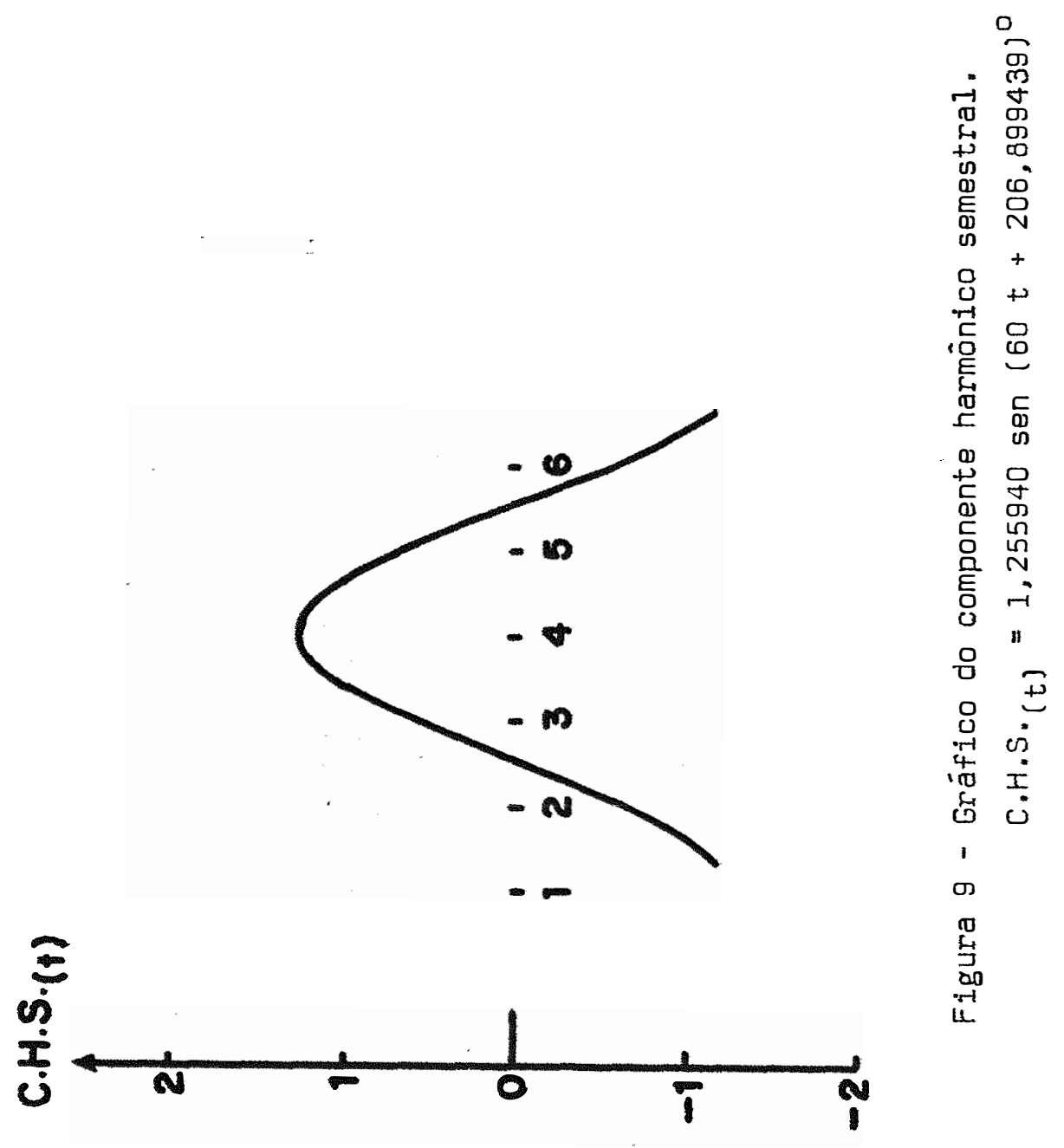


78.

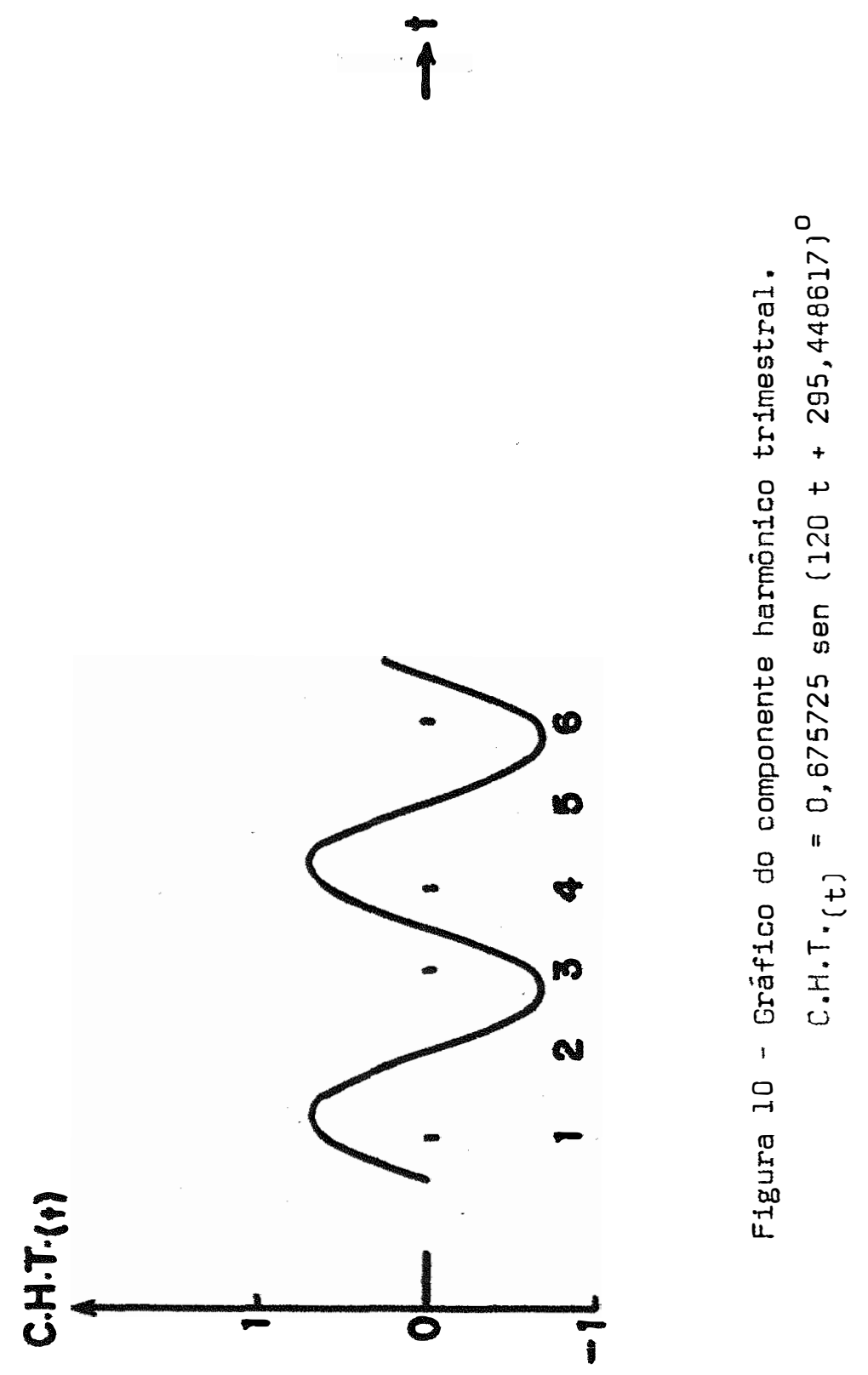




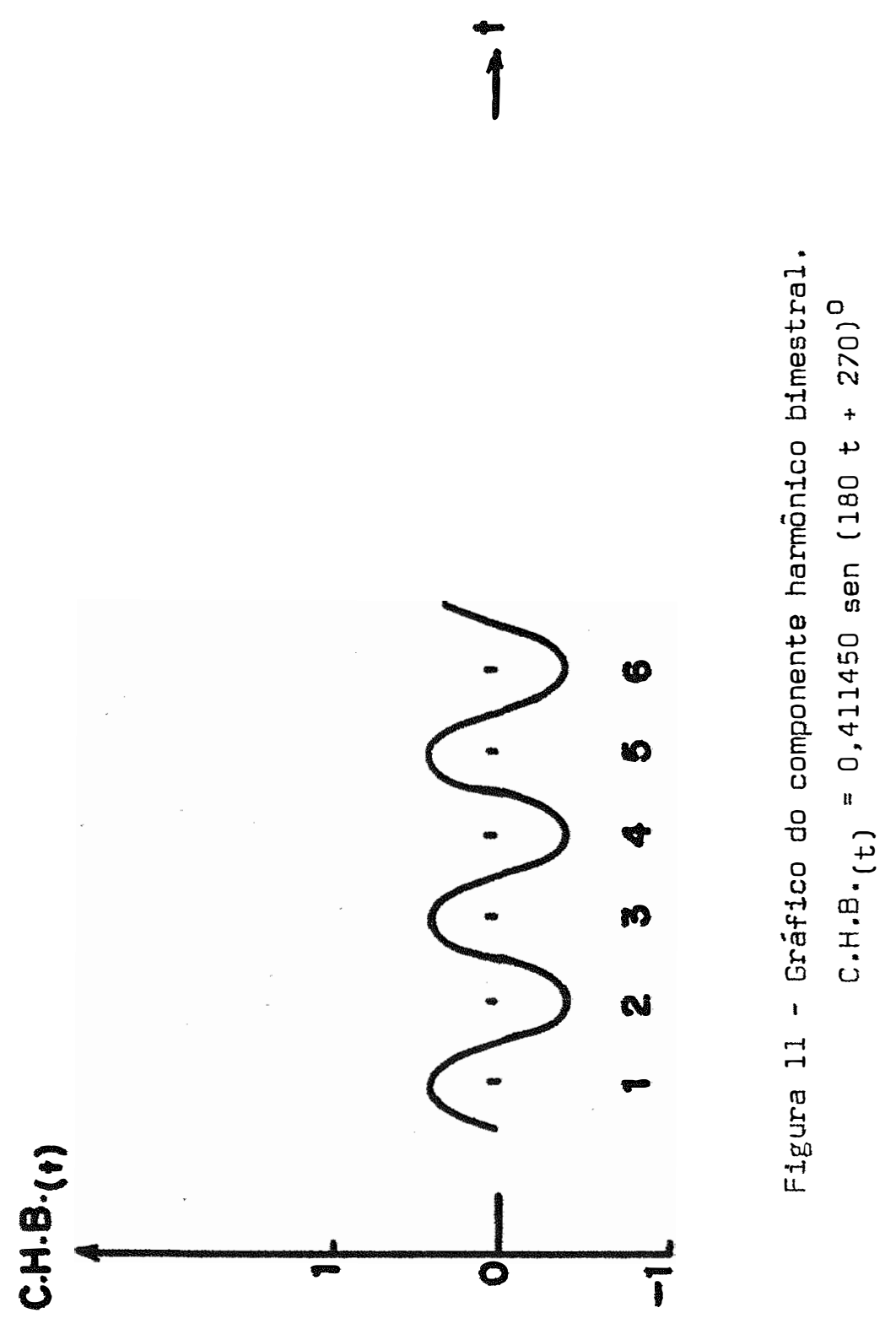


80.

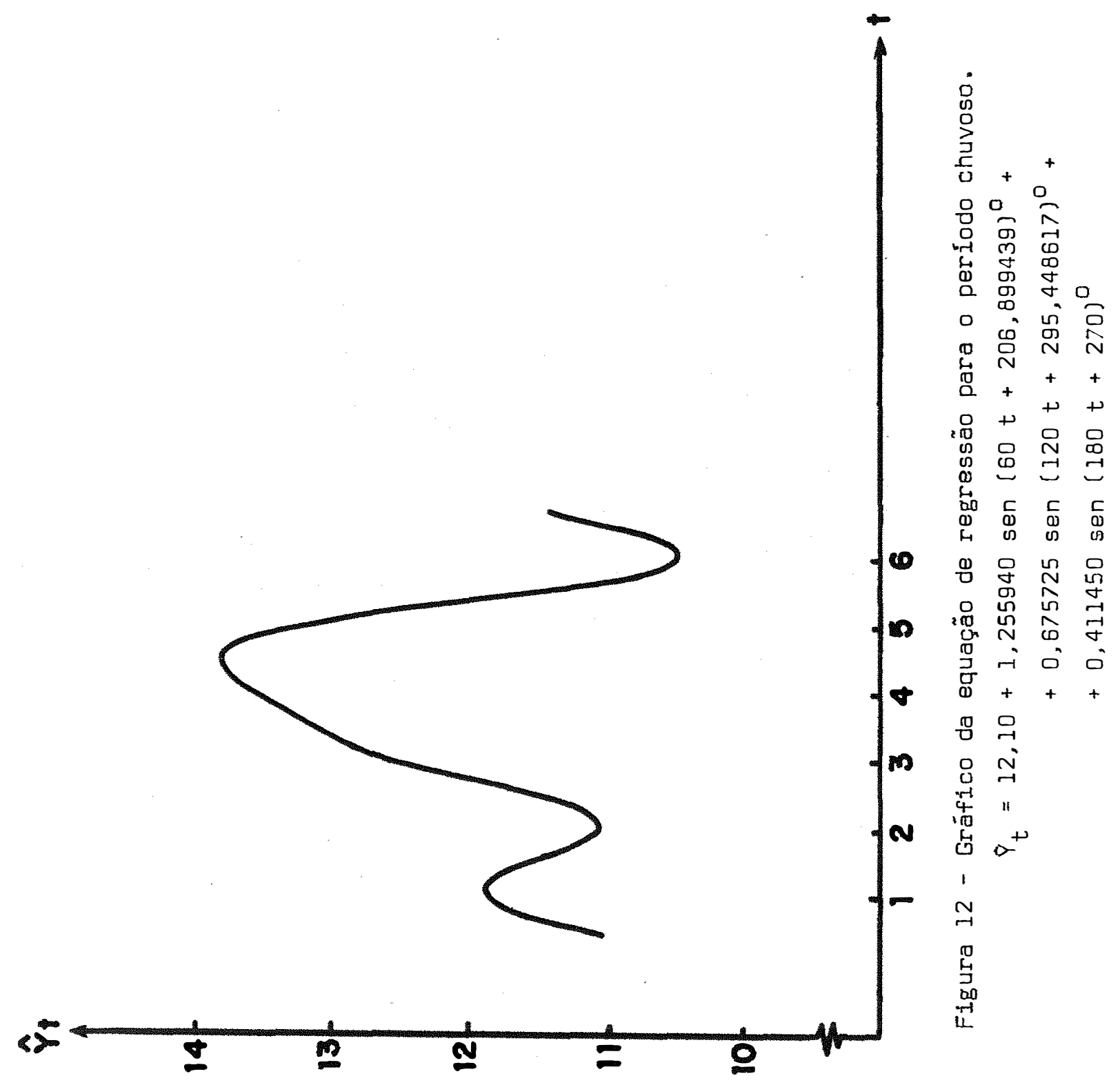


81.

\section{CONCLUSÕES}

De forma geral, pode-se concluir que:

6.1 - Bandeirantes apresenta um período seco (abril a setembro) e um período chuvoso (outubro a março), bem definidos. O período chu voso é o responsável por $69,40 \%$ da precipitação anual.

6.2 - Para o período anual, a equação de regressão estimada foi:

$$
\begin{aligned}
\hat{P}_{t}=9,77 & +3,360495 \operatorname{sen}(30 t+70,590522)^{0}+ \\
& +0,252515 \operatorname{sen}(60 t+60,704294)^{0}+ \\
& +1,171624 \operatorname{sen}(90 t+281,983787)^{0}
\end{aligned}
$$

onde: $\varphi_{t}=$ estimativa da raiz quadrada da precipitação referente ao mês $t$ 。

6.2 .1 - Para o período anual, o modelo explica 98,02\% das variações devidas a meses. 
6.2.2 - Somente o componente anual é responsável por 86,96\% das variações devidas a meses.

6.2.3 - Pela equação obtida, estima-se a ocorrência de um máximo de chuvas, durante o mês de janeiro $\left(\hat{\gamma}_{1}=13,534372\right)$ e, um mínimo, durante o mês de agosto $\left(\hat{\gamma}_{8}=6,069651\right)$.

6.3 - Para o período seco, a equação de regressão estimada foi:

$$
\begin{aligned}
P_{t}=7,44 & +0,882221 \operatorname{sen}(60 t+8,327296)^{\circ}+ \\
& +1,065809 \operatorname{sen}(120 t+73,821335)^{\circ} .
\end{aligned}
$$

onde: $\bar{\varphi}_{t}$ é a estimativa da raiz quadrada da precipitação para o mês t.

6.3.1 - Para o período seco, o modelo explica 99,54\% das variações devidas a meses.

6.3.2 - Apenas o componente semestral é responsável por $40,47 \%$ das variações devidas a meses.

6.3.3 - Pela equação obtida verifica-se um valor mínimo de chuva, durante o mês de agosto $\left(\phi_{5}=5,981745\right)$.

6.4 - Para o período chuvoso, a equação de regressão estimada foi:

$$
\begin{aligned}
\hat{\gamma}_{t}=12,10 & +1,255940 \operatorname{sen}(60 t+206,899439)^{\circ}+ \\
& +0,675725 \operatorname{sen}(120 t+295,448617)^{\circ}+ \\
& +0,411450 \operatorname{sen}(180 t+270)^{\circ} .
\end{aligned}
$$

onde: $P_{t} \dot{e}$ a estimativa da raiz quadrada da precipitação referente ao mês $t$. 
83.

6.4.1 - Para o período chuvoso, o modelo explica 98,02\% das variações devidas a meses.

6.4 .2 - Apenas o componente semestral é responsável por $66,48 \%$ das variações devidas a meses.

6.4 .3 - Pela equação obtida verifica-se a ocorrência de um máximo de chuvas durante o mês de janeiro $\left(\hat{\varphi}_{4}=13,497844\right)$. 
84.

\section{SUMMARY}

On this study, the harmonic analysis were aplicated of monthly quantities of rainfall in Bandeirantes County, during 48 years $(1930-1977)$.

The original data were ajusted for months of thirty days and after were transformed into $Y=\sqrt{X}$.

The harmonic components of analysed elements were settled for three different cases: annual period, dry period, rainy period.

Statistical analyses of variance demonstrated the stability of harmonics components to each one of the three cases, after the test of normality of the components were envolving in analysis.

The confiance intervals were stabilished to orthogo- 
nal contrasts and their corresponding period ocillations, and regression equations obtained, are given as:

a) Annual period (january - december):

$$
\begin{aligned}
\hat{Y}_{t}=9,77 & +3,360495 \sin (30 t+70,590522)^{0}+ \\
& +0,252515 \sin (60 t+60,7044294)^{\circ}+ \\
& +1,171624 \sin (90 t+281,983787)^{\circ}
\end{aligned}
$$

$t=1,2, \ldots, 12$

$\hat{q}_{t}=$ the estimate of square root of rainfall occurs in $t$ month.

b) Dry period (april - september):

$$
\begin{aligned}
\hat{y}_{t}=7,44 & +0,882221 \sin (60 t+8,327296)^{\circ}+ \\
& +1,065809 \sin (120 t+73,821315)^{\circ} \\
t=1,2, \ldots, 6 . &
\end{aligned}
$$

c) Rainy period (october - march):

$$
\begin{aligned}
& \hat{y}_{t}=12,10+1,255940 \sin (60 t+206,899439)^{\circ}+ \\
&+0,675725 \sin (120 t+295,448617)^{\circ}+ \\
&+0,411450 \sin (180 t+270)^{\circ} \\
& t=1,2, \ldots, 6 .
\end{aligned}
$$




\section{BIBLIOGRAFIA}

AMARAL, E., 1968. Análise Harmônica. Pesquisa Agropecuária Brasileira, 3: 7-43.

AMARAL, E., 1975. Análise Harmônica e Previsão a Longo Prazo. Apre sentado na Reunião Comemorativa do $20^{\circ}$ Aniversārio da Região Bra sileira da Sociedade Internacional de Biometria. Piracicaba, 34 pp. Anais。

ANDERSON, T.W., 1971. The Statistical Analysis of Time Series. No va York, John Wiley and Sons, $704 \mathrm{pp}$.

BLISS, C.I, 1958. Periodic Regression in Biology and Climatology. New Haven, Connecticut Agr. Exp. Station, 55 pp. (Bol. 615).

COCHRAN, W.G. e G.M. COX, 1978. Diseños Experimentales. 1. Ed., 5. Reimpressão, México, Ed. Trillas, 661 pp. 
CONRAD, V. e L.W. POLLAK, 1950. Methods in Climatology. Massachusetts. Harvard University Press, $459 \mathrm{pp}$.

DUARTE, G.S., 1974. Curva Epidemiológica da Ferrugem Alaranjada do Cafeeiro na Zona da Mata - MG. Piracicaba, ESALQ/USP, 65 pp. (Dissertação de Mestrado).

GODOY, H.; F。 PIMENTEL GOMES e I.R. NOGUEIRA, 1961. Análise Estatística de Dados Pluviométricos de Campinas. Bragantia, Campinas, 20: $357-371$.

PEREIRA, N.S.C., 1978. Regressão Periódica Aplicada a Dados Pluvio métricos Mensais do Município de Grajaú - MA. Piracicaba, ESALQ/ USP, 66 pp. (Dissertação de Mestrado).

PIMENTEL GOMES, F., 1976. Curso de Estatística Experimental. 6? Edição, Piracicaba, ESALQ, 430 pp + 15 tabelas.

POMPEU MEMÚRIA, J.M., 1955. Análise Estatística das Precipitações Pluviométricas Mensais de Morro Velho (MG). Boletim de Agricultu ra da Secretaria da Agricultura do Estado de Minas Gerais, $n^{8} \mathrm{~s}$ 5 e 6 .

SILVA, J.B., 1977. Análise Harmônica das Precipitações Pluviométrí cas Pentadais. Pelotas, UfPel. 216 pp. (Tese de Livre-Docência).

SNEOECOR, G.W. e W.G. COCHRAN, 1976. Statistical Methods. 6. Edição, Iowa, The Iowa State University Press, 593 pp.

SPIEGEL, M.R., 1976. Anälise de Fourier. São Paulo, McGraw Hill do Brasil, 249 pp. Coleção Schawn. 
THIEBAUT, J.T.L. 1976. O Emprego da Anālise Harmônica no Estudo das Precipitações Mensais do Município de Viçosa - MG. Piracica ba, ESALQ/USP, 92 pp. (Dissertação de Mestrado). 
89.

9. APENDICES 


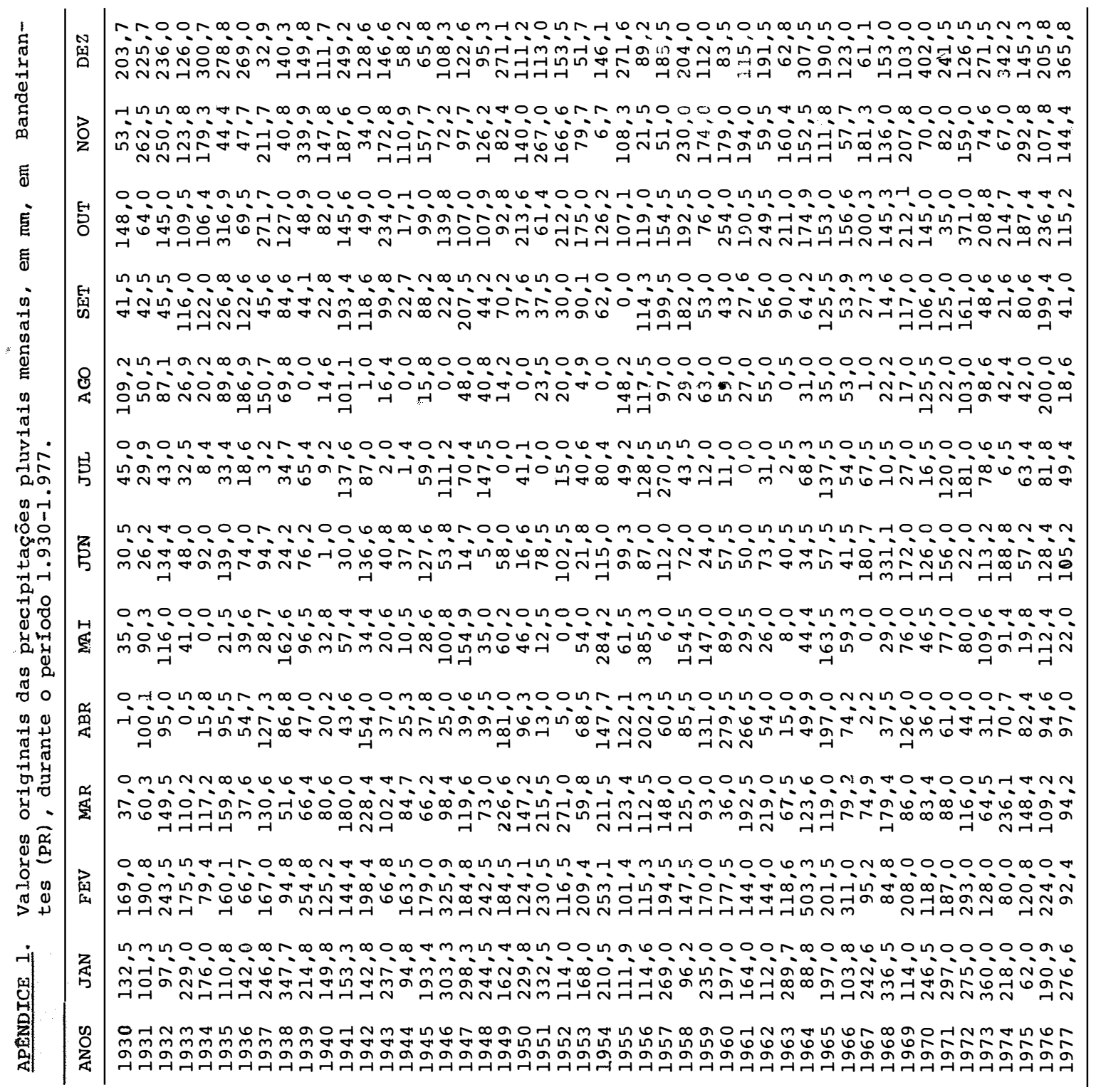




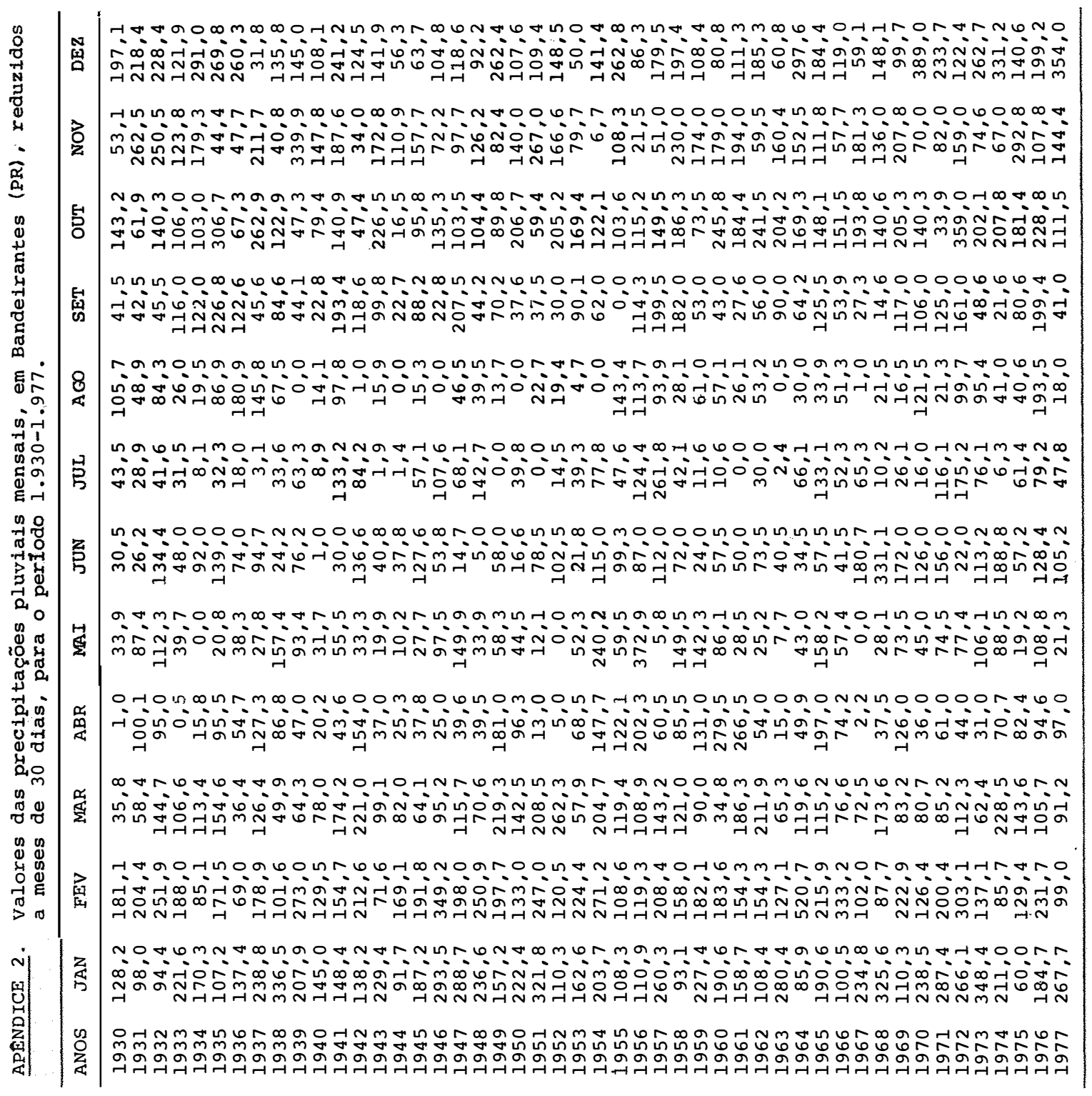




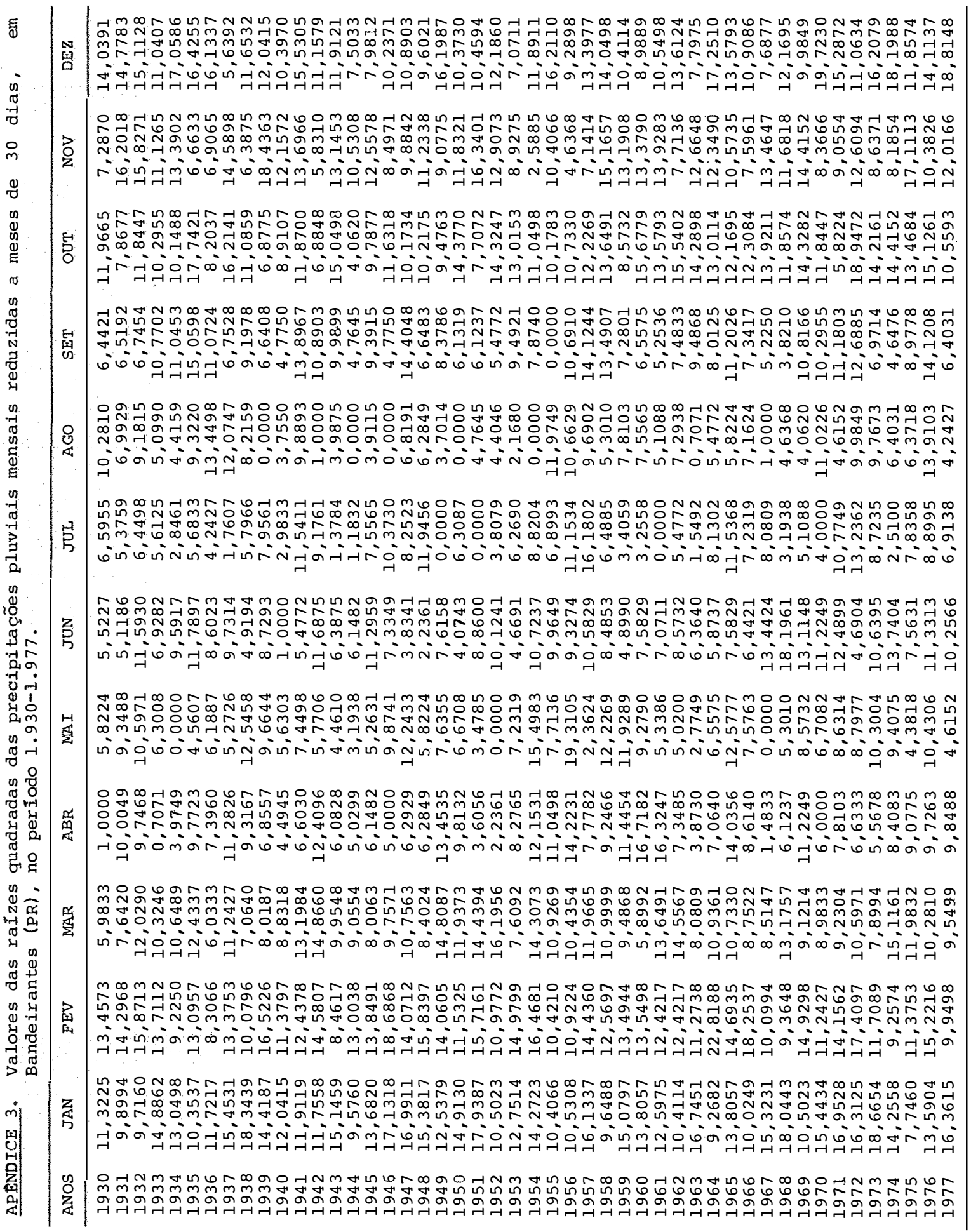




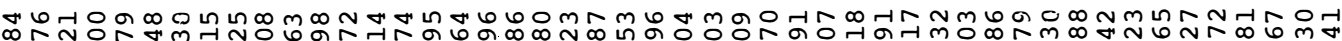

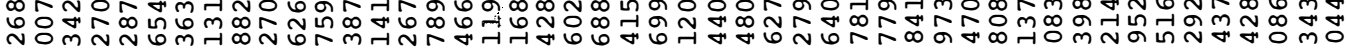

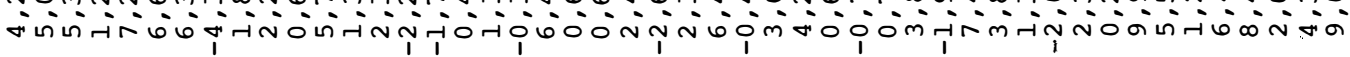

กีー

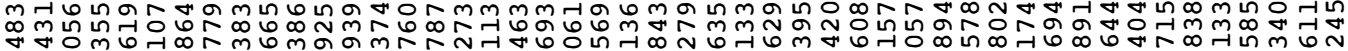

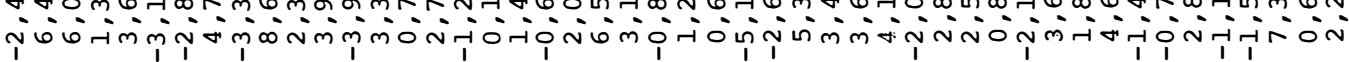

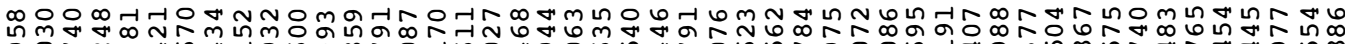

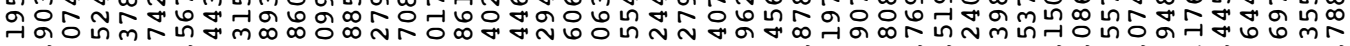

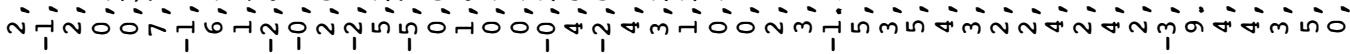

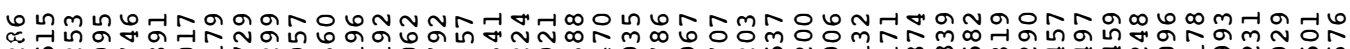

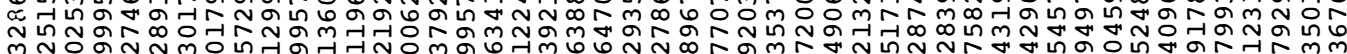
mppón

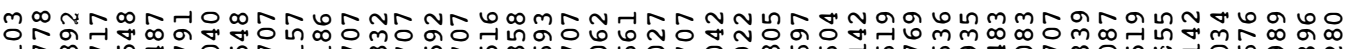
弪施

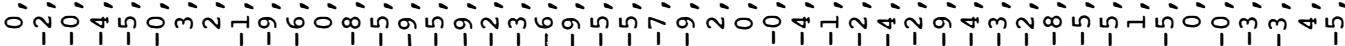

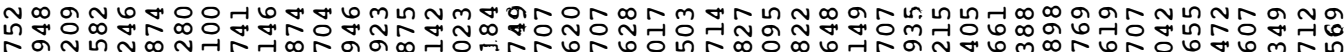

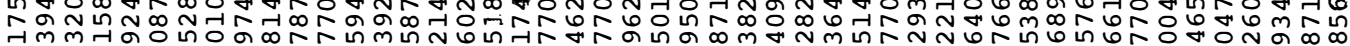
Pिp

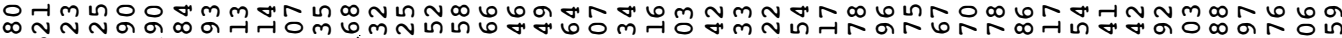
获 Fíñ

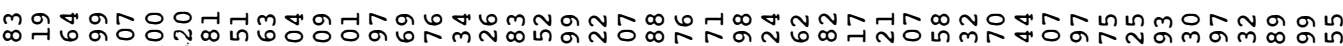
为

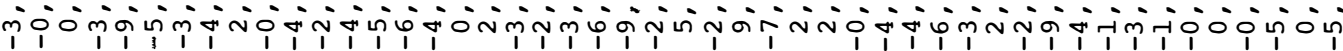

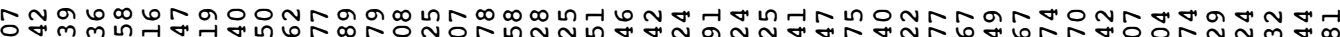

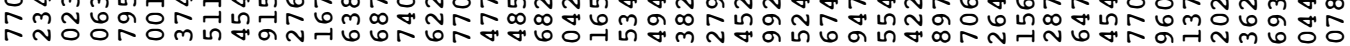

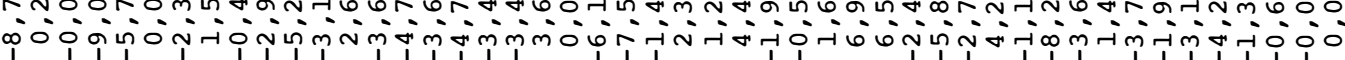

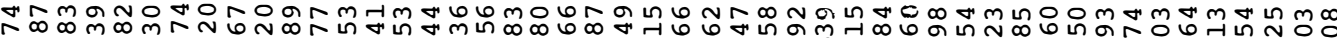

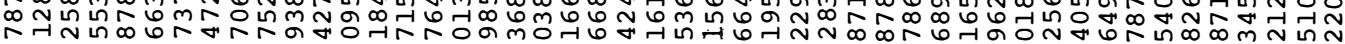

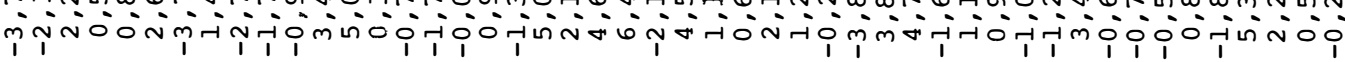

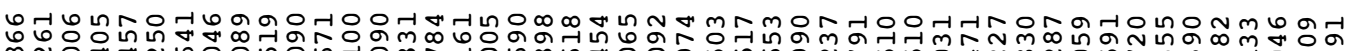

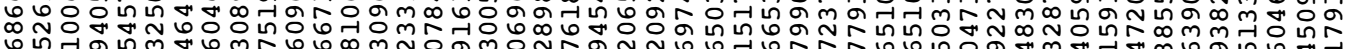

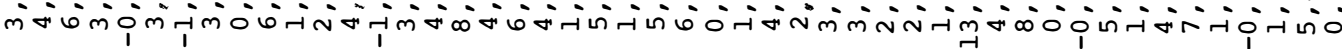

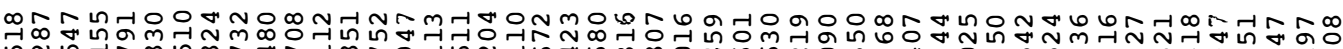

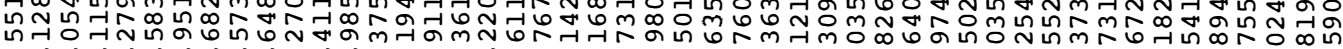

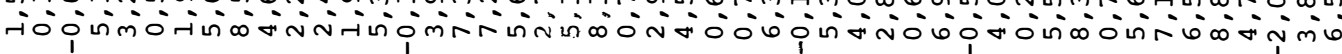



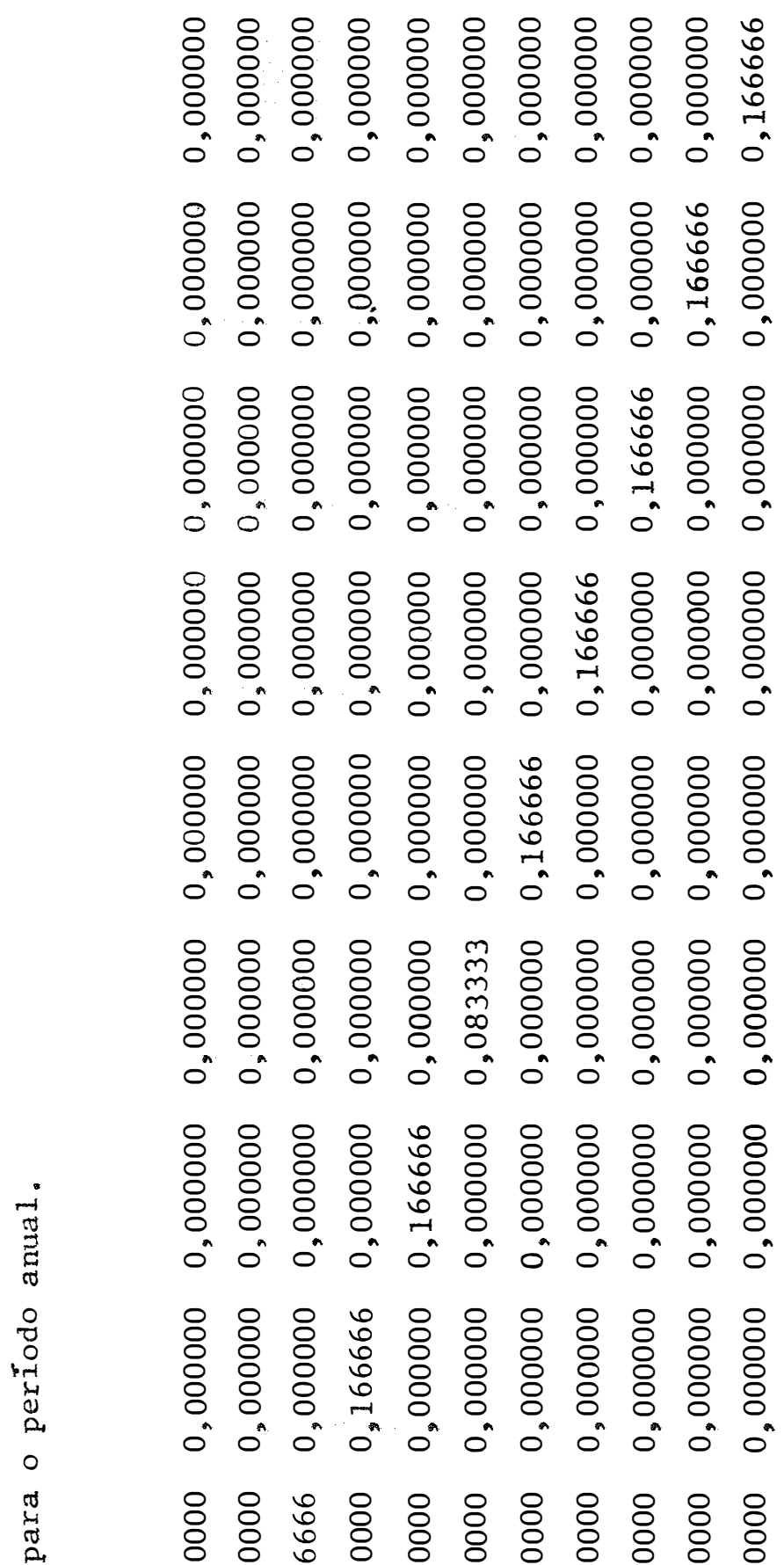

is
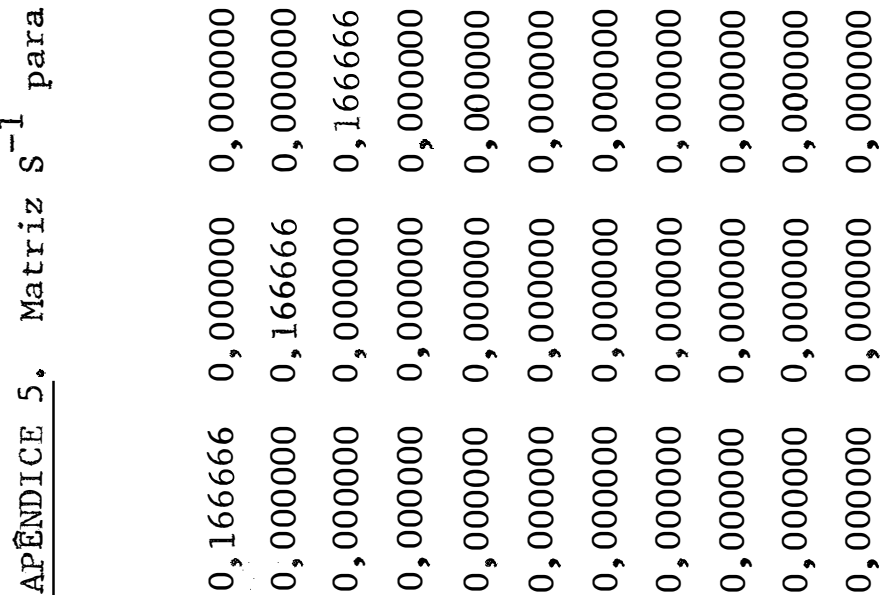

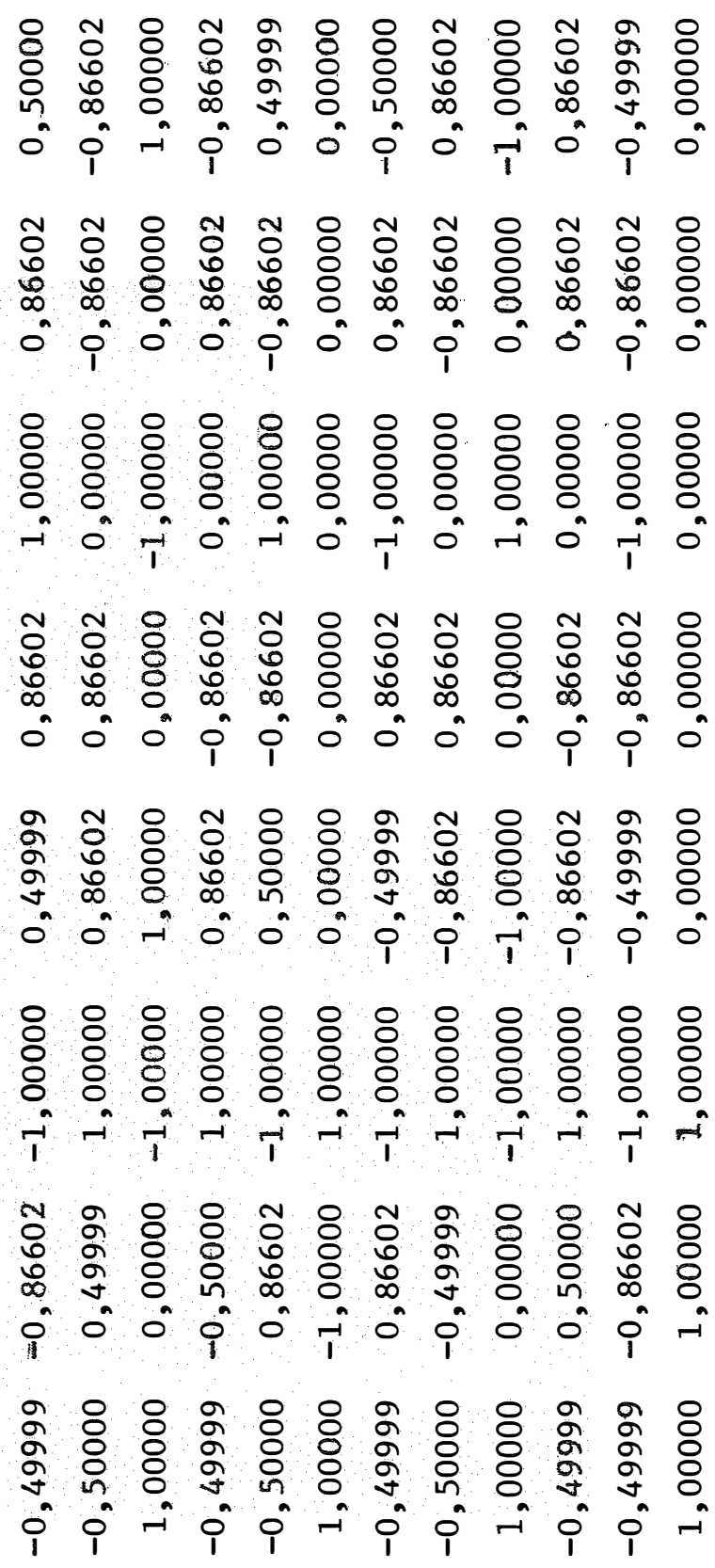

0

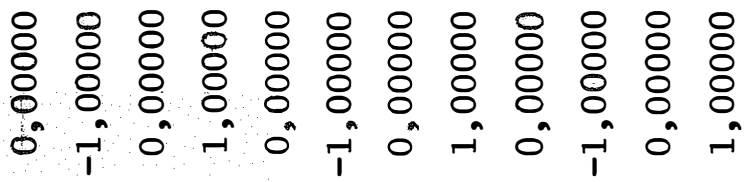

$\frac{N}{4}$

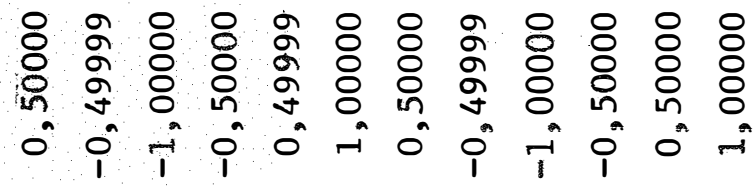




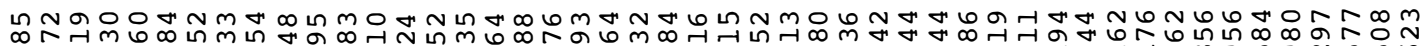

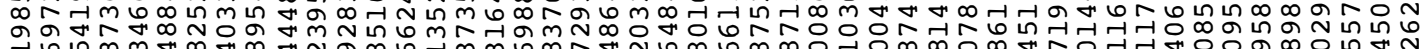

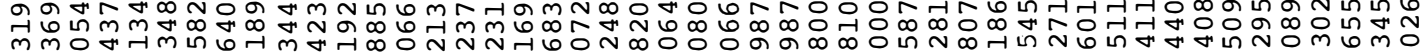

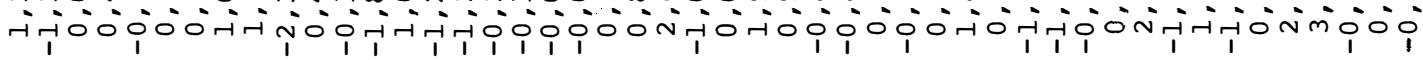

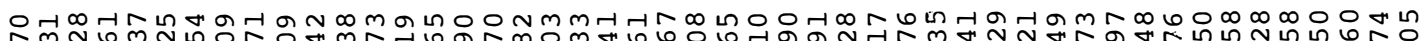

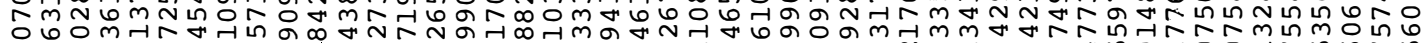

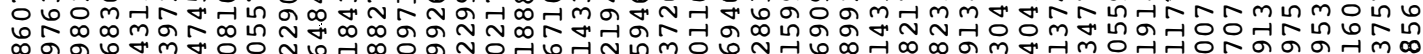
írióriói

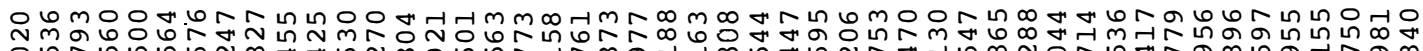

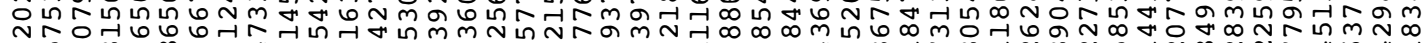

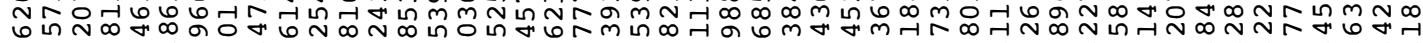
ój-iojórióm

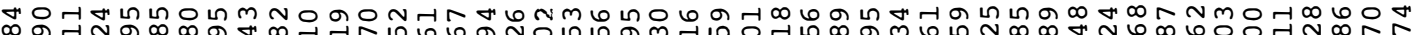

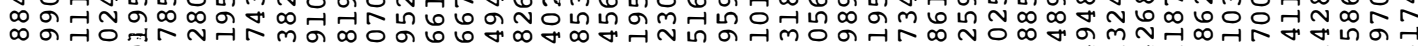
సু⿱

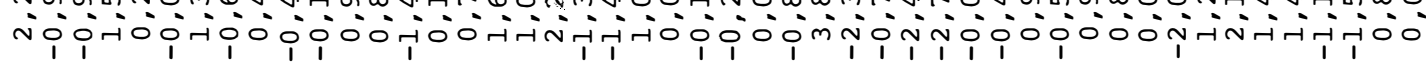

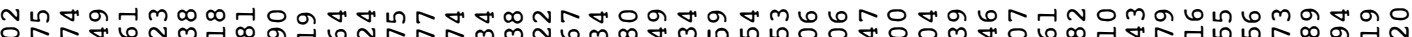

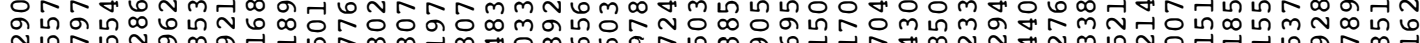
N

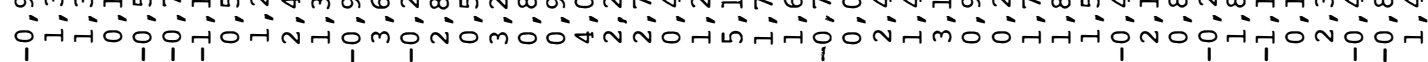

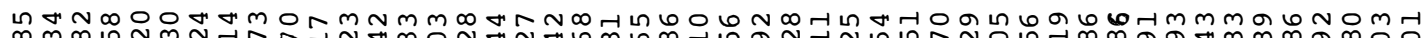

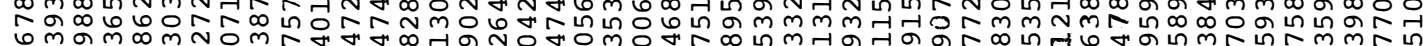
om

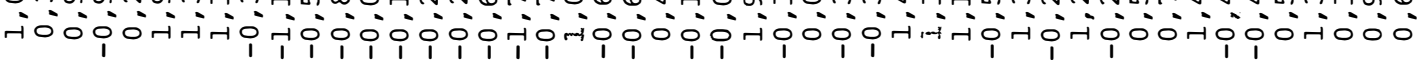

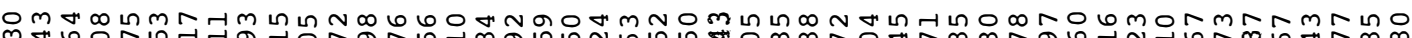

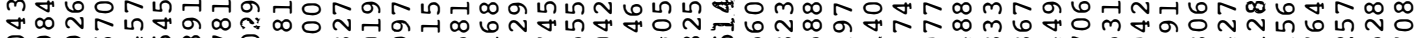

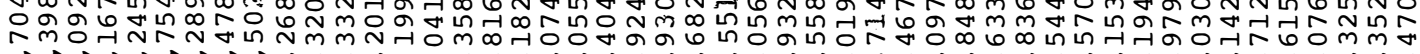

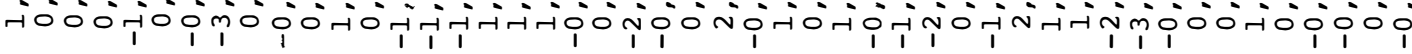

แ mૅ̄m సెळ

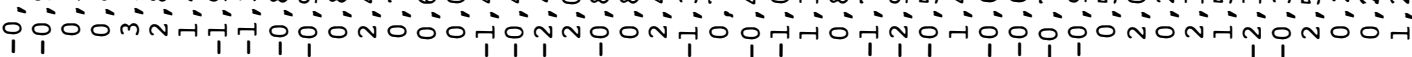

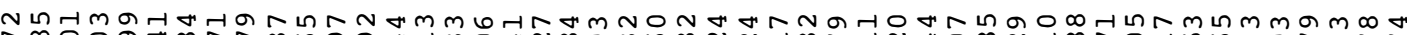
స⿻에 m小N

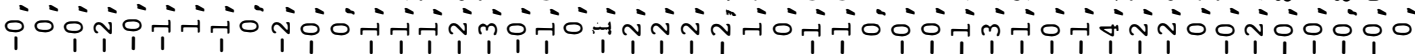

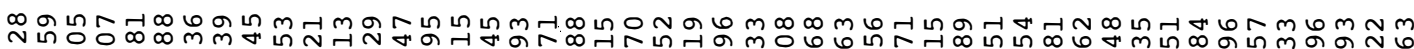

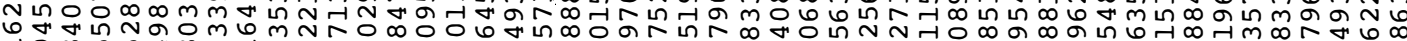

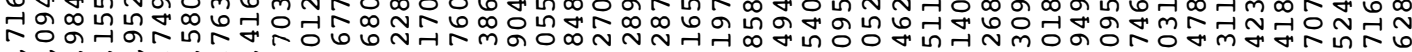

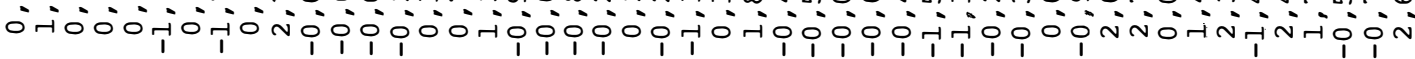

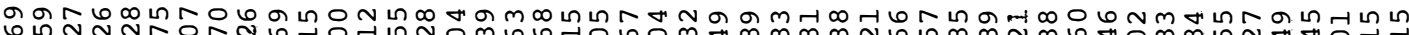

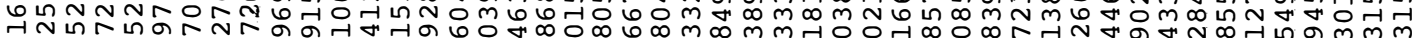
హె m̄ñ 
APENDICE 8. Matriz Y' para o periodo seco.

\begin{tabular}{|c|c|c|c|c|c|}
\hline $\begin{array}{r}-6,4428 \\
2,5621 \\
2,3039 \\
-6,7357 \\
-3,4678 \\
2,3295 \\
-0,0468 \\
3,8399 \\
1,8738 \\
-0,5871 \\
-2,9483 \\
-0,8397 \\
4,9668 \\
-1,3600 \\
-2,4129 \\
-1,2946 \\
-2,4428 \\
-1,1499 \\
-1,1579 \\
6,0108 \\
2,3704 \\
-3,8372 \\
-5,2067 \\
0,8336 \\
4,7103 \\
3,6070 \\
6,7804 \\
0,3353 \\
1,8038 \\
4,0027 \\
9,2754 \\
8,8820 \\
-0,0943 \\
-3,5698 \\
-0,3788 \\
6,5928 \\
1,1711 \\
-5,9595 \\
-1,3190 \\
3,7821 \\
-1,4428 \\
0,3674 \\
-0,8095 \\
-1,8750 \\
0,9655 \\
1,6346 \\
2,2834 \\
2,4060\end{array}$ & $\begin{array}{r}-1,6204 \\
1,9059 \\
3,1543 \\
-1,1420 \\
-7,4428 \\
-2,8821 \\
-1,2541 \\
-2,1702 \\
5,1031 \\
2,2215 \\
-1,8125 \\
0,0070 \\
-1,6722 \\
-2,9818 \\
-4,2490 \\
-2,1797 \\
2,4313 \\
4,8005 \\
-1,6204 \\
0,1926 \\
-0,7719 \\
-3,9643 \\
-7,4428 \\
-0,2109 \\
8,0555 \\
0,2708 \\
11,8678 \\
-5,0344 \\
4,7842 \\
4,4861 \\
1,8361 \\
-2,1042 \\
-2,4228 \\
-4,6679 \\
-0,8853 \\
5,1349 \\
0,1334 \\
-7,4428 \\
-2,1418 \\
1,1303 \\
-0,7346 \\
1,1885 \\
1,3549 \\
2,8576 \\
1,9646 \\
-3,0610 \\
2,9879 \\
-2,8276\end{array}$ & $\begin{array}{r}-1,9201 \\
-2,3242 \\
4,1502 \\
-0,5146 \\
2,1488 \\
4,3470 \\
1,1595 \\
2,2885 \\
-2,5234 \\
1,2864 \\
-6,4428 \\
-1,9655 \\
4,2447 \\
-1,0553 \\
-1,2946 \\
3,8532 \\
-0,1079 \\
-3,6087 \\
-5,2067 \\
0,1729 \\
-3,3685 \\
1,4172 \\
2,6814 \\
-2,7737 \\
3,2809 \\
2,5221 \\
1,8845 \\
3,1401 \\
1,0424 \\
-2,5438 \\
0,1400 \\
-0,3717 \\
1,1303 \\
-1,0788 \\
-1,5691 \\
0,1400 \\
-1,0007 \\
5,9996 \\
10,7533 \\
5,6720 \\
3,7821 \\
5,0471 \\
-2,7523 \\
3,1967 \\
6,2976 \\
0,1202 \\
3,8885 \\
2,8138\end{array}$ & $\begin{array}{r}-0,8473 \\
-2,0669 \\
-0,9930 \\
-1,8303 \\
-4,5967 \\
-1,7595 \\
-3,2001 \\
-5,6821 \\
-1,6462 \\
0,5133 \\
-4,4595 \\
4,0984 \\
1,7332 \\
-6,0644 \\
-6,2595 \\
0,1136 \\
2,9302 \\
0,8094 \\
4,5028 \\
-7,4428 \\
-1,1340 \\
-7,4428 \\
-3,6349 \\
-1,1738 \\
1,3776 \\
-0,5435 \\
3,7106 \\
8,7374 \\
-0,9543 \\
-4,0369 \\
-4,1870 \\
-7,4428 \\
-1,9655 \\
-5,8936 \\
0,6873 \\
4,0940 \\
-0,2109 \\
0,6380 \\
-4,2490 \\
-2,3339 \\
-3,4428 \\
3,3321 \\
5,7934 \\
1,2807 \\
-4,9328 \\
0,3929 \\
1,4566 \\
-0,5290\end{array}$ & $\begin{array}{r}2,8382 \\
-0,4499 \\
1,7386 \\
-2,3437 \\
-3,0269 \\
1,8792 \\
6,0070 \\
4,6319 \\
0,7730 \\
-7,4428 \\
-3,6878 \\
2,4465 \\
-6,4428 \\
-3,4553 \\
-7,4428 \\
-3,5312 \\
-7,4428 \\
-0,6237 \\
-1,1579 \\
-3,7414 \\
-7,4428 \\
-2,6783 \\
-3,0382 \\
-5,2748 \\
-7,4428 \\
4.5321 \\
3,2202 \\
2,2473 \\
-2,1418 \\
0,3674 \\
0,1136 \\
-2,3339 \\
-0,1489 \\
-6,7357 \\
-1,9655 \\
-1,6204 \\
-0,2804 \\
-6,4428 \\
-2,8060 \\
-3,3807 \\
3,5798 \\
-2,8276 \\
2,5421 \\
2,3244 \\
-1,0396 \\
-1,0710 \\
6,4676 \\
-3,2001\end{array}$ & $\begin{array}{r}-1,0007 \\
-0,9236 \\
-0,6974 \\
3,3275 \\
3,6025 \\
7,6170 \\
3,6296 \\
-0,6900 \\
1,7550 \\
-0,8020 \\
-2,6778 \\
6,4640 \\
3,4475 \\
2,5471 \\
-2,6783 \\
1,9486 \\
-2,6678 \\
6,9620 \\
-0,7945 \\
0,9357 \\
-1,3109 \\
-1,3190 \\
-1,9655 \\
2,0492 \\
0,4311 \\
-7,4428 \\
3,2483 \\
6,6816 \\
6,0479 \\
-0,1627 \\
-0,8853 \\
-2,1892 \\
0,0404 \\
2,0440 \\
0,5696 \\
3,7598 \\
-0,1011 \\
-2,2178 \\
-3,6218 \\
3,3738 \\
2,8528 \\
3,7375 \\
5,2457 \\
-0,4714 \\
-2,7952 \\
1,5349 \\
6,6780 \\
-1,0396\end{array}$ \\
\hline
\end{tabular}


APÊNDICE 9. Matriz $S^{-1}$ para os periodos seco e chuvoso.

$\begin{array}{lllll}0,333333 & 0,000000 & 0,000000 & 0,000000 & 0,000000 \\ 0,000000 & 0,333333 & 0,000000 & 0,000000 & 0,000000 \\ 0,000000 & 0,000000 & 0,166666 & 0,000000 & 0,000000 \\ 0,000000 & 0,000000 & 0,000000 & 0,333333 & 0,000000 \\ 0,000000 & 0,000000 & 0,000000 & 0,000000 & 0,333333\end{array}$


APENDICE 10. Matriz $X^{\prime}$ para os periodos seco e chuvoso.

$\begin{array}{rrrrr}0,50000 & -0,49999 & -1,00000 & 0,86602 & 0,86602 \\ -0,49999 & -0,50000 & 1,00000 & 0,86602 & -0,86602 \\ -1,00000 & 1,00000 & -1,00000 & 0,00000 & 0,00000 \\ -0,50000 & -0,49999 & 1,00000 & -0,86602 & 0,86602 \\ 0,49999 & -0,50000 & -1,00000 & -0,86602 & -0,86602 \\ 1,00000 & 1,00000 & 1,00000 & 0,00000 & 0,00000\end{array}$


APENDICE 11. Matriz $\beta$ para o periodo seco.

\begin{tabular}{|c|c|c|c|c|}
\hline & & & 37 & - \\
\hline & 782 & 542 & & \\
\hline 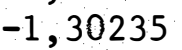 & & & & \\
\hline & & & & \\
\hline & & & -0 , & \\
\hline & & -0 & & \\
\hline & & -1 & -1 & \\
\hline & & -3 & & $-1,2$ \\
\hline & 1 & & & -1 \\
\hline & & & & \\
\hline & & 0, & & 0 \\
\hline & & & -2, & \\
\hline & & & & \\
\hline & & -0 , & & 0 \\
\hline & & -0 , & & \\
\hline & & & & \\
\hline & & & & \\
\hline & & & & -1 \\
\hline & & & -1 , & \\
\hline & & -1 , & & \\
\hline & 0 & & & \\
\hline & & -1 & & -1 \\
\hline & & -1 & -1 & \\
\hline & & & & \\
\hline & & & & \\
\hline & & -3 & & \\
\hline & & 1 , & & -1 \\
\hline & & & -4 & \\
\hline & & & & \\
\hline & & -0 , & & -1 \\
\hline & -1 , & -2 , & & \\
\hline & & -2 , & 4, & \\
\hline & & -0 , & -0 , & \\
\hline & & & & \\
\hline & & 0 , & & \\
\hline & -1 , & & & 550 \\
\hline & & -0 , & & 960 \\
\hline & & -0 , & -2 & 22 \\
\hline & & -2 & & 0 \\
\hline & & & & 6 \\
\hline & & -1 , & -0 & -2 \\
\hline & & & & \\
\hline & & & -2 & \\
\hline & & & -0 & 752 \\
\hline & & & & \\
\hline & & & -0 & 81 \\
\hline & & & -0 & 1 \\
\hline & 320 & $-1,06935$ & 0,9 & 2,2819 \\
\hline
\end{tabular}


APÊNDICE 12. Matriz Y' para o período chuvoso.

\begin{tabular}{|c|c|c|c|c|c|}
\hline 0 , & $-4,8116$ & 1,9405 & $-0,7761$ & 1,3586 & $-6,1$ \\
\hline$-4,2$ & 4,1031 & 2,6797 & $-2,1991$ & 2,1981 & $-4,4566$ \\
\hline-0, & 3,7285 & 3,0142 & $-2,3826$ & 3,7727 & -0 \\
\hline 1,8 & $-0,9721$ & $-1,0578$ & 2,7875 & 1,6126 & $-1,7$ \\
\hline$-1,9497$ & 1,2916 & 4,9600 & 0,9512 & $-2,8736$ & $-1,449$ \\
\hline 5,4141 & $-5,4353$ & 4,3269 & $-1,7449$ & 0,9971 & 0 , \\
\hline 3,8949 & $-5,1921$ & 4,0351 & $-0,3768$ & $-3,7920$ & \\
\hline 4,1 & 2,4512 & $-6,4595$ & 3,3545 & 1,2766 & -0 \\
\hline 1,0 & $-5,7111$ & $=0,4453$ & 6,2452 & $-2,0189$ & -5, \\
\hline 5, & 6,3377 & $-0,0$ & 2,3200 & 4,4240 & -4, \\
\hline 79 & 0,0586 & $-1,7015$ & $-0,0570$ & $-0,7$ & -3 \\
\hline 0 , & 1,5980 & 3,4319 & 0,0832 & 0,3 & 1 \\
\hline 5, & $-6,2677$ & -0 & $-0,3$ & 21 & \\
\hline 2, & 1,0 & -0 , & 3 , & -3 & -2 \\
\hline -8, & $-1,5$ & $-4,5$ & -2 & 51 & \\
\hline-2 , & $0, L$ & $-4,1$ & 334 & 05 & -4 \\
\hline-0 , & -3, & $-1,8614$ & 31 & 82 & -2 \\
\hline-1 & $-2,2$ & $-1,2082$ & 4,8925 & $1, \mathrm{c}$ & -1 \\
\hline-1 & $-0, \varepsilon$ & $-2,2$ & 3,2831 & 3 , & - \\
\hline-2 & -3, & 4,1001 & 0,4 & 1, & 2 \\
\hline & -0 & $-1,7$ & 2,8144 & -0 , & -0 \\
\hline -4, & 4,2 & $-1,6$ & 5,8401 & 75 & 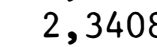 \\
\hline 2, & 0,8 & 0,0874 & $-1,5962$ & -1, & 4, \\
\hline 0,9167 & $-3,1$ & $-5,0275$ & 0 , & 13 & -4 \\
\hline-1 & $-9,5$ & -0 & 36 & 94 & \\
\hline & -1, & 4, & -1 , & -1 & -1 \\
\hline-1 & $-7,2$ & $-2,8088$ & $-1,5$ & -1 , & \\
\hline 0,1283 & $-4,9572$ & 1,2991 & 4, & 74 & \\
\hline 1,5 & 3,0670 & 1,9512 & $-2,4$ & 11 & -1 \\
\hline$-3,5254$ & 1,0922 & $-1,6871$ & 11 & 57 & \\
\hline 3,5793 & 1,2804 & $-3,1097$ & 1 , & 12 & \\
\hline 1,4807 & 1,8297 & $-1,5487$ & 0,4 & 31 & \\
\hline 3,4416 & $-4,3850$ & 1,5138 & $-1,6871$ & 0 , & \\
\hline 2,1912 & 0,5662 & $-4,3012$ & 4,6464 & -0 , & \\
\hline 0,9128 & 0,2504 & 5,1524 & $-2,8304$ & 10, & \\
\hline 0, & $-1,5251$ & 1,4807 & 1,7071 & 48 & -1 \\
\hline 0 , & $-4,5026$ & $-1,1899$ & $-2,0736$ & 6,1 & \\
\hline 1, & 1,3661 & $-4,4110$ & 3,2245 & $-1,9991$ & -3 \\
\hline-0 , & $-0,4367$ & 0,0709 & $5,94,57$ & -2 & 1 \\
\hline & 66 & $-2,1136$ & $-1,5962$ & 11 & \\
\hline$-0,2538$ & -3 & 7,6244 & 3,3447 & $-0,8558$ & -3 \\
\hline-6 & -3 , & 3,1885 & 4.8542 & 76 & \\
\hline 6 , & 08 & $-1,0352$ & 4,2139 & 11 & \\
\hline 2 , & $-3,4615$ & 4,1093 & 668 & $-0,3896$ & -4 \\
\hline 166 & $-3,9133$ & 6,1002 & 2,4271 & $-2,8412$ & \\
\hline & 127 & $-0,2411$ & $-4,3526$ & $-0,7232$ & \\
\hline & -1 , & 2,0151 & 1,4917 & 3,1230 & \\
\hline & -0 , & 6,7162 & 4,2628 & $-2,1487$ & \\
\hline
\end{tabular}


APÊNDICE 13. Matriz $\hat{\beta}^{\prime}$ para o periodo chuvoso.

\begin{tabular}{|c|c|c|c|c|}
\hline $\begin{array}{l}73 \\
12 \\
31 \\
69\end{array}$ & $\begin{array}{r}-0, \\
0, \\
-1, \\
1, \\
1, \\
1, \\
-4, \\
-1, \\
-2, \\
-1, \\
1, \\
2, \\
-1, \\
-0, \\
-2, \\
-2, \\
-1, \\
-2, \\
2, \\
-1, \\
-1, \\
1, \\
-3, \\
1, \\
2, \\
0, \\
0, \\
-0, \\
-1, \\
-4, \\
-0, \\
1, \\
-3, \\
-0, \\
-0, \\
-1, \\
-3, \\
-0, \\
-2, \\
1, \\
0, \\
-3, \\
-0, \\
3, \\
-0, \\
-0, \\
1, \\
\end{array}$ & 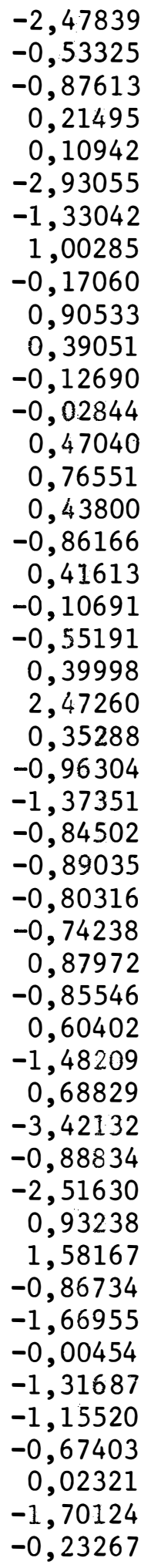 & $\begin{array}{r}-1,59530 \\
-0,03661 \\
0,61080 \\
-2,07135 \\
0,36497 \\
0,20976 \\
-1,41976 \\
0,55875 \\
-3,16102 \\
-1,62454 \\
-0,67937 \\
0,27338 \\
-3,93202 \\
1,32433 \\
-2,30562 \\
-1,49697 \\
-4,52926 \\
-3,17675 \\
-2,82039 \\
-2,32233 \\
-0,06824 \\
-2,77351 \\
1,66061 \\
-1,67102 \\
-4,93697 \\
-0,07006 \\
-1,75613 \\
-3,23357 \\
1,90418 \\
-1.96590 \\
0,49115 \\
0,71834 \\
0,12141 \\
-0,30722 \\
-1,94176 \\
-1,66165 \\
-2,41740 \\
0,56675 \\
-1,12289 \\
0,95590 \\
-1,86911 \\
-4,68559 \\
-0,62513 \\
-2,17116 \\
-0,34140 \\
3,30778 \\
-0,95358 \\
-1,07831\end{array}$ & $\begin{array}{r}1,80873 \\
-0,07006 \\
1,64682 \\
1,95818 \\
-1,28100 \\
-0,87536 \\
0,73751 \\
-0,04997 \\
1,67905 \\
2,04850 \\
-3,72049 \\
0,20448 \\
-1,01507 \\
1,63970 \\
2,56203 \\
-1,30320 \\
2,21670 \\
-0,12598 \\
1,51282 \\
3,61870 \\
3,31928 \\
-2,09935 \\
0,89841 \\
1,43020\end{array}$ \\
\hline
\end{tabular}

